\title{
DIE DIATOMEEN DES DOLLART-EMSGEBIETES
}

\author{
A. VAN DER WERFF* \\ (mit 32 Tafeln und 22 Stabdarstellungen)
}

\section{EINLEITUNG}

Ein Gebiet wie der Dollartraum, der aus Sand- und Schlickplaten besteht, die bei Flut überspült werden, bei Ebbe größtenteils bloßgelegt werden und dann durch tiefe oder untiefe Wasserrinnen und Priele voneinander getrennt sind, bildet für die Diatomeen einen außergewöhnlichen Lebenskreis. Wechselweise von Salzwasser überschwemmt oder austrocknend in einer prallen Sonne, manchmal auch mit salzarmen Regenwasser duchtränkt und großen Temperaturschwankungen ausgesetzt, ist es nur bestimmten, zu spezifischen Assoziationen vereinigten Arten möglich, sich in einer derartigen Umgebung zu behaupten. Auf diesen Umstand haben schon BrockmanN (1935) und Hustedt (1939) hingewiesen.

Es zeigt sich, daß in gleichwertigen Biotopen diese eurytopen, euryhalinen und eurythermen Assoziationen nicht nur in Holland, sondern u.a. auch in Deutschland, England und Schottland vorkommen. Innerhalb des Biotops entstehen kleinere, jedoch gleichfalls spezifische Artengruppierungen von Diatomeen, auf wenig nährstoffreichem Sandboden aber manchmal andere als auf einem Schlickboden, der viel organische Stoffe enthält.

Für Sandböden werden z.B. Cocconeis peltoides, Dimerogramma minor, Navicula crucifera, Nitzschia acuminata und linkei, Pinnularia ambigua und cruciformis, Plagiogramma staurophorum und Tropidoneis lepidoptera genannt, während dagegen Tropidoneis elegans und Surirella gemma eher einen weichen Schlickboden bevorzugen dürften. Hauptsächlich auf Sand, vercinzelt auch auf Schlick, leben Navicula finnmarchica und forcipata, Amphora laevissima, Nitzschia spathulata und panduriformis, Pleurosigma aestuarii und Triceratium alternans. Indifferent in

-) Geologische Dienst, Haarlem. bezug auf den Boden scheinen zu sein: Navicula flanatica und phyllepta, Rhaphoneis amphiceros, Amphora coffeaeformis, Achnanthes hauckiana, Nitzschia hybrida, Plagiogramma vanheurckii, Diploneis bombus und Opephora pacifica, die sowohl auf Sand- als auf Schlickboden vorkommen.

Was von den Bodendiatomeen gilt, kann in gewissem Sinne auch von den Planktonarten gelten, die in den tiefen Stromrinnen und in den untiefen Prielen und Wattenlachen vorkommen. Zwar ist für diese Arten die Möglichkeit zum Austrocknen gering, aber auch sie sind einer stark wechselnden Salzkonzentration, Temperatur und Lichtquantität ausgesetzt. Selbstverständlich kommen die echten Planktondiatomeen im Dollart-Emsgebiet nur in den tiefen Stromrinnen vor, in denen die Gezeitenbewegung eine wichtige Rolle spielt. Daneben ist jedoch die Zufuhr von Süßwasser aus der Ems und vom umgebenden Land von großem. Einfluß auf die Entwicklung des Planktons. Mit der Flut wird Plankton aus dem Wattenmeer mittransportiert, aber dieses stirbt infolge der sich schnell ändernden ökologischen Umstände größtenteils ab in einem Raum, der sich zwischen den imaginären, über die Tonnen G2-E4 und G3-E6 gezogenen Linien, etwa $10 \mathrm{~km}$ NO von Knock befindet.

Auf dieser Strecke findet Sedimentierung abgestorbener Diatomeen und anderes organischen Materials statt.

Von den vielen nur ziemlich schwach verkieselten planktonischen Wattenmeer-Diatomeen (Biddulphia sinensis, Chaetoceros spec., Guinardia flaccida, Lithodesmium undulatum, Lauderia borealis, Rhizosolenia spec., Thalassiosira spec., u.a.) lösen sich die Schalen schon auf, bevor sie den Boden erreicht haben; auch werden sie vom Ebbestrom zu einem großen Teil 
wieder nach dem Wattenmeer zurückbefördert. Diese Planktondiatomeen findet man im Bodenmaterial der Rinnen also kaum zurück. Die wenigen in diesem Material befindlichen Diatomeen sind vertreten durch die leeren Schalen neritisch-mariner Arten der Geschlechter Coscinodiscus, Actinocyclus, Podosira, Melosira, u.a., manchmal vermischt mit den gleichfalls leeren Schalen etwa fluvialer Süßwasserarten wie Melosira granulata, Diatoma elongatum, Synedra spec. und Epithemia spec.

Diese Diatomeen findet man außer im Bodenmaterial aus Rinnen und Prielen, auch örtlich abgelagert im Material der Platen. Da herrschen jedoch Arten vor, die sich an Ort und Stelle entwickeln und bei Niedrigwasser eine gelbbraune oder gelbgrüne Schicht am Boden bilden. Bei einer Untersuchung stellt es sich heraus, daß sie aus einer ungeheuer großen Anzahl von Individuen von manchmal nur einer geringen Anzahl Spezies besteht: Pleurosigma angulatum, Gyrosigma balticum und fasciola, Nitzschia sigma, Navicula digitoradiata, u.a.

Manche dieser Arten scheinen Antagonisten zu sein; sie bilden dann und wann durch ein "Niemandsland" voneinander getrennte Stellen. Eine diesbezügliche nähere Untersuchung würde unsere Kenntnisse von der Ökologie der Diatomeen ohne Zweifel vergrößern. Sowohl die planktonischen ${ }^{\circ}$ ) als die benthonischen ${ }^{\circ}$ ) Diatomeen fördern die Sedimentbildung und also die
Zunahme des Bodenmaterials, durch Absonderung von Gallertmassen, sei es um die im Wasser schwebenden, oft zu Kolonien vereinigten Zellen herum, sei es um die sich auf dem Sand oder Schlick mit Hilfe ihrer Rhaphe fortbewegenden Individuen. Im ersten Fall wird auch der im Wasser befindliche Schlamm gefangen, so daß sich Flocken bilden, die leicht auf den Boden heruntersinken und dort bei nicht zu großer Stromstärke mittels besonderer Bodenarten (Cymatosira belgica, Plagiogramma vanheurckii, u.a.) festgelegt worden. Im zweiten Fall werden die mit der Flut herbeitransportierten, sich über den Platen befindenden Schlammpartikeln nach Ablagerung von den Bodendiatomeen zusammengeleimt und während der Ebbe mit einer Schicht sich lebhaft bewegender Individuen bewachsen und so verankert.

Da die vorliegende Dollartuntersuchung an erster Stelle von sedimentologischem Standpunkt aus vorgenommen wurde, ist so viel wie möglich versucht worden, den Einfluß der Diatomeen auf die Sedimentbildung zu verfolgen, 1. durch die Feststellung, ob da, wo durch das Absterben des Planktons starke Sedimentierung organischer Stoffe stattfindet, die Diatomeen eine wichtige Rolle spielen, 2. durch die Untersuchung, welche Diatomeen bei der Ablagerung des herbeitransportierten oder an Ort und Stelle gebildeten Materials in der Hauptsache mitwirken.

\section{UNTERSUCHUNGSMETHODEN}

Für das Feststellen der Zonen, wo das Absterben stattfindet, wurden aus dem Wasser der Ems von der Mündung bis etwa $30 \mathrm{~km}$ stromaufwärts Planktonproben entnommen, manchmal an der Oberfläche sowie am Boden. Eine immer gleiche Wassermenge wurde durch ein feinmaschiges Planktonnetz gegossen und die mikroskopische Untersuchung des lebenden Fanges gab nicht nur ein Bild der wichtigsten Diatomeen, die an der Stelle der Probeentnahme anwesend waren, sondern auch des Zustandes, in dem sie sich befanden. Auch auf andere vorhandene Organismen richtete sich die Aufmerksamkeit, besonders wenn sie in großen Mengen auftraten und mehr oder weniger kennzeichnend für süßeres, mehr oder weniger verschmutztes Wasser (Rotatoria, Tintinnoidea) waren. Nachdem die lebende Materie beobachtet worden war, wurde sie in die Probeflasche zurückgespült und fand Fixierung mit Formalin statt. Nach einem einstündigen Niederschlag in einem Meßglas wurde das Sedimentsvolumen festgestellt.

-) Besser: planktischen und benthischen.
Die benthonischen Diatomeen wurden durch vorsichtiges Abkratzen einer dünnen Schicht des Bodenmaterials gesammelt und auch sie wurden wo möglich gleich in lebenden Zustand unter dem Mikroskop beobachtet. Um der oft anwesenden Foraminiferen willen fand dann Fixierung mit 96-prozentigem $\mathrm{Al}-$ kohol statt.

Von beiden Kategorien wurden später Diatomeenpräparate gemacht, 1. durch Färbung eines kleinen Teiles des Materials mit Rose bengale, so daß an der karminroten Farbe des Zelleninhalts und der Chromatophoren festgestellt werden konnte, welche Arten tatsächlich lebend vorkamen und welche nur als leere Schalen oder abgestorbene Individuen vertreten waren; 2. durch Behandlung mit $\mathrm{H}_{2} \mathrm{O}_{2}$ und $\mathrm{KMnO}_{4}$, wobei durch die starke Oxydation der organische Inhalt der Diatomeen zerstört wurde und die Schalen nach Auswaschung in Syrax oder Hyrax für die nähere Artenbestimmung eingeschmolzen wurden. Nach Determination der Mehrzahl der vorhandenen Arten wurde das prozentuale Verhältnis für die 
Anzahl der marinen (M), brackischen (B) und süßen (S) Arten bestimmt. Um einen Einblick in die ökologischen Verhältnisse zu gewinnen, wurden die Ergebnisse dieser MBS-Bestimmung mit denen der

\section{EINTEILUNG DER}

A. Die benthonischen Diatomeen.

a. auf den Platen und Küstenstreifen in

I. der," Oude Westereems" bis Rottumeroog;

II. der Emsmündung und dem „Oostfriesche Gaatje;

III. dem Dollart;

b. auf dem Boden der Flüsse;

IV. Emsflusses (+ Leda bis Leer);

c. auf den Rändern der Platen an den Rinnen und Prielen;

d. auf dem Boden der Rinnen und Priele.
Bestimmungen über $\mathrm{NaCl}, \mathrm{CaCO}_{3}$, organische Stoffe, Schlamm- und Sandgehalt des Bodens verglichen, welche von anderen Mitarbeitern vorgenommen wurden.

\section{A. Die Benthonischen Diatomeen}

Die benthonischen Diatomeen wurden untersucht:

Gebiet I, Oude Westereems bis Rottumeroog:

Gebiet II, Emsmündung und Oostfriesche Gaatje:

Gebiet III, Dollart:

Gebiet IV, Emsfluß:

Von diesen Gebieten wurden insgesamt 229 Proben untersucht und darin wurden 133 an Ort und Stelle lebende und außerdem 113 abgestorbene Arten von Diatomeen beobachtet. Vgl. die dazugehörigen Pro- a. auf den Platen und Küstenstreifen von:

Profil 1, Sparregat $\mathrm{O} \rightarrow \mathrm{W}(1956)$

Profil 2, Sparregat SO $\rightarrow$ NW (1954)

Profil 3, Oostmolen Goliath (1956)

Profil 4, Robben Plate (1954)

Profil 5, Paap Plate (1954)

Profil 6, Küstenstreifen zwischen Delfzijl und Oterdum (1956)

Profil 7, Noordwad, südlich von Reide (1953)

Profil 8, Kerkeriet Plate (1953)

Profil 9, Kerkeriet-, Reider- und Hering Plate (1954)

Profil 10, Maan Plate (1954)

Profil 11, Hoogzand Plate (1954)

Profil 12, Geise Plate (1954)

b. auf dem Boden des Flüssen Ems und Leda von Emden bis Leer (1954).

file 1-16 und die Probenlisten und graphischen Stabdarstellungen 1-16. Von den Tafeln 4, 8, 11 und 1316 sind keine Profilzeichnungen vorhanden.

\section{ALLGEMEINES}

Es stellte sich heraus, daß die Platen und Küstenstreifen sehr einförmig mit Diatomeen bewachsen waren. Von den 126 dort lebend angetroffenen Arten bilden nur 55 die eigentliche Vegetation des Bodens.
Diese Arten kamen näml. in den Untersuchungsabschnitten mindestens an 5 bis 10 v.H., jedoch meistens an 25 bis 50 v.H. oder mehr der Stationen, wo Probeentnahme stattfand, vor; an keiner einzigen 
Station wurden jedoch alle 55 Arten zugleich angetroffen, die Höchstzahl betrug 45 (Tafel C). Die übrigen 71 Arten kamen sehr zerstreut, örtlich aber in großer Individuenzahl vor. In letzterem Fall war eine solche Art kennzeichnend für ein bestimmtes Milieu, das aber durch das Fehlen ausführlicher chemischer und physikalischer Daten nicht näher umschrieben werden kann. Zwar konnten die Daten über den Gehalt an $\mathrm{NaCl}, \mathrm{CaCO}_{3}$ und organischen Stoffen im Boden benutzt werden, aber es zeigte sich, daß diese Werte, in Prozenten ausgedrückt und in bezug auf den trockenen Boden, für die Entwicklung der Diatomeen in ihrem wasserreichen Milieu keine Bedeutung hatten. Wohl ergab es sich, daß eine deutliche Wechselbeziehung bestand zwischen dem Gehalt an Schlamm, organischen Stoffen, $\mathrm{CaCO}_{3}$ und manchmal $\mathrm{NaCl}$ in dem Sinne, daß deren Werte zunahmen bei abnehmendem Sandgehalt und geringer wurden, wenn der Sandprozentsatz stieg. Veränderungen im Schlamm- und/oder Sandgehalt verursachten keine Änderungen im MBS-Verhältnis der Diatomeen, obgleich dadurch manchmal Artenverschiebungen stattfanden.

Neben der genannten Anzahl von 126 lebenden benthonischen Arten wurden von 96 weiteren Arten die leeren Schalen angetroffen, so da $B$ angenommen werden darf, daß in den Sommersaisonen 1953-1956 auf den Platen und Küstenstreifen im Dollart-Emsgebiet mindestens 222 benthonische Diatomeenarten vorkamen. Ohne Zweifel war diese Anzahl noch größer, aber eine vollständige Bestimmung aller vorhandenen Diatomeenarten fiel aus dem Rahmen der Untersuchung. Außerdem fanden sich diese weiteren Arten in einer so geringen Individuenzahl, da $\beta$ sie bei der Sedimentbildung kaum eine Rolle spielten.

Die Diatomeenvegetation auf den Platen wechselte von Jahr zu Jahr ziemlich stark und schien unter anderm von den Witterungsverhältnissen abhängig zu sein. So war in dem kalten, nassen Sommer des Jahres 1954 die Vegetation ärmer als im Jahre 1956, als die Verhältnisse durch höhere Temperaturen und größere Lichtintensitäten günstiger waren. $\mathrm{Da}$ die Probeentnahmen in verschiedenen Jahren erfolgten, hat es sich herausgestellt, daß eine gute Vergleichung der Vegetationen nicht möglich war. Außerdem fanden sie alle ausschließlich in den Sommermonaten statt, so daß dies keine Ubersicht der Vegetationen in den verschiedenen Jahreszeiten ergab.

Trotzdem hat sich folgendes gezeigt:

1. daß auf den höheren Teilen der Platen und Küstenstreifen eine beschränkte Anzahl von Diatomeenarten, manchmal in großer Individuen- anzahl, lebt, während sich an den niedrigeren, an den Rinnen und Prielen gelegenen Stellen meistens weniger, aber manchmal mehr Arten entwickeln, die dann jedoch in einer geringeren Individuenanzahl auftreten;

2. daß von der Geise Plate bis an die Paap Plate regelmäßig ungefähre Süßwasserarten lebend vorkommen, oft bis oder über 10 v.H. der sämtlichen Artenanzahl, mit Ausnahme des Küstenstreifens zwischen Oterdum und Delfzijl; NW der Paap Plate werden diese Diatomeen nur ganz ausnahmsweise lebend angetroffen;

3. daß die Diatomeenvegetation der Platen im Dollart-Emsgebiet zum ausgesprochen brackischen Typ gehört; in den meisten Fällen gehören etwa $50 \%$ der Arten zu der B-Gruppe (Cl-Gehalt des Wassers 1.000-5.000, S-Gehalt 1.800-9.000 mg/l). Dies gilt in besonderem Maße für die „Maan Plate“, die Kerkeriet-, Reider- und Hering Plate und den „Noordwad“ S von Reide, wo sogar bis $87 \%$ B-Arten vorkommen kann;

4. daß bestimmte Arten von Diatomeen im ganzen Gebiet auf allen Platen und Küstenstreifen angetroffen werden und andere Arten in größerem oder geringerem Maße auf spezifische Milieus beschränkt sind (Tafel $C$ und $D$ ).

Letztere Erscheinung führt zu der Besprechung (a) der Diatomeenvegetation auf den einzelnen Platen und Küstenstreifen, wobei die Namen der Arten in ökologischer Folge angeordnet sind.

Gebiet I, „Oude Westereems“

Profil 1, „Sparregat" $W \rightarrow O$ (1956) (VIII)

(Vgl. Tafel 1)

In diesem stark sandigen Milieu wurden 50 lebende Diatomeenarten angetroffen, von denen 5 über den ganzen Teil der Plate, der bei Ebbe bloßgelegt wird, vorkamen und zwar Biddulphia aurita, Cymatosira belgica, Nitzschia spathulata, Plagiogramma vanheurckii und Pleurosigma aestuarii. Nur einige dieser Arten, namentlich Biddulphia aurita, Cymatosira belgica und vielleicht vereinzelt Plagiogramma vanheurckii kamen auch auf dem Boden der untiefen Priele vor; die meisten anderen Arten, unter denen Melosira sulcata, Nitzschia panduriformis und insbesondere Navicula rostellata bevorzugten in diesem Gebiet die höheren Teile und kamen in den Prielen oder auf deren Rändern kaum vor. Eine Ausnahme bildete Pleurosigma aestuarii, die zwar überall vor- 
kam, ihre größte Entwicklung jedoch auf einem hochgelegenen Punkt erreichte. Diese Art bildete zusammen mit Navicula rostellata die Hauptvegetation des zentralen Teiles der Plate. Merkwürdig war da das häufige Auftreten der gesellig lebenden Blaualge Merismopedia glauca (Ehr.) Naeg., die sowohl in süßem als in brackischem Wasser über einem Schlickboden vorkommt, die aber in der westlichen Ostsee bei einem durchschnittlichen S-Gehalt an der Oberfläche von 15-19\% (etwa $5.000-10.000 \mathrm{mg} / \mathrm{Cl} / \mathrm{l}$ ) nicht mehr vorhanden ist (LAKowrTz, 1929). Da diese Alge zusammen mit der Brackwasserdiatomee Nitzschia tryblionella var. debilis lebend im "Sparregat" vorkam, muß da der Oberflächensalzgehalt der Gebiete, die bei Ebbe bloßgelegt werden, ab und zu viel niedriger gewesen sein und nicht mehr als höchstens $2 \%$ (etwa $1100 \mathrm{mg} / \mathrm{Cl} / \mathrm{l}$ ) betragen haben. Es stellte sich heraus, daß hier ziemlich viel Tintinnoidea (Protozoa) vorkamen, was auf die Zufuhr von nährstoffreichem, mehr oder weniger verschmutztem Wasser hinweist. Die Anwesenheit leerer Schalen der sessilen Diatomeen Rhoicosphenia curvata und Cocconeis placentula ist gleichfalls ein Beweis dafür. Vermutlich zog also im Moment der Probeentnahmen ein Wasserstrom in NW Richtung nach dem Wattenmeer, der aus dem Groninger Kanalisierungssystem herrührte.

Die Schlußfolgerungen bezüglich dieses Profils beruhen auf einer Probeentnahme vom 6. September 1956. Am 19. September 1956 konnte am Nachmittag bei Ebbe wieder eine der Sandplaten im Sparregat besucht werden und es war möglich, die an vier Stellen lebende Diatomeenflora an Ort und Stelle zu untersuchen.

Stelle 1 bestand aus ziemlich trockenem, geriffeltem Sand und war hauptsächlich mit Nitzschia closterium bewachsen, die sich schnell und lebhaft zwischen den Sandkörnern fortbewegte.

Stelle 2 war etwas nässer und schlammreicher; da bestand die Vegetation aus Nitzschia closterium, Pleurosigma aestuarii und Amphiprora alata.

Stelle 3 war der Rand einer kleinen Priele, wo hauptsächlich Pleurosigma aestuarii und eine Navicula spec. die Vegetation bildeten.

Stelle 4 bestand aus schlammigem Sand, der mit Pleurosigma aestuarii und vermutlich Navicula digitoradiata dicht bewachsen war.

Aus diesen mit einigen Wochen Zwischenraum, bei verschiedenen Witterungsverhältnissen und Belichtungen vorgenommenen Probeentnahmen geht hervor, wie variabel die Bodenvegetation in demselben Gebiet sein kann. In den Proben vom 6. September 1956 kamen Nitzschia closterium und Amphiprora alata noch nicht vor; am 19. September 1956 waren beide Arten massenhaft vorhanden! Eine gute Ubersicht der Sedimentierung im Dollart-Emsgebiet mit Hilfe der Diatomeen könnte man denn auch nur bekommen, wenn an einigen charakteristischen Stellen wenigstens einmal im Monat während eines Jahres unter allen Witterungsverhältnissen und zu verschiedenen Stunden eine Probeentnahme stattfände.

\section{Profil 2, ,Sparregat“ NW $\rightarrow$ SO (1954) (VI)}

(Vgl. Tafel 2)

In diesem Profil wurden 38 Arten Diatomeen lebend wahrgenommen; 23 davon stimmten mit den im Jahre 1956 im Profil 1 (,Sparregat" $\mathrm{W} \rightarrow \mathrm{O}$ ) angetroffenen Arten überein. Profil ,Sparregat“ NW $\rightarrow$ SO wurde gekennzeichnet durch das Auftreten von Biddulphia aurita, Cymatosira belgica, Pleurosigma aestuarii, Tropidoneis vitrea, Amphora proteus, Gyrosigma balticum und Navicula digitoradiata über die ganze Länge. Es zeigte sich, daß der Rand der „Sparregat"-Priele sehr sandig war und in Ubereinstimmung damit war der $\mathrm{NaCl}$ - und $\mathrm{CaCO}_{3}$-Gehalt ziemlich niedrig. Die Diatomeenflora hatte da jedoch einen ausgesprochen marin-brackischen Charakter (MB), der sich auf dem flachen, höher gelegener. Teil der Plate plötzlich änderte und bei annähernd gleichem $\mathrm{NaCl}-$ und $\mathrm{CaCO}_{3}$-Gehalt des Bodens einen viel weniger salzigen Charakter bekam, mit einem sogar deutlich süßen Einschlag an Station 323 (MBS $58: 32: 10$ ). Obgleich dieser Einschlag an Station 324 schon geringer wurde und bei 325 ganz schwand, machte die Diatomeenvegetation des Bodens nach wie vor einen brackischen Eindruck, trotz des an dieser letzten Station plötzlich stark zunehmenden $\mathrm{NaCl}-$ und $\mathrm{CaCO}_{3}$-Gehalts und der zunehmenden Menge an Schlamm und organischen Stoffen. An Station 326 war der Boden wieder viel sandiger und mit einer geringeren Menge an Schlamm und organischen Stoffen hatte er nur einen mäßigen $\mathrm{NaCl}$ und $\mathrm{CaCO}_{3}$-Gehalt. Die Diatomeenflora war hier arm an Arten (9!), aber zeigte gleichfalls eine deutlich brackische Zusammensetzung (MBS $44: 56: 0$ ), die auch an den folgenden Stationen zum Ausdruck kam, obschon der Gehalt an $\mathrm{NaCl}, \mathrm{CaCO}_{s}$, Schlamm und organischen Stoffen des Bodens wieder zunahm. Der brackische Charakter wurde noch verstärkt durch das Auftreten der Blaualge Merismopedia glauca (Ehr.) Naeg. an Station 322, gerade dort, wo der salzige Platenrand zum süßeren mittleren Teil hinübergeht. Nicht nur im Jahre 1956, sondern auch im Jahre 1954 gab es also in diesem Gebiet schon einen Strom von mehr oder weniger süßem, eutrophem Wasser, so da $\beta$ angenommen werden darf, daß hier nicht von 
einer gelegentlichen Situation gesprochen werden muß, sondern von einer, auf jeden Fall in den Sommermonaten regelmäßig auftretenden Erscheinung. Der Inhalt des Bodenmaterials, das am 13. August 1954 nordwestlich von Rottumeroog gesammelt wurde, ergab, was die Diatomeen betrifft, nichts Besonderes. (Vgl. Tafel 2).

Gebiet II, „Oostfriesche Gaatje“ und Emsmündung Profil 3, „Oostmolen Goliath“ (1956) (IX)

(Vgl. Tafel 3)

Die Diatomeenvegetation dieses Küstenstreifens zeigte ein sehr gleichmäßiges Bild. Es wurden 66 Arten Diatomeen lebend angetroffen, von denen 17 Arten über die ganze Länge des Profils: Amphora laevissima, Biddulphia aurita, Cymatosira be'gica, Melosira sulcata, Navicula cancellata, Navicula crucifera, Nitzschia spathulata, Striatella delicatula, Navicula forcipata, Navicula phyllepta, Gyrosigma fasciola, Nitzschia hybrida, Amphora coffeaeformis, Amphora proteus, Navicula digitoradiata, Nitzschia apiculata und Navicula rostellata. Nur am äußersten Rand der Plate kam außerdem die litorale Planktondiatomee Coscinodiscus granii vor; an diesem Rande und einige hundert Meter einwärts auf der Plate wurden als mehr besondere Arten Nitzschia linkei, Thalassiosira decipiens und Tropidoneis lepidoptera angetroffen, beide letztere auf ungefähr der halben Länge des Profils. Achnanthes hauckiana kam hauptsächlich auf dem höher gelegenen Teil der Plate vor; Navicula rostellata erreichte hier eine optimale Entwicklung. Plagiogramma staurophorum, Pleurosigma angulatum, Amphiprora alata, Nitzschia punctata fo. constricta und Cylindrotheca gracilis beschränkten sich ausschließlich auf den Teil des Küstenstreifens, der auf den Deich zu immer mehr ansteigt.

Die Stationen 396 und 398, in geringer Entfernung von einem Damm der Landgewinnungsarbeiten, zeigten einen stärker brackischen Einschlag als die übrigen (MBS resp. 55: 45:0 und 57:43:0); ein deutliches Süßwasseranzeichen fehlte jedoch.

Die häufig auftretende Blaualge Merismopedia glauca und die vereinzelte Anwesenheit leerer Schalen sessiler, eutropher mehr oder weniger Süßwasserdiatomeen wie Cocconeis pediculus und Cocconeis placentula wiesen darauf hin, daß auch in diesem Gebiet im Jahre 1956 sich eine mehr oder weniger nährstoffreiche, süßere Oberflächenströmung in der Richtung des Wattenmeeres bewegte. Um einen höheren Gehalt an $\mathrm{CaCO}_{3}$, organischen Stoffen und Schlamm (und vielleicht auch an $\mathrm{NaCl}$ ) im Boden kümmerten die Diatomeen sich nicht; eine Flora von nahezu derselben Zusammensetzung wurde sowohl vor dem obenerwähnten Damm beobachtet als am Damm selbst.

\section{Profil 4, Robben Plate (1954) (Vgl. Tafel 4)}

Für diese Plate konnte man einen Sand- und einen Schlammteil unterscheiden, letzterer mit einem hohen Gehalt an organischen Stoffen, $\mathrm{NaCl}$ und $\mathrm{CaCO}_{3}$. In den 4 Proben, die von der Plate selbst herrühren, kamen 26 Arten Diatomeen lebend vor; 8 dieser Arten, näml. Biddulphia aurita, Cymatosira belgica, Melosira sulcata, Plagiogramma vanheurckii, Striatella delicatula, Tropidoneis vitrea, Gyrosigma balticum und Navicula digitoradiata kamen auf der ganzen Länge des Profils vor, sowohl auf dem Sand- als auf dem Schlammteil. Navicula forcipata dagegen fand sich ausschließlich auf dem Sandteil, Rhaphoneis amphiceros ausschließlich auf dem Schlammteil, obgleich diese Art, die sich auch gerne an Sandkörner hängt, dafür nicht kennzeichnend ist. Die Blaualge Merismopedia glauca wurde in diesem Gebiet nicht angetroffen, aber dennoch wiesen die vereinzelt vorkommenden leeren Schalen der Diatomee Cocconeis placentula u.a. auch hier auf eine Mischung des salzigen Wassers aus der Emsmündung mit eutrophem, mehr oder weniger süßem Wasser hin.

In hohem Maße wurde dieser Hinweis verstärkt durch das MBS-Verhältnis der leeren Diatomeenschalen am Boden einer an die Robben Plate grenzenden Rinne (Probeentnahmestelle 311), das 61 : $34: 5$ betrug.

Auf dem Boden dieser Rinne gab es keine Diatomeenvegetation; gegenüber einer großen Armut an lebenden Arten (nur 4) stand eine ziemlich große Anzahl Arten, von denen nur die leeren Schalen anwesend waren (44). Vermutlich werden diese Schalen nach dem Absterben der Individuen aus der Umgebung in die Rinne hineingespült, in der sie sich dann offenbar ablagern können. Es ist jedoch auch denkbar, daß die Individuen lebend aus der Umgebung herbeitransportiert werden, in der Rinne keine Möglichkeit finden, sich $\mathrm{zu}$ behaupten und sich zu vermehren, und nach dem Absterben wie ein fortwährender „Regen“ leerer Schalen unter gewissen Umständen niederschlagen.

Profil 5, Paap Plate (1954) (V) (Vgl. Tafel 5)

Die Ränder dieser Plate zeigten nur eine ärmliche Vegetation an Diatomeen, sogar an der Probeentnahmestelle 263, wo der Boden schlammreich war und infolgedessen einen hohen Gehalt an organischen Stoffen, $\mathrm{CaCO}_{3}$ und $\mathrm{NaCl}$ besaß. Insgesamt wurden 72 Arten lebend wahrgenommen, hauptsächlich jedoch auf dem höher gelegenen flachen Teil der Plate. 
Hie und da wurden auch mehr oder weniger süßje Arten lebend angetroffen. Etwa 20 Arten kamen über die ganze Länge des Profils vor: Biddulphia aurita, Cymatosira belgica, Melosira sulcata, Navicula finnmarchica, Navicula palpebralis, Nitzschia panduriformis, Plagiogramma vanheurckii, Striatella delicatula, Navicula flanatica, Navicula forcipata, Navicula phyllepta, Pleurosigma aestuarii, Rhaphoneis amphiceros, Tropidoneis vitrea, Amphora coffeaeformis, Amphora holsatica, Amphora proteus, Navicula digitoradiata, Navicula rostellata und Nitzschia sigma. Einige Arten: Tropidoneis lepidoptera und Pinnularia ambigua beschränkten sich hauptsächlich auf den westlichen Teil der Plate, der etwa ein Drittel der ganzen Breite umfaßt; Gyrosigma fasciola, die auch in der Hauptsache an der Westseite vorkam, erreichte ungefähr die halbe Breite der Plate.

Von West nach Ost nahm der $\mathrm{NaCl}-$ Gehalt des Bodens allmählich zu; Versalzung des Milieus zeigte sich auch einigermaßen im MBS-Verhältnis der Diatomeen, dessen Prozentsatz mariner (M) Arten in W-O Richtung gleichfalls langsam zunahm. Von einem deutlichen Zusammenhang zwischen den Diatomeen und dem Sand/Schlamm-Verhältnis mit den besonders mit letzterem verbundenen Gehaltwerten an organischen Stoffen, $\mathrm{CaCO}_{3}$ und $\mathrm{NaCl}$ des Bodens war auch in diesem Gebiet nichts bemerkbar.

Das ziemlich häufige Auftreten von Tintinnoidea könnte auch hier auf eine periodische Überschwemmung der Plate mit nährstoffreichem, mehr oder weniger verschmutztem Wasser hinweisen.

Profil 6, Küstenstreifen zwischen Oterdum und Delf$\approx i j l$ (1956) (VII) (Vgl. Tafel 6)

Die Proben dieses Küstenprofils gaben auf einer verhältnismäßig kurzen Strecke ein vollständiges und deutliches Bild der Zusammensetzung des Bodens und der darauf vorkommenden Diatomeen. An der Dollartseite des Profils war der Boden sehr sandig und wenig schlammreich. Der Gehalt an organischen Stoffen und $\mathrm{CaCO}_{3}$ war niedrig. Der NaCl-Gehalt des Bodens wurde nicht bestimmt, aber der Cl-Gehalt des Wassers muß zwischen 6000 und $8000 \mathrm{mg} / 1$ (S 10.800 und $14.400 \mathrm{mg} / \mathrm{l}$ ) gewesen sein. Der steil ansteigende Küstenstreifen wurde in der Richtung NO-SW weniger sand- und mehr schlammhaltig; infolgedessen nahm der Gehalt an organischen Stoffen und $\mathrm{CaCO}_{3}$ allmählich zu. Zwischen dem sandigen Teil des Küstenstreifens und dem Deich befand sich eine etwa $100 \mathrm{~m}$ breite Depression, in der der Schlammgehalt zusammen mit dem an organischen Stoffen und $\mathrm{CaCO}_{3}$ plötzlich stark anstieg. Die Diatomeenvegetation des Bodens kümmerte sich nicht sehr um diese Unterschiede. Zwar war die Entwicklung der Brackwasserarten an den Stationen 342 und 352 etwas stärker, aber von einem deutlichen $\mathrm{Zu}$ sammenhang mit der Zusammensetzung des Bodens konnte nicht die Rede sein. Süße Diatomeenarten kamen überhaupt nicht vor. Insgesamt wurden nur 25 Arten lebend angetroffen, von denen 6 über nahezu die ganze Länge des Profils. Es waren Cymatosira belgica, Pleurosigma angulatum, Striatella delicatula, Pleurosigma aestuarii, Nitzschia hybrida und Navicula digitoradiata.

Biddulphia aurita und Melosira sulcata kamen hier nicht mehr über die ganze Länge ohne Unterbrechung vor; Thalassiosira decipiens und Navicula flanatica befanden sich ausschließlich auf dem höheren mittleren Teil des Küstenstreifens. Die Diatomeenflora war im allgemeinen ziemlich arm, sowohl an Arten als an Individuen.

\section{Gebiet III, Dollart}

Profil 7, „Noordwad“ südl. von Reide (1953) (I)

(Vgl. Tafel 7)

Nahezu dasselbe Bild, das Profil 6, der Küstenstreifen zwischen Oterdum und Delfzijl, im Jahre 1956 zeigte, konnte schon im Jahre 1953 auf dem "Noordwad“ beobachtet werden. Auch hier ein ziemlich steil ansteigender Küstenstreifen an einer tiefen Rinne auf der Ostseite, im allgemeinen stark sandig und nur am äußersten Rande etwas schlammreicher und mit einem höheren Gehalt an organischen Stoffen, $\mathrm{CaCO}_{3}$ und $\mathrm{NaCl}$. Bis etwa an die halbe Breite des Küstenstreifens nahm der Sandgehalt des Bodens regelmäßig $a b$, zeigte dann eine plötzliche Abnahme von 67 bis $59 \%$ und senkte sich dann wieder regelmäßig. In demselben Maße nahm der Schlammgehalt und auch der an organischen Stoffen, $\mathrm{CaCO}_{3}$ und $\mathrm{NaCl}$ zu. Auf die Diatomeenvegetation hatten diese Veränderungen keinen deutlichen Einfluß; von einer Artenverschiebung vom sandigen nach dem schlammreichen Teil des Küstenstreifens war nicht die Rede, vielleicht nur dies, daß Bacillaria paradoxa für letzteren Teil eine gewisse Vorliebe zeigte. Im allgemeinen war die Diatomeenvegetation arm, sowohl an Arten als an Individuen. Es wurden 40 Arten lebend wahrgenommen, von denen keine einzige über die ganze Länge des Profils. Für 8 Arten, näml. Cymatosira belgica, Nitzschia panduriformis, Diploneis bombus, Rhaphoneis amphiceros, Amphora proteus und Gyrosigma ivansbeckii wäre dies vielleicht möglich gewesen und vielleicht auch für Gyrosigma fasciola und Nitzschia sigma, denn es zeigte sich, daß diese imstande waren, die offenbar sehr ungünstigen Umstände der Probeentnahmestellen 42 und 43 zu überbrücken. Diese 
beiden Arten verschwanden aber zwischen den Stationen 52 und 57.

Hie und da wies das MBS-Verhältnis der lebend angetroffenen Arten auf einen Einfluß von Süßwasser hin, besonders am östlichen Rande des Küstenstreifens war dies der Fall. Die Vegetation machte als Ganzes einen brackischen und keinen marinen Eindruck. Auffallend war das plötzliche Vorherrschen der Brackwasserart Achnanthes hauckiana an Station 45.

Profil 8, Sand Plate Kerkeriet (1953) (Vgl. Tafel 8)

Der Rand dieser Plate war gleichfalls schlammreich und hatte einen dementsprechend hohen Gehalt an organischen Stoffen, $\mathrm{CaCO}_{3}$ und $\mathrm{NaCl}$. Die über die ganze Profillänge gleichmäßige Diatomeenvegetation, welche 32 lebende Arten umfaßte, machte einen ziemlich brackischen Eindruck und zeigte hie und da einen süßen Einschlag, besonders an den Stationen 74, 76 und 77. Die beiden letzten Stationen waren reich an Individuen. Acht Arten kamen nahezu über die ganze Länge des Profils vor, sowohl auf dem schlammreichen als auf dem sandigen Teil. Es waren Cymatosira belgica, Navicula palpebralis, Navicula forcipata, Pleurosigma aestuarii, Rhaphoneis amphiceros, Amphora proteus, Caloneis amphisbaena var. subsalina und Navicula digitoradiata. Auf dem höheren sandigen Teil kamen besonders Navicula finnmarchica, Opephora pacifica, Pinnularia cruciformis, Gyrosigma fasciola, Hantzschia virgata, Nitzschia linkei und Fragilaria schulzii vor. Von irgendwelchem Zusammenhang zwischen der Diatomeenvegetation und dem Gehalt an Sand/Schlamm, organischen Stoffen, $\mathrm{CaCO}_{s}$ und $\mathrm{NaCl}$ des Bodens konnte auch hier nicht gesprochen werden.

Profil 9, „Hering- und Reider Plate, Kerkeriet und Noordwad" (1954) (III) (Vgl. Tafel 9)

Dieses lange Profil ging über vier hochgelegene Platen, die durch einen breiten Prielen- und Rinnenstreifen (172-190) und zwei kleine Priele (192/193 und 196) voneinander getrennt waren. Erstgenannter bestand aus drei verhältnismäßig untiefen Prielen (171, 181 und 166), die von drei immer tiefer gelegenen Rücken abgewechselt wurden, von denen letzterer in einer tiefen Rinne (66) endete. Es stellte sich heraus, daß der Boden der Hering Plate von $O$ nach W stark sandig, arm an Schlamm und organischen Stoffen war und nur einen mäßigen Gehalt an $\mathrm{CaCO}_{3}$ und $\mathrm{NaCl}$ besaß. Die beiden auf diese Plate folgenden Rücken machten denselben Eindruck, aber auf dem dritten nahm der Sandgehalt ab, der Gehalt an Schlamm, organischen Stoffen und $\mathrm{NaCl}$ langsam $\mathrm{zu}$, während der $\mathrm{CaCO}_{3}$-Gehalt plötzlich stark anstieg. Die Reider Plate zeigte von $O$ nach $W$ einen abnehmenden Sand- und einen zunehmenden Schlammgehalt im Boden, verbunden mit einer entsprechenden Zunahme des Gehalts an organischen Stoffen und $\mathrm{NaCl}$ und einer viel größeren des $\mathrm{CaCO}_{3}$ Gehalts. Auf „Kerkeriet” blieb das Sand/Schlammverhältnis ungefähr dem des westlichen Teiles der Reider Plate gleich; der Gehalt an organischen Stoffen und $\mathrm{NaCl}$ nahm jedoch zu und besonders der Prozentsatz $\mathrm{CaCO}_{3}$ stieg noch fortwährend. Der Küstenstreifen zum Schluß hatte einen etwas geringeren Sand- und einen etwas höheren Schlammgehalt, besonders an der Küste. Dort war auch der Prozentsatz organischer Stoffe und $\mathrm{NaCl}$ höher und besonders der von $\mathrm{CaCO}_{3}$ (gut 10\%)., Ausnahmen bildeten die Stationen 188 und 186, wo ein sehr niedriger Gehalt an Schlamm und ein entsprechender an organischen Stoffen, $\mathrm{CaCO}_{3}$ und $\mathrm{NaCl}$ des Bodens festgestellt wurde, und die Stationen 196 und 206, wo gerade das Umgekehrte der Fall war. Wie auch auf den anderen Platen kümmerte sich die Diatomeenvegetation nicht um diese Unterschiede; sie machte im allgemeinen einen stark wechselnden, mehr oder weniger brackisch-marinen Eindruck und zeigte hie und da einen süßen Einschlag. Dies war besonders der Fall auf der Hering Plate und stellenweise auf der Reider Plate, nur in geringem Maße auf „Kerkeriet“ und überhaupt nicht auf dem Küstenstreifen. Die Anzahl der Diatomeenarten nahm von $O$ nach W allmählich ab.

Es wurden insgesamt 67 Arten wahrgenommen; 9 davon wurden, wenn auch mit einigen Unterbrechungen, über die ganze Länge des Profils angetroffen. Es waren Cymatosira belgica, Nitzschia panduriformis, Nitzschia spathulata, Opephora pacifica, Navicula phyllepta, Rhaphoneis amphiceros, Achnanthes hauckiana, Amphora holsatica und Amphora proteus. Besonders auf der Hering- und Reider Plate und auch auf „Kerkeriet“ wurden Biddulphia aurita, Pleurosigma angulatum, Navicula flanatica und Navicula digitoradiata angetroffen; diese Arten fehlten auf dem „Noordwad“-küstenstreifen fast ganz. Dies war auch im Jahre 1953 der Fall. Navicula palpebralis, Pinnularia cruciformis, Navicula forcipata, Fragilaria schulzii, Navicula rostellata, Caloneis amphisbaena und Opephora martyi beschränkten sich hauptsächlich auf die Hering- und Reider Plate; auf „Kerkeriet“ kamen diese Arten im Jahre 1954 kaum vor, im Gegensatz zum Jahre 1953, als sie, mit Ausnahme der drei zuletztgenannten Arten, auf der ganzen Länge eines etwas nördlicher gelegenen Profils über diese Plate angetroffen wurden. Dagegen wurde Gyrosigma fasciola ausschließlich auf „Kerkeriet" wahrgenommen. Caloneis brevis und Hantzschia 
marina hatten offenbar eine Vorliebe für das Prielenund Rückengebiet zwischen den Probeentnahmestellen 171 und 181, während Nitschia punctata + var. constricta und Nitzschia sigma hauptsächlich auf den höheren Teilen der Reider Plate, von „Kerkeriet“ und des „Noordwad"küstenstreifens vorkamen. Eine außerordentlich reiche Vegetation an Navicula flanatica, Navicula phyllepta und Navicula rostellata wies die Probeentnahmestelle 167 auf, die einen etwas höheren Gehalt an Schlamm und $\mathrm{CaCO}_{3}$ besaß als die benachbarten Stationen.

\section{Profil 10, Maan Plate (1954) (II) (Vgl. Tafel 10)}

Die Maan Plate bildet ein Ganzes, dessen höchster Punkt etwas über NAP liegt. Von der tiefen Rinne an der NW-Seite ging das Profil in der Richtung NWSO bis an die Probeentnahmestelle 145, von der aus die Richtung NNO-SSW eingeschlagen wurde bis an eine schmale, dennoch einige Meter tiefe Rinne (Station 163). Vom NW-Rand bis an den Knick im Profil war der Boden stark sandig und enthielt wenig Schlamm und organische Stoffe; der $\mathrm{CaCO}_{3}$-Gehalt nahm jedoch nach der Mitte der Plate allmählich zu. Der NaCl-Gehalt dagegen war über die ganze Plate ungefähr derselbe und verhältnismäßig gering. Weiterhin im Profil, hinter dem Knick, also in SSWRichtung, sank der Sandgehalt und nahmen die Prozentsätze an Schlamm, organischen Stoffen und $\mathrm{CaCO}_{3}$ zu. Besonders am Rande der Plate war dies der Fall. Die Diatomeenvegetation zeigte ein ganz anderes Bild. Vorwiegend brackisch, mit einem fast für die ganze Länge geltenden süßen Einschlag, nahm die Anzahl lebender Arten nach dem höchsten Punkt der Plate hin erst zu und später, nach dem Knick, allmählich wieder ab. Eine Ausnahme bildete Station 151, wo viele lebende Arten angetroffen wurden. Insgesamt kamen 70 Arten in diesem $\mathrm{Zu}-$ stand vor, von denen 7, wenn auch mit einigen Unterbrechungen, über das ganze Profil. Es waren: Cymatosira belgica, Navicula finnmarchica, Navicula flanatica, Achnanthes hauckiana, Amphora proteus, Navicula digitoradiata und Opephora martyi. Fast nicht an der SSW-Seite der Plate, jedoch weiter überall anwesend waren Biddulphia aurita, Navicula palpebralis und Pleurosigma angulatum; Navicula forcipata fehlte sowohl am NW- als am SSW-Ende des Profils und Rhaphoneis amphiceros kam auf dem am höchsten gelegenen mittleren Teil der Plate nicht vor. Auf den NW-Teil beschränkten sich: Amphora ostrearia, Tropidoneis lepidoptera, Pleurosigma aestuarii und Navicula rostellata; nach dem Knick im Profil traten dafür an die Stelle Nitzschia panduriformis, Nitzschia hybrida, Nitzschia punctata, Amphora coffeaeformis, Amphora holsatica und Navicula clementis. Der höchste Teil der Plate kennzeichnete sich durch die Arten Melosira sulcata, Diploneis didyma, Caloneis amphisbaena, Nitzschia sigma und Navicula hungarica, eine sehr veränderliche Süßwasserart. Auffallend war der einigermaßen zunehmende $\mathrm{NaCl}-\mathrm{Gehalt}$ des Bodens nach dem Knick und der ziemlich starke süße Einschlag, den die Diatomeenvegetation dort zeigte, woraus hervorgeht, daß die Bodendiatomeen vermutlich mehr auf die chemische Zusammensetzung des sie überspülenden Wassers eingestellt sind als auf die des Bodens. Von einer deutlichen Einteilung in "Schlamm“- und „Sand"arten konnte auch nicht gesprochen werden, obgleich die Stationen 160-163 deutlich schlammreicher waren als die übrigen.

Profil 11, Hoogzand Plate (1954) (Vgl. Tafel 11)

Im allgemeinen war der Sandgehalt des Bodens dieser Plate hoch, im Gegensatz dazu war der Gehalt an Schlamm und organischen Stoffen niedrig. Der Prozentsatz $\mathrm{CaCO}_{3}$ nahm vom Rande nach der Mitte der Plate langsam ab; der NaCl-Gehalt war überall ungefähr dasselbe. Ausnahmen bildeten die Stationen 258 und 256, erstere, hoch auf der Plate, mit einem niedrigeren Gehalt and Sand und einem höheren an Schlamm und organischen Stoffen und besonders mit einem stark erhöhten Prozentsatz $\mathrm{CaCO}_{3}$, letztere mit einem hohen Gehalt an Sand und einem ziemlich hohen Gehalt an organischen Stoffen und einem verringertem Prozentsatz $\mathrm{CaCO}_{3}$ !

Die etwas salziger eingestellte Diatomeenvegetation hatte hie und da dennoch einen süßen Einschlag. Insgesamt wurden 46 Arten lebend angetroffen, von denen 15, wenn auch mit Unterbrechungen, über die ganze Länge des Profils. Es waren: Biddulphia aurita, Cymatosira belgica, Navicula crucifera, Navicula palpebralis, Pinnularia cruciformis, Plagiogramma vanheurckii, Tropidoneis lepidoptera, Hantzschia marina, Navicula flanatica, Pleurosigma aestuarii, Achnanthes hauckiana, Amphora proteus, Fragilaria schulzii, Navicula digitoradiata und Navicula rostellata. Vielleicht hätten auch Navicula finnmarchica und Opephora pacifica wohl überall auf dem Profil vorkommen können; sie wurden jedoch an verschiedenen Stationen nicht angetroffen. Navicula phyllepta, Hantzschia virgata, Nitzschia hybrida, Nitzschia linkei, Navicula clementis und Caloneis amphisbaena kamen ausschließlich auf dem östlichen Teil des Profils vor. Es zeigte sich, daß eine Anzahl der genannten Arten besonders an den Stationen 253 und 254 fehlten; anscheinend zeigten diese Stationen keinen Unterschied mit den benachbarten. 
Die Bodenproben aus einem Priel etwas NO des Profils (259-262) ergaben dasselbe Bild wie die Proben der Plate. Die meisten der überall vorhandenen Arten kamen auch auf dem Boden dieses untiefen Priels vor; einige Arten jedoch: Striatella delicatula, Rhaphoneis amphiceros und Amphora coffeaeformis wurden fast ausschließlich in dem Priel wahrgenommen, ebenso wie die Blaualge Merismopedia spec., die an Station 259 angetroffen wurde. Es stellte sich heraus, daß auch in diesem Gebiet die chemische Beschaffenheit des Bodens keinen Zusammenhang mit der Diatomeenvegetation, besonders mit dem MBS-Verhältnis der Arten, zeigte.

\section{Profil 12, Geise Plate (1954) (IV) (Vgl. Tafel 12)}

Es zeigte sich, daß die Geise Plate aus einem sandigeren NO-Teil und einem schlammreicheren SW-Teil bestand; die Grenze zwischen beiden Gebieten lag ungefähr halbwegs der Profillänge, wo die Proben entnommen wurden. Von NO aus nahm der Sandgehalt in der Richtung dieser Grenze $\mathrm{zu}$, der noch verhältnismäßig hohe Gehalt an Schlamm, organischen Stoffen und $\mathrm{CaCO}_{3}$ ab; nach dieser Grenze fand gerade das Umgekehrte statt. Der NaCl-Gehalt des Bodens änderte sich nur wenig. Die Diatomeenvegetation wurde durch die genannten Veränderungen nicht beeinflußt und machte über die ganze Länge des Profils einen gleichmäßig brackischen Eindruck mit einem ziemlich starken süßen Einschlag. Die Gesamtzahl der lebend wahrgenommenen Arten betrug 46; in der Richtung NO-SW nahm die Anzahl vorhandener Arten allmählich ab. Station 237 machte mit nur 3 lebenden Arten einen außergewöhnlich armen Eindruck. Sechs Arten: Cymatosira belgica, Opephora pacifica, Achnanthes hauckiana, Amphora proteus, Fragilaria schulzii und Navicula clementis, kamen mit nicht allzu großen Unterbrechungen über nahezu die ganze Länge des Profils vor. Auf dem sandigeren NO-Teil der Plate wurden Biddulphia aurita, Navicula finnmarchica, Navicula palpebralis, Navicula flanatica, Navicula phyllepta, Nitzschia hybrida, Amphora holsatica und Navicula digitoradiata mehr angetroffen als auf dem schlammreichen SWTeil. Ausschließlich, oder nahezu ausschließlich kamen auf dem NO-Teil vor: Pleurosigma angulatum, Navicula forcipata, Amphora coffeaeformis, Caloneis amphisbaena und Navicula hungarica. Man könnte daraus schließen, daß die Arten beider zuletzt genannten Kategorien gewissermaßen einem Sandboden vorziehen; bei einem Vergleich mit anderen Gebieten zeigt es sich jedoch, daß manche dieser Arten auch auf Schlammböden vorkommen und also in dieser Hinsicht indifferent sind. Es muB also angenommen werden, daß auch andere, noch unbekannte und vielleicht wichtigere Faktoren beim Zustandekommen einer Bodenvegetation von Diatomeen auf dem Watt eine Rolle spielen!

\section{Gebiet IV}

b. Der Emsfluß und die Leda bis Leer (Vgl. Tafel 13) Der Boden der Ems bildet ein für sich bestehendes ökologisches Gebiet. Dieser Boden, der immer unter Wasser steht und oberflächlich abwechselnd von salzigerem oder süßerem Wasser überschwemmt wird, einer ziemlich starken organischen und vielleicht auch chemischen Verschmutzung ausgesetzt ist und in diesem Zusammenhang den Einfluß eines wechselnden Sauerstoffgehaltes erfährt, kann nicht ohne weiteres mit dem des Estuarium verglichen werden. Höchstens besteht eine gewisse Âhnlichkeit mit dem Boden der großen Stromrinne der Emsmündung und des „Oostfriesche Gaatje“, obgleich verschiedene Faktoren u.a. im Zusammenhang mit der größeren Tiefe eine andere Rolle spielen als in der Ems selbst.

Der Boden der großen Stromrinne war schon arm an lebenden Diatomeenarten; es wurden dort insgesamt nur 39 angetroffen, von denen es sich zeigte, daß 4 am verbreitetsten waren. (Vgl. unter Abt. d). Von diesen 4 Arten kamen 3 noch auf dem Boden der Ems beim Wachtschiff Pogum vor, näml. Biddulphia aurita, Cymatosira belgica und Plagiogramma vanheurckii. Auf dem Emsboden zwischen Emden und der Mündung der Leda wurden viel weniger lebende Arten angetroffen, näml. insgesamt 22, während auf dem Boden der Leda bis Leer insgesamt 10 lebende Arten gefunden wurden, von denen $7 \mathrm{zu}$ sammen mit der Ems. Etwas mehr stromaufwärts von Pogum, ungefähr bei Ditzum, wurden nur noch $\mathbf{5}$ lebende Arten beobachtet und noch mehr stromaufwärts, im Gebiet zwischen Oldersum und Kritzum kamen auf dem Boden der Ems keine lebenden Diatomeen mehr vor. Erst hinter Terborg wurden wieder 6 Arten lebend angetroffen, von denen Cyclotella striata und Melosira granulata die wichtigsten waren. Besonders erstere Brackwasserart nahm stromaufwärts mengenmäßig stark zu und kam zwischen Groß Sollborg und der Mündung der Leda in großer Anzahl lebend auf dem Boden der Ems vor. In etwas geringerem Maße war dies der Fall auf dem Boden der Leda in der Nähe von Esklum.

Aus dem Vorhandensein von Süßwasserarten wie Melosira granulata und Melosira varians, Stephanodiscus astraea var. minutula, Fragilaria capucina und Fragilaria intermedia zeigte sich deutlich der Einfluß des süßeren Flußwassers, obgleich sich die Nähe des Meeres durch die größere Anzahl mariner und brack- 
ischer Arten unwiderleglich anzeigte. Aus den Werten des MBS-Verhältnisses der Bodenproben aus dem Jahre 1954 ging jedoch mehr hervor. Stromaufwärts von Pogum, wo das MBS-Verhältnis der lebenden Diatomeen und der leeren Schalen $64: 9: 27 \mathrm{bzw}$. $56: 28: 16$ betrug, kam bis Terborg eine salzige Zone des Absterbens vor, mit einem MBS-Verhältnis für die leeren Schalen von $64: 23: 13,62: 32: 6$ und $60: 30: 10$. Stromaufwärts von Terborg änderte sich dieses Bild plötzlich. Die lebenden Diatomeen zeigten ein MBS-Verhältnis von $17: 33: 50$, die leeren Schalen von $35: 36: 29$, was auf eine starke Versüßung hinweist. Noch mehr stromaufwärts, bei Jengum, fing aber schon eine neue Versalzung an, die jedoch nicht mit dem Meer, sondern vermutlich mit Zufuhr von salzigem Wasser aus dem Binnenland zusammenhing. Das MBS-Verhältnis betrug bei Jengum $17: 67: 16$ bzw. $40: 30: 30$, aus dem eine starke Zunahme der brackischen Arten hervorgeht. In der Richtung der Ledamündung nahm der versalzende Einfluß noch zu, was sich durch eine größere Anzahl $(M+B)$-Arten zeigt, von denen die wichtigste, Coscinodiscus rothii var. normani (= Actinocyclus normanii) mehr als eine mesohaline, denn als eine polyhaline Art zu betrachten ist, so daß von Versalzung durch Meerwasser nicht die Rede sein kann. Da die Verbrackung außerdem auch auf dem Boden der Leda zum Ausdruck kam, muß mit großer Wahrscheinlichkeit eine Salzwasserzufuhr aus dem Binnenland für möglich gehalten werden. (Tafel 13).

c. Die Vegetation auf den Rändern der Platen den Rinnen und Prielen entlang. Vgl. Tafel 14 und 15.

Aus den Beschreibungen der Platen und Küstenstreifen ging schon hervor, da $\beta$ die etwa $10 \mathrm{~m}$ breiten Randzonen im allgemeinen eine weniger artenreiche Diatomeenvegetation zeigten als die höher gelegenen Teile. Außerdem war nur eine geringe Anzahl Arten imstande, sich an der Niedrigwasserlinie zu behaupten und einige davon: Biddulphia aurita, Coscinodiscus granii, Actinoptychus undulatus und Coscinodiscus excentricus gehören mehr zum neritischen Plankton als zu den richtigen Bodenbewachsern, so $\mathrm{da} ß$ in dieser letzten Kategorie nur Cymatosira belgica, Plagiogramma vanheurckii, Pleurosigma aestuarii und Navicula digitoradiata übrigblieben. Unter gewissen Umständen bildeten besonders die beiden zuletztgenannten Arten dennoch eine umfangreiche, individuenreiche Vegetation auf den Uferrändern von Rinnen und Prielen, die dadurch eine gelbbraune Farbe bekamen. Sowohl auf sandigem, als auf schlammreichem Boden kam diese Erscheinung vor und es zeigte sich nicht, daß ein deutlicher $\mathrm{Zu}$ - sammenhang mit dem $\mathrm{CaCO}_{s-}$ oder $\mathrm{NaCl}-\mathrm{Gehalt}$ des Bodens vorlag.

\section{d. Auf dem Boden von Rinnen und Prielen}

(Vgl. Tafel 14 und 15)

Der Boden der tieferen Priele und der Stromrinnen scheint kein günstiges Milieu für die Entwicklung der Diatomeen zu sein. Mit Ausnahme eines kleinen Priels auf der Hoogzand Plate (Tafel 9), in dem eine größere Anzahl lebender Bodenarten angetroffen wurde, machte dieser Lebenskreis einen sehr armen Eindruck. Im östlichen Dollartgebiet, näml. „Schanskerdiep“, „Grote Gat“ und Dollartmündung änderte sich die Anzahl lebend beobachteter Bodenarten von 0-8 pro Station; die Anzahl der nur als leere Schalen angetroffenen Arten wechselte dagegen von 10-50 pro Station. In der Emsmündung wurde dasselbe festgestellt; näml. die Anzahl lebender Arten wechselte von 1-6, die der leeren Schalen von 28-53 pro Station. Mehr nach Westen, in der Bucht von Watum, war die Anzahl lebender Arten pro Station etwas günstiger, näml. 3-15; die der leeren Schalen wechselte von 18-43. In diesem Gebiet wurden insgesamt 37 lebende Arten auf dem Boden der Stromrinne beobachtet, von denen nur eine Art Rhaphoneis amphiceros auf nahezu allen Stationen (Tafel 14).

Ein anderes Untersuchungsgebiet bildeten die Rinnen siidl. von Reide, in denen 0-11 lebende Bodenarten angetroffen wurden, während von 11-39 Arten pro Station nur die leeren Schalen vorkamen. Es wurden da insgesamt 33 Arten lebend beobachtet, von denen 3, Cymatosira belgica, Rhaphoneis amphiceros und Amphora proteus auf nahezu allen Stationen (Tafel 15).

Die große Stromrinne (Gebiete III, II, I)

(Vgl. Tafel 16)

Auch auf dem Boden der großen Stromrinne, die sich von der Ems über das "Oostfriesche Gaatje“, zwischen der Hond- und der Paap Plate hindurch an der "Bocht van Watum“ nach Station 319 in der "Oude Westereems" zwischen Rottumeroog und Borkum erstreckt, kamen auf dem Boden insgesamt nicht mehr als 39 Diatomeenarten lebend vor. Von denen waren nur 4 Arten, Biddulphia aurita, Cymatosira belgica, Plagiogramma vanheurckii und Rhaphoneis amphiceros auf den meisten Stationen vorhanden. Pro Station wechselte die Anzahl lebender. Arten zwischen 0 und 17; die der leeren Schalen jedoch zwischen 24 und 75. Sowohl von den in diesem Gebiet lebend vorkommenden Arten als von denjenigen, die nur als leere Schalen anwesend waren, wurde das MBS-Verhältnis bestimmt (Tafel 16).

Hustedt (1939) hat schon bemerkt, daß im Dol- 
lart-Emsgebiet anscheinend ein Ubermass an nichtmarinen Diatomeen im Sediment vorkommt, gegenüber einer Minderzahl an marinen Arten, obgleich letztere so weit stromaufwärts im Emsfluß angetroffen werden, daß Sedimentzufuhr aus dem Meer wahrscheinlich ist.

In dem von mir untersuchten Material wurden auf der Linie $\mathrm{O}-\mathrm{W}$, die östl. von Emden anfängt und über die Mündung der Ems, das „Oostfriesche Gaatje“, die Verbindung zwischen der Hond- und der Paap Plate und die „Bocht van Watum“ nach Station 319 zwischen Rottumeroog und Borkum in der „Oude Westereems“ verläuft, 82 nichtmarine und 71 marine Arten angetroffen, über 18 Stationen verteilt. Wenn man hierbei eine ähnliche Bearbeitung vornimmt, wie die von HUSTEDT (1939) dann stimmen die Ergebnisse gut miteinander überein, so daß angenommen werden könnte, daß die Diatomeen im Dollart-Emssediment hauptsächlich aus dem Wattenmeer und der Nordsee herbeitransportiert werden.

Eine nähere Betrachtung des MBS-Verhältnisses für die ganze Stromrinne der Ems bis Rottumeroog zeigte jedoch, daß von einer regelmäßig zunehmenden Versalzung dennoch nicht gesprochen werden konnte, daß diese aber örtlich von einer scharf abgegrenzten, ziemlich starken Versüßung unterbrochen wurde. Dies kam besonders zum Ausdruck in dem MBS-Verhältnis der Arten leerer Schalen. An Station 221 z.B. zeigte dieses einen ziemlich starken brackischen Einschlag mit einer süßen Beimischung, die an Station 241 westl. von Emden noch zugenommen hatte (möglicherweise Einfluß des Jade-Emskanals). Sowohl bei den leeren Schalen als bei den lebenden Arten kam dies zum Ausdruck. An Station 242 wurde der salzige Einfluß etwas größer, nahm an Station 281, etwas westl. von Knock noch zu, aber bog an Station 282, etwa $2 \mathrm{~km}$ westlicher, plötzlich scharf nach süß um. Dies läßt sich besonders an dem MBS-Verhältnis der leeren Schalen beobachten. An Station 302, oben am Leitdamm, kam diese Versüßung, die vermutlich mit der Ausmündung des Jade-Emskanals bei Knock zusammenhängt, auch in der lebenden Flora zum Ausdruck. An Station 303 waren alle lebenden Bodendiatomeen verschwunden, während ein hoher Prozentsatz „süßer “ (SB) Arten als leere Schalen vorhanden war. Diese „süßen“ Arten verschwanden an Station 304 und waren auch an Station 244, zwischen den Platen Hond und Paap, nicht mehr da, obgleich sich der brackische Einschlag behauptete. Die wenigen lebenden Arten, die an letzterer Station vorgefunden wurden, waren ausschließlich marin. Von Station 243 bis einschließlich 315 , also im ganzen westlichen Teil der „Bocht van Watum“, war das als leere Schalen auf dem Boden vorkommende Diatomeenmaterial durch einen wechselnden, jedoch abnehmenden Prozentsatz „süßer“ (SB) Arten gekennzeichnet, die westl. der Station 315 nicht mehr vorhanden waren. An den Stationen 243 und 312 setzte sich die lebende Diatomeenflora noch aus brackischen und marinen Arten zusammen, westlich der zuletzt genannten Station wurden aber ausschließlich marine Arten in lebendem Zustande angetroffen. In der „Bocht van Watum“ findet Zufuhr von mohr oder weniger süßem Wasser durch die Schleusen in Delfzijl und die Ausmündungen des Abwassersystems der Städte Groningen und Appingedam statt. Zwar tritt hier kein völliges Absterben auf, aber die Anzahl der auf dem Boden lebenden Diatomeenarten ist nur sehr gering und beträgt höchstens 8. Mehr westlich nimmt diese Anzahl örtlich bis 14 an Station 316 und 17 an Station 318 zu. Es ist jedoch eine Tatsache, daß zugleich unter dem Einfluß des zugeführten ,süßen“ Wassers an bestimmten Stellen eine starke Sedimentierung leerer Diatomeenschalen auftritt; eine solche Stelle scheint sich vor der Landspitze von Knock zu befinden.

\section{Speziell Untersuchungen}

1. Schlickufer bei Farmsum. 2.8.1954 um etwa 23.00 Uhr; vollkommen finster, nur das Leuchttierchen (Noctiluca miliaris) gab wahrnehmbares Licht. Die Diatomeen bildeten eine glimmende Schicht auf dem gerade bloßgelegten Schlick; es waren hauptsächlich die Arten Surirella gemma (BM) und Pleurosigma angulatum (M), beide in optimalen lebendem Zustande.

2. Rand der Hering Plate, NW-Teil Maan Plate, Station 117. 3.8.1954 um 8.30 Uhr bei bewölktem Himmel. Beobachtet wurde: Navicula rostellata (B) in großen Mengen und einige Individuen von Surirella gemma (BM) und Pleurosigma angulatum (M), alle lebend.

3. Geise Plate, Station 222. 29.7.1954, Temperatur des Wassers etwa $16{ }^{\circ} \mathrm{C}$. Keine Vegetation, einige Exemplare der brackischen Arten Navicula rostellata, Surirella gemma und Nitzschia sigma, der marinen Biddulphia aurita und Pleurosigma angulatum und auch der süß-brackischen (SB) Melosira granulata, alle lebend.

4. Geise Plate, Priel $650 \mathrm{~m}$ vom $\mathrm{N}$-Rand, Stationen 236/237. 29.7.1954. Keine Vegetation; vereinzelt lebend: Cylindrotheca gracilis (B) und Nitzschia sigma (BS).

5. Rand der Hoogzand Plate. 3.8.1954. Temperatur des Wassers $23^{\circ} 5$, Lufttemperatur $22^{\circ} 5$ C. Keine 
Vegetation, nur vereinzelt lebend: Navicula rostellata (B) und Nitzschia linkei (BM).

6. NW-Teil der Paap Plate. 5.8.1954. Keine Vegetation, vereinzelt lebend: Surirella gemma (BM), Pleurosigma angulatum (M), und Navicula rostellata (B).

7. Maan Plate. 21.7.1954. Auf trockenen Randleiste in diffusem Tageslicht. Vegetation lebender Pleurosigma angulatum (M), Amphora (spec. div.), Nitzschia linkei (BM), Navicula digitoradiata (B), Navicula rostellata (B), Caloneis amphisbaena (BS), u.a. außerdem viele lebende Kolonien der Blaualge Merismopedia glauca. Nematoden waren in großer Anzahl im Bodenmaterial anwesend; es war merkwürdig, daß mehrere in ihrem Darmkanal viele Diatomeen enthielten, die in kürzeren oder längeren Reihen geordnet waren. Nur spul- förmige Arten wurden im Darmkanal vorgefunden; Pleurosigma angulatum, obgleich in großen Mengen vorhanden, kam nicht darin vor. Vielleicht ist die sigmoide Gestalt dieser Art ungeeignet, aufgenommen zu werden, oder aber ist die Art zu breit, durrch die Mundöffnung hindurchzugehen. Es fragt sich, ob die Diatomeen passiv mit dem Schlamm hineingesogen werden oder ob sie vielleicht aktiv aufgesucht und verzehrt werden.

8. Maan Plate, etwa $1500 \mathrm{~m}$ vom NW-Rand entfernt. 27.7.1954. Zwischen den Randleisten. Es besteht kein Unterschied zwischen den in den Furchen und diejenigen auf den Randleisten vorkommenden Arten, vielleicht etwas weniger $A m$ phoren und etwas mehr leere Schalen der übrigen Arten. Auch hier viel Merismopedia und mit Diatomeen gefüllten Nematoden.

\title{
ZUSAMMENFASSUNG DER BENTHONISCHEN ERGEBNISSE
}

Mit insgesumt wenigstens 246 Arten, von denen 133 lebend, ist das Dollart-Emsgebiet im allgemeinen nicht arm an Diatomeen. Ortlich können diese Organismen in einer so großen Individuenzahl vorkommen, daß der Boden eine gelbbraune Farbe bekommt. Dies ist besonders der Fall auf den höher gelegenen Platen und Küstenstreifen, manchmal aber auch an deren Rändern. In den Rinnen und Prielen kommen nur wenig Diatomeenarten zur Entwicklung. Die $\mathrm{Zu}-$ sammensetzung der Biozönosen weist auf das Milieu eines durch die Gezeiten beeinflußten Brackwassergebietes hin, das in mehr oder weniger deutliche Zonen eingeteilt, in westlicher Richtung salziger wird und über eine Zone des Absterbens in das Wattenmeer hinüberleitet. Die Adsorption chemischer Bestandteile an den Tonmineralien und den organischen Stoffen im Boden ist so groß, daß Beeinflussung der Diatomeenflora durch diese chemischen Bestandteile nicht mehr möglich ist, so daß von irgendwelchem Zusammenhang damit nicht die Rede ist.

Diatomeenarten, die auf eine Sedimentierung während bestimmter geologischer Perioden oder auf einen Unterschied im Klima im Vergleich zum heutigen hinweisen, wurden nicht angetroffen; die wenigen, von der jetzigen Flora abweichenden Individuen wurden zu sporadisch beobachtet, um in dieser Hinsicht Schlüsse ziehen zu können. Es fällt auf, daß bestimmte, allgemein in Brackwassermilieus vorhandene Arten nicht in lebendem Zustand beobachtet wurden, z.B. Arten wie Campylodiscus clypeus und echeneis (B), Diploneis interrupta (B), Nitzschia navicularis (B), Scoliopleura tumida (BM) u.a. Von diesen Arten wurden wohl an vielen Stellen die leeren Schalen gefunden, so da $\beta$ angenommen werden $m u B, d a ß$ sie sich dennoch in lebendem Zustand in der Nähe befinden, oder in anderen Jahreszeiten vorhanden sein.

Ein deutlicher Unterschied zwischen der Vegetation eines Sand- und eines Schlickbodens konnte im allgemeinen nicht beobachtet werden; vielfach treten in beiden Fällen nahezu dieselben Arten auf. Manchmal scheint auf dem Schlick die Diatomeenvegetation etwas reichhaltiger zu sein.

Auf Sandböden kommt viel ziemlich grober Diatomeengrus vor; im Schlamm ist dieser Grus viel feiner und es macht einen wichtigen Bestandteil davon aus.

\section{B. Die Planktonischen Diatomeen}

\author{
Gebiet I a. "Oude Westereems“ \\ Gebiet II b. „Bocht van Watum" und „Oostfriesche Gaatje“ \\ Gebiet III c. Hauptpriel des Dollarts \\ d. Kleineren Prielen des Dollarts \\ Gebiet IV e. Ems von Emden bis Linesch und Leda bis Leer
}

Insgesamt wurden 87 Planktonproben untersucht und 103 in totem Zustande angetroffen (Vgl. die Tafeln darin wurden 99 Arten in lebendem und außerdem und die Stabdarstellungen Nr. 17-22). 


\section{B. Die Planktonischen Diatomeen}

Es wäre nicht richtig gewesen, eine rezente sedimentologische Untersuchung vorzunehmen, ohne dabei das Plankton im Betracht zu ziehen das im Wasser, worin die Sedimentierung stattfindet, vorkommt. Die planktonischen Organismen spielen ja bei dieser Sedimentation eine wichtige Rolle, nicht nur weil sie dem Sediment nach ihrem Absterben organogenes Material liefern, sondern besonders durch den Einfluß, den sie in lebendem Zustand auf die Zusammensetzung des Sediments im Zusammenhang mit ihrer Lebensfunktion ausüben. Gallert- und ölbildung, die das spezifische Gewicht ändern und Zellen mit langen Stacheln, die die Koagulation beeinflussen, bestimmen gleichfalls die Ablagerungsfähigkeit des im Wasser schwebenden Materials. Dieses Material besteht zum Teil aus den gröberen und feineren Bruchstücken von schalenbildenden Organismen und besonders aus den zum Teil umgeänderten organischen Stoffen aus den Koproiden der tierische Organismen. Die Schalen der Diatomeen verleihen bei massenhaftem Auftreten dem Sediment eine charakteristische graue oder weiße Farbe. Diese Schälchen können, wenn sie von zartem Bau sind (Chaetoceros, Rhizosolenia), nach dem Absterben des Protoplasmas unmittelbar, und wahrscheinlich von innen aus, von den freiwerdenden Produkten angegriffen und aufgelöst werden; sie tragen also nicht zur Sedimentbildung bei. Das ist aber wohl der Fall bei den kräftig $ح$ r gebildeten Schälchen der Gattungen Aulacodiscus, Actinocyclus, Coscinodiscus, u.a., die nicht so leicht gelöst werden und daher wohl unmittelbar zur Sedimentbildung beitragen. Dieser Unterschied tritt sowohl bei den Süßwasser- als bei den marinen Arten auf. Unter diesen erstgenannten tragen z.B. Asterionella und Fragilaria fast nicht, Epithemia und Surirella dagegen wohl zur Sedimentbildung bei. Im Zusammenhang damit möchten wir auf die Artenliste der als leere Schalen auf dem Boden des Ems-Dollartgebietes angetroffenen Diatomeen verweisen (Tafel B).

Schon im Jahre 1939 veröffentlichte HustedT eine Abhandlung über die Diatomeen dieses Gebietes. Darin kam aber nicht klar zum Ausdruck, welche Arten da in lebendem, absterbendem oder schon abgestorbenem Zustand, also als leere Schalen, anwesend waren. Bei der vorliegenden Untersuchung wurde gerade darauf besonders geachtet. Die aus der Planktonuntersuchung gezogenen Schlußfolgerungen beziehen sich, wie die der Benthosuntersuchung, nur auf den Zustand in den Monaten halb Juli-halb September, also auf den Ubergang vom Sommer- zum Herbstplankton.
Das Plankton in den Gebieten I (,Lauwers-Rottumeroog“), II (,Bocht van Watum" und "Oostfriesche Gaatie“) und III (Dollart bis Nieuwe Statenzijl)

Tafel 17 gibt eine Übersicht der Diatomeen, die am 19. und 20. September 1956 im Plankton der drei obengenannten Gebiete angetroffen wurden. Deutlich ist hier der Übergang der marinen Biocoenose aus dem offenen Wattgebiet, über die marin-brackische, z.T. autochthone (Proben 485-486) Biocoenose zu jener der Absterbungszone beim Úbergang vom Polyhalinikum und $\alpha$-Mesohalinikum (Proben 479473) und weiter $\mathrm{zu}$ jener des weniger brackischen $\beta$-Mesohalinikums (Proben 472-470) zu sehen. Eine Zonierung, ungefähr übereinstimmend mit der Einteilung von KüHL und MANN (1954), war dabei zu beobachten. Das aus dem Wattenmeer herrührende neritisch-marine Plankton wurde vor allem durch die in lebendem Zustand anwesenden Centricae: Actinocyclus ehrenbergii, Coscinodiscus concinnus und Coscinodiscus perforatus var. cellulosa gekennzeichnet; in den großen Rinnen kam vor allem die mehr pelagische Lauderia borealis vor. Die hydrochemischen Daten von KüHL und MaNN vom 4. bis 8 . Oktober 1951, lauten wie folgt: Wassertemperatur $13-15^{\circ} \mathrm{C}$, Salzgehalt (S) $31-32 \%, \mathrm{pH} \pm 7.7, \mathrm{CaO}$ $\pm 375, \mathrm{Si} \pm 1.0, \mathrm{NH}_{4}$ und $\mathrm{NO}_{2} \pm 0.0 \mathrm{mg} / \mathrm{l}, \mathrm{O}_{2}$ $\pm 95 \%$ Sättigung. Noch unbekannte Faktoren verursachen in diesem Gebiet aber fortwährend Änderungen. Am 5. September 1956 wurde z.B. das Diatomeenplankton in der Rinne "Sparregat" (Probe $378 \mathrm{~A}$ ) aus 36 Arten zusammengesetzt, von denen 27 in lebendem Zustand; 14 Tage später, am 9. September 1956 wurden an derselben Stelle nur 11 Arten angetroffen, von denen 4 lebend! Es befand sich damals $2.0 \mathrm{~cm}^{3}$ Sinkstoffe in 1001 Wasser (Probe 481). Auch an anderen Stellen in diesem Gebiet wurden derartige Ergebnisse wahrgenommen. So enthielt das Plankton vom 9. September 1956 auf der Station 480 nur 9 Diatomeenarten, von denen 4 in lebendem Zustand. Die Menge Sinkstoffe betrug $1.7 \mathrm{~cm}^{3}$ pro 100 I Wasser. Morgens am 20. September 1956 betrug die Menge, bei steigender Flut auf der etwas westlicher gelegenen Station $482,9.3 \mathrm{~cm}^{3} / 1001$ Wasser; unter den 18 Diatomeenarten, die im Plankton vorkamen, befanden sich nur 3 in lebendem Zustand. Bei der folgenden Flut an demselben Datum enthielt das Plankton an derselben Stelle (Probe 486) 17 Diatomeenarten, von denen 9 lebend; die Sinkstoffenquantität war nur $2.6 \mathrm{~cm}^{3} / 100 \mathrm{l}$. Wahrscheinlich hat sich hier die Beimischung von süßem, verunreinigtem Wassers geltend gemacht; darauf könnte die Armut 
an lebenden Arten der obengenannten Probe hinweisen, die im Gegensatz zu den Proben 482 und 486 bei fallendem Wasser entnommen wurde. Bei einer Vergleichung der Probeentnahme des Jahres 1956 aus dieser Umgebung mit der aus dem Jahre 1954 über die ganze "Oude Westereems“ und einen Teil der „Bocht van Watum“ (Tafel 18) fällt es auf, da $B$ in letzterem Fall bei einer weniger starken Verunreinigung zwar gleichfalls hohe Sinkstofwerte und ziemlich niedrige Gesamtzahlen Diatomeenarten im Plankton vorkamen, diese Zahlen bezogen sich jedoch fast ganz auf lebende Arten, was im Jahre 1956 nicht der Fall war.

Am 19. September 1956 zeigten sich die ersten Absterbungserscheinungen in der marinen Biocoenose an der Station 479, mitten in der „Oude Westereems“. Obschon die Werte von KüHL und ManN hier im Jahre 1951 noch keine großen Unterschiede mit den schon genannten zeigten, war jedoch ein Fallen des Salzgehalts bis $30 \%$ und des CaO-Gehalts bis $\pm 350 \mathrm{mg} / 1$ merkbar.

Auf Grund dieser Tatsache wurde die imaginäre Grenzlinie zwischen Gebiet I und II denn auch etwas westlich von Station 479 gezogen.

Die Absterbungserscheinungen setzten sich am 19. September 1956 in östlicher Richtung fort. Daraus läßt sich erklären, daß im Mündungsgebiet des Dollarts nur wenig vitale Diatomeen in geringer Artenzahl (Stationen 474, 473) inmitten von viel Detritus angetroffen wurden. Dieser Detritus bildete, als er sich absetzte, eine kompakte Masse im Gegensatz zu dem voluminösen, wenig Detritus enthaltenen SinkStoffe aus den meerwärts entnommenen Proben Nr. 485 und 486 (Vgl. Tafel 17).

Das "Schanskerdiep“ (Gebiet III, Dollart) machte im September 1956 einen stark verunreinigten Eindruck und die Diatomeenflora war, vermutlich deswegen, außerordentlich arm an lebenden Arten. Einige davon, Melosira granulata und Melosira varians, stammten unverkennbar aus dem Binnenwasser. Die während der Flut entnommene Wasserprobe 469 enthielt gar keine lebenden Diatomeen und machte den Eindruck, durch die Tide aufgestautes, verunreinigtes Wasser zu sein. Eine derartige Armut an lebenden Diatomeenarten zeigte sich auch schon bei der Untersuchung der Bodenproben dieses Gebietes (vgl. Tafel 14, Stationen 12-20).

Im Jahre 1956 bildeten also das „Oostfriesche Gaatje“ und der "Mond van de Dollart" ein ausgedehntes Absterbungsgebiet für marine Organismen, besonders für die Diatomeen. Dieses Gebiet gehörte damals zum größten Teil in die von KüHL und MaNN (1951) festgestellte polyhaline und für einen kleinen
Teil in die $\alpha$-mesohalinen Zone. Selbstverständlich verschieben sich die Grenzen dieser Zonen fortwährend in östlicher oder westlicher Richtung, aber sie umfassen jedenfalls ein Gebiet, in dem sich weder die marinen, noch die limmischen Diatomeen ordentlich entwickeln können. Eine starke Ausdehnung richtiger Brackwasserorganismen könnte also erwartet werden; was die Diatomeen betrifft z.B. von Coscinodiscus commutatus, von Coscinodiscus (= Actinocyclus) normanii, von Brackwasser-Thalassiosira- und Chaetoceros-arten, wie das in der "Zuiderzee" vor der Eindeichung der Fall war. Davon war hier aber gar keine Rede, nicht im Jahre 1956 und auch nicht im Jahre 1954, obschon damals in derselben Jahreszeit ein viel günstigeres Plankton-bild erreicht wurde als im Jahre 1956 (Tafel 17).

Im Jahre 1954 wurden z.B. an den Stationen 319 und $318 \mathrm{bzw} .15$ und 16 Diatomeenarten angetroffen, von denen bzw. 14 und 13 lebend; im Jahre 1956 kamen an der Station 480, in der Mitte zwischen den Stationen 319 und 318, nur 9 Diatomeenarten vor, von denen 4 lebend. Dasselbe gilt von den Stationen 316 und 315, wo im Jahre 1954 bzw. 14 und 17 Arten vorkamen, von denen bzw. 14 und 15 in lebendem Zustand, während im Jahre 1956 an den in der Nähe liegenden Stationen 479 und 478 bzw. 12 und 15 Arten angetroffen wurden, von denen bzw. 9 und 6 zwar noch lebend, aber in deutlich absterbendem Zustand beobachtet wurden (Tafel 17 und 18).

Es stellte sich aber heraus, daß ein derartiger Zustand stark abwechseln konnte, denn eine Probeentnahme am 11., 12. und 13. Sept. 1956, auf verschiedener Tiefe in der „Bocht van Watum “(Stationen 452-454, 460-462 und 457-459), ergab ein viel günstigeres Bild, das viel Ubereinstimmung mit dem der Stationen 314, 313, 312 aus dem Jahre 1954 zeigte (Tafel 19 und 18).

Eine Vergleichung der Proben 452 und 460 mit den gleichwertigen Proben 487, 488 und 489, die 10 Tage später entnommen wurden, gibt ein Bild der großen Schwankungen, die in der „Bocht van Watum “ auftreten können und die zum Teil unzweifelhaft mit der Abführung der Abwässer in der nähe der Stationen 490 und 491, resp. von Appingedam und von der Stadt Groningen zusammenhängen (Tafel 19).

Die Profile 452-454, 460-462 und 457-459 zeigen von W. nach O. eine Abnahme der durchschnittlichen Anzahl lebender Arten gegenüber einer Zunahme der Durchschnittszahl von Arten, die nur als leere Schalen wahrgenommen wurden. Vor allem war diese Erscheinung an den in größerer Tiefe entnommenen Proben des Profils 457-459 gut zu beobachten. Ein 
deutlicher Unterschied in der Zusammensetzung der Diatomeenflora in den bei Flut entnommenen Proben 452-454 und den bei Ebbe entnommenen Proben 460-462 war aber nicht festzustellen. Die beiden Planktonproben 455-456, dì bzw. an der Oberfläche und auf $3.50 \mathrm{~m}$ Tiefe an einer Stelle $\pm 10 \mathrm{~km}$ östl., in der "Mond van de Dollart" entnommen wurden, zeigten am 14. September 1956 zwar noch Übereinstimmung mit den Proben 457-459 vom 13. Sept. 1956; mit den Proben 430-438, ab Termunten über „Landpunt van Reide“ nach Kerkeriet Plate, war aber kein Zusammenhang mehr zu beobachten (Tafel 20).

Selbstverständlich mußten diese starken Abwechselungen auch bei der Sedimentbildung zum Ausdruck kommen. Einigermaßen war das der Fall in den Werten der Sinkstoffquantitäten pro 1001 Wasser, die gleichfalls großen Schwankungen unterlagen. Dabei muß aber der Tatsache Rechnung getragen werden, daß Plankton mit viel Chaetoceros und anderen, hervorstehende Teile und Haare tragenden Organismen wie z.B. Polychaetenlarven, einen sehr voluminösen Niederschlag gibt, der verhältnismäßig weinig organogenes Material enthält, während ein detritusreiches Plankton einen wenig voluminösen Niederschlag geben kann, der viel organogenes Material enthält. In den Tafeln müssen deshalb die Sinkstoffwerte, soweit möglich, mit den geschätzten Quantitäten Detritus und Coproiden, angedeutet durch $\mathbf{r}, \mathrm{c}$ und cc, verglichen werden.

Sehr wichtig für die Sedimentbildung an der Küste des Ems-Dollartgebietes ist die Abführung von mehr oder weniger stark verschmutztem Wasser durch Schleusen, Düker und Abzugskanäle. Die Abführungen durch den Schleusen von Nieuwe-Statenzijl, Delfzijl, Knock und Emden und durch die Abzugskanäle in der „Bocht van Watum“ üben einen sehr merklichen Einfluß auf die Beschaffenheit und $\mathrm{Zu}$ sammensetzung des Planktons aus, bis auf eine große Entfernung von der Abführungsstelle. Um über dieses Problem etwas mehr zu erfahren, wurden am 20. Juli 1954 Planktonproben aus der nördlichen Ausmündung des "Schanskerdiep“ in den Dollart und zwar westlich, in der Mitte und östlich der Stromrinne entnommen. Westlich dieser Rinne kamen 12 Arten vor, von denen nur einige in lebendem Zustand. Neben vielen leeren Schalen wurde auch eine geringe Menge Diatomeenbruchstücke angetroffen; die Probe enthielt außerdem viele Pollen. Das MBS-Verhältnis war $50: 17: 33$. In der Mitte dieser Rinne kamen nur 8 Diatomeenarten vor, von denen gleichfalls nur einige Arten in lebendem Zustand. Die Probe enthielt viele Diatomeenbruchstücke; das MBS-Verhältnis betrug
$90: 10: 10$ ! Die östlich des „Schanskerdiep“ entnommene Probe enthielt 11 Arten, von denen einige lebend. Außer vielen leeren Schalen kam in dieser Probe eine viel größere Menge Diatomeenbruchstücke als in den beiden anderen Proben vor. Das MBSVerhältnis betrug $56: 26: 13$. Die drei obengenannten Proben waren so schnell wie möglich nacheinander gesammelt. Aus dieser Probeentnahme ging deutlich hervor, daß das meiste Salz enthaltende Wasser sich in der Mitte der Rinne und das süßeste Wasser sich an der westlichen Seite befand.

Am 3. August 1954 wurden Planktonproben um eine lange Stromnaht herum entnommen, die sich in derselben Stromrinne des "Schanskerdiep" beim Zusammentreffen des salzigen und süßen Wassers bildete. Vor der Stromnaht, im süßerem Wasser, wurden 12 Diatomeenarten angetroffen, von denen mehrere in lebendem Zustand, außerdem kamen Naupliuslarven von Copepoden, viel Rotatoren und auch ein Anzahl Exemplare der Grünalge Scenedesmus quadricauda vor, was auf Nährstoffreichtum hinwies. Das Vorkommen von Kartoffelstärke in dieser Probe bestätigte diese Vermutung. Pro 1001 Wasser lagerte sich $2.0 \mathrm{~cm}^{3}$ Material ab $\left(1.2 \mathrm{~cm}^{3}\right.$ organogene, torfartige Substanz und $0.8 \mathrm{~cm}^{3}$ feiner Sand). Vermutlich bestand die süßere Wassermenge aus abgelassenem Wasser, das aus dem Binnenland herstammte. Das Plankton der Stromnaht selbst enthielt nur 2 Arten Diatomeen, beide in lebendem Zustand. Leere Schalen kamen ausschließlich im Sinkstoffe vor, das pro 1001 Wasser $14.0 \mathrm{~cm}^{3}$ betrug. Es bestand aus einer Mischung von Sand und organogenem Material und machte einen flockigen Eindruck.

Hinter der Stromnaht, im salzigeren Wasser, kamen 11 Arten Diatomeen vor, von denen sehr viel lebende Exemplare. Dieses Wasser enthielt außerdem Copepoden mit ihren Naupliuslarven, die Blaualge Merismopedia glauca, die einzellige, kolonienbildende Grünalge Pediastrum boryanum und viele Fäden der Grünalge Tribonema spec. Der Sinkstoff enthielt neben einer kleinen Menge aus feinem Sand, viel organisches Material in der Form von Coproiden und Torf; die Quantität betrug $2.4 \mathrm{~cm}^{3} / 100 \mathrm{l}$ Wasser.

Aus dieser Probeentnahme zeigte sich, da $\beta$ in einer Stromnaht, in der Süß- und Salzwasser aneinder grenzen, eine Bildung organogener Flocken stattfindet, die entweder Organismen in lebendem und abgestorbenem Zustand fangen, oder von diesen gefangen werden, aber die auf jeden Fall ein größeres spezifisches Gewicht bekommen als das des Wassers und also zur Ablagerung kommen, wenn das Milieu nicht zu unruhig ist. Dieses Sediment wird also au- 
tochthon gebildet und stammt nicht aus dem Wattenmeer.

Ein anderes Bild der Sedimentation geben zwei am 5. September 1956 bei fallendem Wasser entnommene Planktonproben, die eine aus einer Rinne im sog. Sparregat bei Rottumeroog (Probe 378 A), die andere (Probe 378 B) zum Vergleich, aus einer untiefen Wasserschicht über dem Rande einer Plate in dieser Rinne. In letzterem Fall wurde sehr sorgfältig nur das über dem Platenrande stehende Wasser abgesiebt, ohne Aufwühlung des schon sedimentierten Materials. Probe 378 A enthielt 37 Arten Diatomeen, von denen 27 in lebendem Zustand. Von den 10 nur als leere Schalen vorkommenden Arten mußten 7 als nicht-planktonisch betrachtet werden. Das Material war ziemlich sauber und enthielt nur wenig Detritus und Coproiden, im Gegensatz zu Probe 378 B, die nur 8 Arten Diatomeen, von denen 3 Arten in lebendem Zustand enthielt, neben sehr viel organischem „Schlamm“ und zermalmten Diatomeen. Offenbar sammelt sich, wenn das Wasser fällt, die Hauptmasse des Planktons in den Rinnen und es bleibt nur ein Teil der sehr häufig vorkommenden Arten in dem über den Platen zurückbleibenden Wasser zurïck. Ist die Plate ganz bloßgelegt, dann kommen die beweglichen Bodendiatomeen zum Vorschein und bilden der bekannte gallertartige gelbbraune Schicht an der Oberfläche. Beim Herannahen der Flut verschwinden sie wieder zwischen den mittlerweile von der Gallertabsonderung verkitteten Bodenteilchen. Obwohl dieser Mechanismus notwendig eingehend studiert werden müßte, ist es einigermaßen verständlich, warum auf den Sand- und Schlammplaten im allgemeinen wenig planktonische und in den Rinnen nahezu keine benthonischen Diatomeen angetroffen werden.

Das Plankton des Emsflusses (Gebiet IV) (Vgl. Tafeln 21 und 22)

Sowohl im Jahre 1954 als im Jahre 1956 wurden Planktonproben aus dem Emsfluß, und im Jahre 1954 auch aus der Leda bis Leer entnommen. In jenem Jahre wurden die Proben an zwei aufeinanderfolgenden Tagen gesammelt, im Jahre 1956 wurde die Strecke Emden-Linesch hin und zurück an einem Tage zurückgelegt, so daß die Proben dieser letzten Fahrt besser mit einander vergleichbar sind, als die der ersten. Aus dem Auftreten der abgestorbenen marinen Diatomeen im Plankton der Leda in der Nähe von Esklum vom 28. Juli 1954 zeigte sich der marine Einfluß auf diesen Nebenfluß der Ems ganz deutlich. Das MBS-Verhältnis der als leere Schalen anwesenden Diatomeen betrug $27: 30: 43$, für die lebenden Arten $0: 39: 61$. Auch dieses Verhältnis deutet auf die Anwesenheit von ziemlich salzigem Wasser in der Leda hin. Vermutlich war hierbei nicht die Rede von Meerwasser sondern von brackischem Wasser aus der Umgebung, das durch Schleusen, Düker und Pumpwerke auf die Leda abgeführt worden war. Daß derartiges Wasser die Ems gleichfalls beeinflußt, zeigt sich aus den Chlorwerten von PostmA (Verh. Kon. Ned. Geol. Mijnb.k. Gen., Geol. Serie XIX, S. 103, 1960), die für Station 215 westl. von Kritzum bei Ebbe $400 \mathrm{mg} / \mathrm{l} \mathrm{Cl}$ fand, während andere Stellen Cl-werte von rund $200 \mathrm{mg} / \mathrm{l}$ aufwiesen. Der brackische Charakter des Emsflusses im Jahre 1954 ging außerdem aus dem MBS-Verhältnissen der lebenden Diatomeenarten hervor. Auch die durch die Flut verursachte Stauung im Fluß kommt manchmal in diesem MBS-Verhältnis zum Ausdruck, z.B. am 27. September 1954 an der Station 212, die ein MBS-Verhältnis der lebenden Diatomeenarten von $0: 14: 86$ aufwies, während man an einer Stelle, so dicht in der Nähe der Flußmündung, einen ordentlichen marinen Einschlag hätte erwarten können. Dieser war im Oberflächenwasser jedoch nicht anwesend, aber wurde erst $\pm 10 \mathrm{~km}$ stromaufwärts bei Hatzum wahrnehmbar (MBS $8: 46: 46$ ). Aus der Probeentnahme vom 28. Juli 1954 zeigte sich, daß die Ems bei Ebbe bis in die Nähe von Kritzum ein gemischtes Brackwasserplankton führt, ohne lebende marine Diatomeen (MBS $0: 40: 60$ ). Diese kommen bei Ebbe erst in der Nähe von Ditzum vor (MBS $23: 31: 46$ ) und nehmen selbstverständlich nach der Mündung des Flusses in den Dollart hin zu (MBS $46: 16: 38)$. Im Zusammenhang mit diesen Erscheinungen wäre es vielleicht besser, im Gegensatz zu KüHL und MaNN das Mischgebiet des Emsflusses zwischen Ditzum und Jengum zu dem Meio-Mesohalinikum statt zum Oligohalinikum zu rechnen, weil damit die Planktonflora und -fauna bei weiten nicht immer in Übereinstimmung sind. Stromaufwärts von Jengum bis zum Kanal von Papenburg könnte die Ems als oligohalin betrachtet werden; bis zur Ausmündung dieses Kanals wurden im Jahre 1956 noch Cl-Werte von $200 \mathrm{mg} / 1$ beobachtet. Erst vorbei Linesch wurde ein Cl-Gehalt von $100 \mathrm{mg} / \mathrm{l}$ gefunden, so daß erst dort von süßem Wasser gesprochen werden kann.

Sehr auffallend war im Jahre 1954 die Zonierung auf Grund der vorkommenden Organismen zwischen Emden und Leer. Erst eine stark verunreinigte Zone bei Ditzum, durch eine starke Entwicklung von Ciliaten. besonders Tintinnoidea, gekennzeichnet; weiter eine Zone zwischen Ditzum und Kritzum mit einer massenhaften Entwicklung von Copepoden 
(Eurytemora spec.); dann von Kritzum bis Bingum eine „Blüte“ der Diatomee Melosira granulata und stromaufwärts von Bingum ein derartige „Blüte“ der Diatomee Cyclotella striata. Die massenhafte Entwicklung dieses letzten Organismus wies wieder auf eine Versalzung des Milieus hin, die vielleicht von dem Bentumer Siel oder von der Leda aus vor sich ging.

Der Salzwassereinfluß in der Ems wurde durch die Probeentnahme vom 3./4. September 1956 noch deutlicher gezeigt. In jenem Jahre waren zwischen Ditzum und der Ausmündung der Leda die ClWerte des Emswassers höher als 1954, näml. 300$1100 \mathrm{mg} / \mathrm{l}$, was unverkennbar der Abführung von stark salzhaltendem Wasser zuzuschreiben war.

Dies zeigte sich aus den Unterschieden in den MBS-Verhältnissen der Diatomeen, die im Jahre 1954 einen lokalen marinen Einfluß verrieten durch das Auftreten lebender mariner Arten an der Oberfläche, während im Jahre 1956 an ungefähr denselben Stellen die MBS-Verhältnisse der lebenden Diatomeen an der Oberfläche wohl ein brackisches, jedoch kein marines Anzeichen gaben. Die hohen Cl-Werte an der Oberfläche an Station 338 B kamen an Station $337 \mathrm{~A}$ in der Tiefe in einem ordentlichen Ansteigen des Prozentsatzes der Brackwasserarten zum Ausdruck. Etwas Ahnliches zeigte sich in weniger starkem Maße an Station $339 \mathrm{C}$ in der Umgebung von Ferstenborg-Dorenborg beim Ubergang des meerwärts gelegenen Ton- und des landwärts gelegenen Sandbodens des Flusses. Bis an diese Stelle wurden auf dem Boden noch leere marine Molluskenschalen angetroffen. Stromaufwärts wiesen die MBS-Verhältnisse der Diatomeen keine großen Schwankungen mehr auf; benthonische und planktonische Formen stimmten ziemlich gut miteinander überein. Zuneh- mender Süßwassereinfluß setzte bei Station $339 \mathrm{H}$ den $\mathrm{Cl}$-Wert des Wassers an der Oberfläche und in der Tiefe bis auf $100 \mathrm{mg} / \mathrm{l}$ herab, welcher Wert als die obere Grenze des echten Süßwassers angenommen wird. Infolgedessen nahmen die in der Tiefe lebenden Brackwasserdiatomeenarten stark an Anzahl ab. Es versteht sich, daß in einem derartigen Gebiet, in dem allerlei Faktoren fortwährend wechseln, auch ein jeweils verschiedenes Sediment gebildet wird.

Aus der Anwesenheit leerer Schalen mariner Diatomeen, sowohl in sich über dem Boden befindlichem Plankton als im Sediment bei Linesch ging hervor, daß der marine Einfluß auf $\pm 40 \mathrm{~km}$ Entfernung vom Meer noch wahrnehmbar war. Die Brackwasserdiatomee Coscinodiscus rothii var. normanii (= Actinocyclus normanii) wurde 1954 und 1956 von Emden bis an die Mündung der Leda lebend angetroffen und im Jahre 1956, gleichfalls in diesem Zustand, stromaufwärts bis ungefähr Nesseburg (Station $339 \mathrm{~F}$ ). Noch mehr stromaufwärts kam diese Art nur in absterbendem Zustand vor, bei einem Cl-Gehalt von $200 \mathrm{mg} / \mathrm{l}$; stromabwärts wurde sie in diesem $\mathrm{Zu}$ stande bei Emden beobachtet, bei einem Cl-Gehalt $>6000 \mathrm{mg} / \mathrm{l}$.

Die im Jahre 1954 auf allen Stationen in der Ems vorkommende Süßbrackische, pelagische Diatomee Melosira granulata, hatte sich 1956 zu einer wahren „Blüte“ entwickelt, die sich von Ditzum bis Linesch und vermutlich noch weiter stromaufwärts ausdehnte. Starke bis sehr starke organische Verunreinigung des Emsflusses wurde 1956 an dem Boden an den Probepunkten 330, 332 A, 334 A, 336 A, 337 A beobachtet, das ist zwischen Emden und ungefähr Jengum und an den Stationen $339 \mathrm{~F}$ und $339 \mathrm{G}$, auf beiden Seiten des Kanals von Papenburg, der vielleicht zu dieser Verunreinigung beiträgt.

\section{VERGLEICH DES DOLLARTS UND DER JADE}

Ungefähr $50 \mathrm{~km}$ östlich des Dollarts befindet sich an der Wesermündung ein Gezeitengebiet, die Jade, das in mancher Hinsicht mit dem Dollart übereinstimmt. Von Brockmann ist dieses Gebiet ausführlich sedimentologisch mit Hilfe der Diatomeen untersucht worden (1935) und daraus, wie auch aus schon früher vorgenommenen Untersuchungen, sind von ihm eine Anzahl Schlußfolgerungen gezogen, die zum größten Teil auch für den Dollart gelten.

1. Unter "Schlick“ versteht BrockmanN die tonartige Ablagerung von den Gezeiten unterworfenen Meeren innerhalb eines Wattgebietes. Schlick ist also immer marinen Ursprungs, aber wird nur unter Einfluß der Tide auf diesen Watten gebildet. Sowohl im
Dollart als in der Jade kommen Schlickablagerungen in großem Umfang vor und, wie aus den darin vorkommenden Diatomeen hervorgeht, stammt in beiden Fällen das Material aus dem Wattenmeer her. Die starke Viskosität des Schlicks scheint großtenteils durch die Diatomeen verursacht zu werden, obwohl auch die Coproiden der tierischen Organismen bedeutend dazu beitragen.

2. Der Schlick besteht hauptsächlich aus anorganischem Material, das mit organischen Bestandteilen untermischt ist, besonders mit Resten der Planktonorganismen, und zwar vor allem Diatomeen. Auch dies scheint im Dollart der Fall zu sein.

3. Schlick rührt nicht in seiner obengenannten 
typischen Bildung vom Meere her; es entsteht auf zweierlei Weisen:

1. In einem Wattgebiet durch Umbildung und Verlagerung von hier schon anwesendem Sediment mittels der Gezeitenbewegung, wobei Sandablagerung keine Rolle spielt;

2. durch Abbau und Umbildung mittels der Gezeitenbewegung von mehr oder weniger sandigem Material aus dem Meere oder/und von den Watten selbst, wobei Neubildung und also Ablagerung auftritt.

Beide Weisen der Schlickbildung scheinen im Dollart aufzutreten und dabei waren, ebenso wie in der Jade, alle Ubergänge des Sandwattes zum Schiickwatt wahrnehmbar. Nach BrockManN beruht die Schlickbildung in den Häfen hauptsächlich auf Verlagerung des schon außerhalb dieses Raumes entstandenen Schlickes.

4. An den Küsten findet Austausch von durch die Gezeitenbewegung an- und abgeführtem Material statt. Das Zunahmegebiet ist jedoch die Küste selbst. Sowohl bei der Dollart- als bei der Jade-Untersuchung zeigte es sich, daß die Diatomeenarten in diesem Prozeß eine wichtige Rolle spielten.

5. Auch in den Flußmündungen kommt ein schlickartiges Sediment vor, in dem die vielen marinen Diatomeen auf marinen Ursprung hinzuweisen scheinen. Es sind jedoch Flußsedimente, die infolge der aufwärts gerichteten Spülwirkung der Gezeitenströme, auf einem Umweg via die Küste wieder in die Flußmündungen geraten und die anwesenden marinen Diatomeen, die hauptsächlich als leere Schalen im Sediment vorkommen, deuten nur auf die Nähe des
Meeres hin. Die im Mündungsgebiet der Ems angetroffenen Diatomeen- und niedrigen Algenarten zeigten, daß diese Erscheinung dort auch regelmäßig auftritt.

6. Die Trübe des Wassers in den Flußmündungen wäre nicht eine Folge der Mischung des salzigen und süßen Wassers, sondern des fortwährenden Hochspülens des unter 5 genannten Schlick-Sediments. Zwar findet kolloidale Ausflockung statt, aber diese ist zu gering, um Trübung verursachen zu können. Vielleicht gilt dies vom Mündungsgebiet der Ems; es stellte sich aber heraus, daß dies für den Dollart nicht immer zutrifft (Vgl. Stromnahtuntersuchung) und das Problem bedarf darum einer näheren Untersuchung.

7. Die Diatomeenvegetation auf dem Boden wäre von der Korngröße der Bodenteilchen abhängig. Bei der Dollart-untersuchung hat sich von einem deutlichen Zusammenhang zwischen der Diatomeenvegetation und der Zusammensetzung des Bodenmaterials nichts gezeigt (Vgl. Bodenprofile).

8. Allochthone Diatomeen werden, zu meist in abgestorbenem Zustand, in Gebieten angetroffen, in denen sie bestimmt nicht leben können; autochthone dagegen, werden zwar verlagert, aber bleiben autochthon, solange sie in ihrem Lebensmilieu angetroffen werden. Dies auf den Dollart anwendend, konnte festgestellt werden, daß eine Anzahl Diatomeenarten (und vielleicht auch andere Organismen) für dieses Gebiet als autochthon betrachtet werden können, umso mehr, als aus der Untersuchung hervorgegangen ist, $\mathrm{da} \beta$ sie sich darin fortpflanzen und vermehren können.

\section{SCHRIFTTUM}

Brockmann, Chr. (1935) - Diatomeen und Schlick im Jade-Gebiet Abh. Senckenb. naturf. Ges. 430, S. 1-64, Frankfurt a. M.

HustedT, Fr. (1939) - Die Diatomeenflora des Küstengebietes der Nordsee vom Dollart zur Elbemündung $\mathrm{I}$. Abh. Nat. Ver. Bremen Bd xxx H 3, S. 572-677.
KüHL, H. und MaNN (1954) - Ubber die Hydrochemie der Unteren Ems, Veröff. Int. Meeresf. Bremerhaven Bd III : 126-158.

LAkowrrz, K. (1929) - Die Algenflora der gesamten Ostsee; Danzig. 
PROBENUMMER

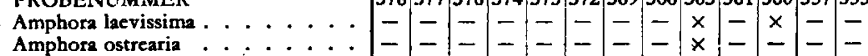

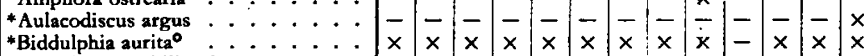

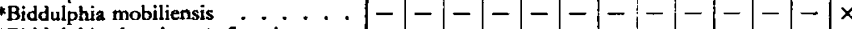

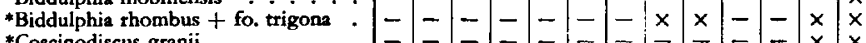

*Coscinodiscus granii .......

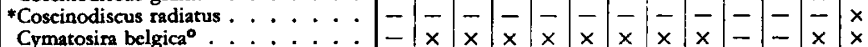

Dimerogramma minor......

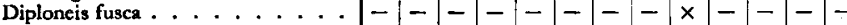

*Melosira sulcata.......... - $\times$ - $-\times \times \times-x-x-$

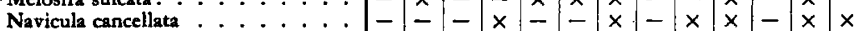

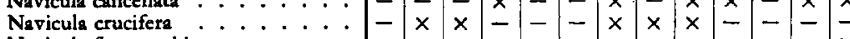

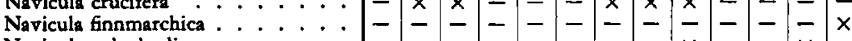

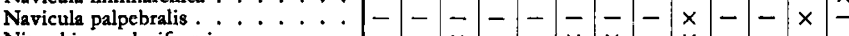

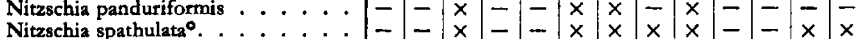

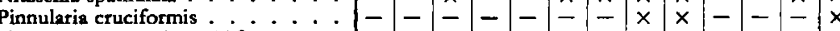

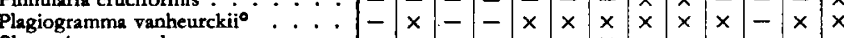

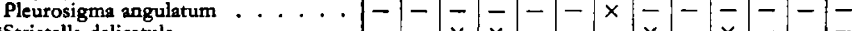

*Striatella delicatula ........ $=-\bar{x} \times \frac{x}{x}=\frac{x}{x} \bar{x}-\bar{x}=$

*Thalassiosira decipiens ..... $=\frac{x}{-}=x \times \frac{x}{x}=\underline{-}=\frac{x}{-}=\frac{x}{x} \bar{x} \bar{x}$

Triceratium alte $=-x-x=x-x \times$

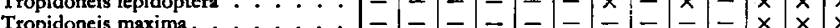

*Coscinodiscus excentricus :....

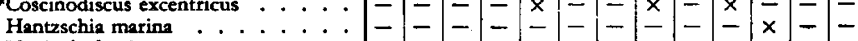

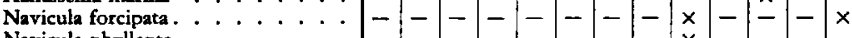

Navicula phyllepta ....... $--------\times-$

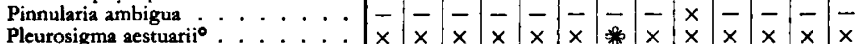

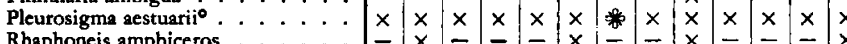

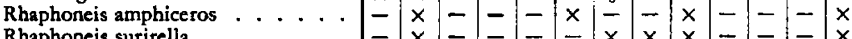

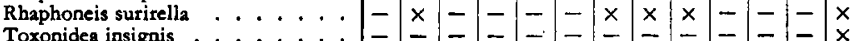

Gyrosigma fasciola ....... - . $_{-}-\mathrm{C}_{-}-\mathrm{-}_{-} \times-{ }_{-}$

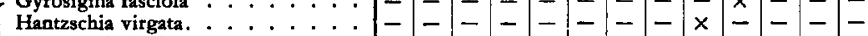

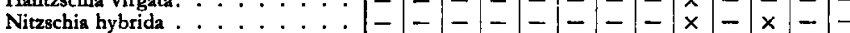

Nitzschiz linkei.......

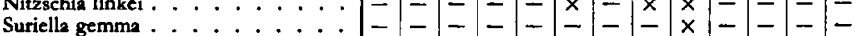

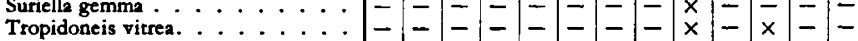

Amphors coffeaeformis $\therefore]_{-}--_{-}--_{-}--_{-} \times$

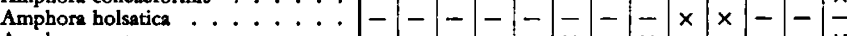

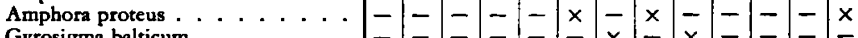

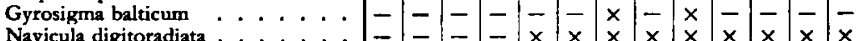

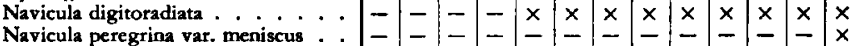

Navicula rostellata. ....... $\bar{x} \times \bar{x} \times \bar{x}-\overline{-} \overline{-} \overline{\times} \times \bar{x}=-\bar{x}$

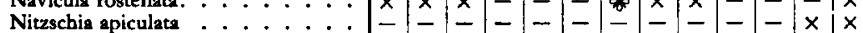

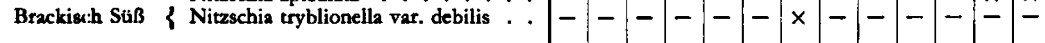

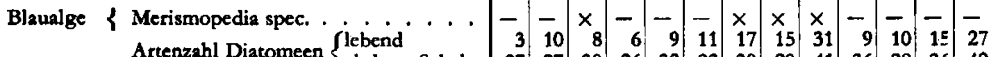
Artenzahl Diatomeen $\left\{\begin{array}{l|r|r|r|r|r|r|r|r|r|r|r|r|r|r|}\text { lebend } & 3 & 10 & 8 & 6 & 9 & 11 & 17 & 15 & 31 & 9 & 10 & 15 & 27 \\ \text { als leere Schalen } & 27 & 27 & 30 & 26 & 32 & 22 & 30 & 29 & 41 & 36 & 28 & 36 & 42\end{array}\right.$

50 lebende Arten von denen $11\left(^{*}\right)$ planktonisch-neritisch und $5\left(^{\circ}\right)$ über nabezu das ganze Profil; $x$ anwesend dominierend

Tafel 1. Profil 1 (VIII), Sparregat W $\rightarrow$ O, 6 September 1956.

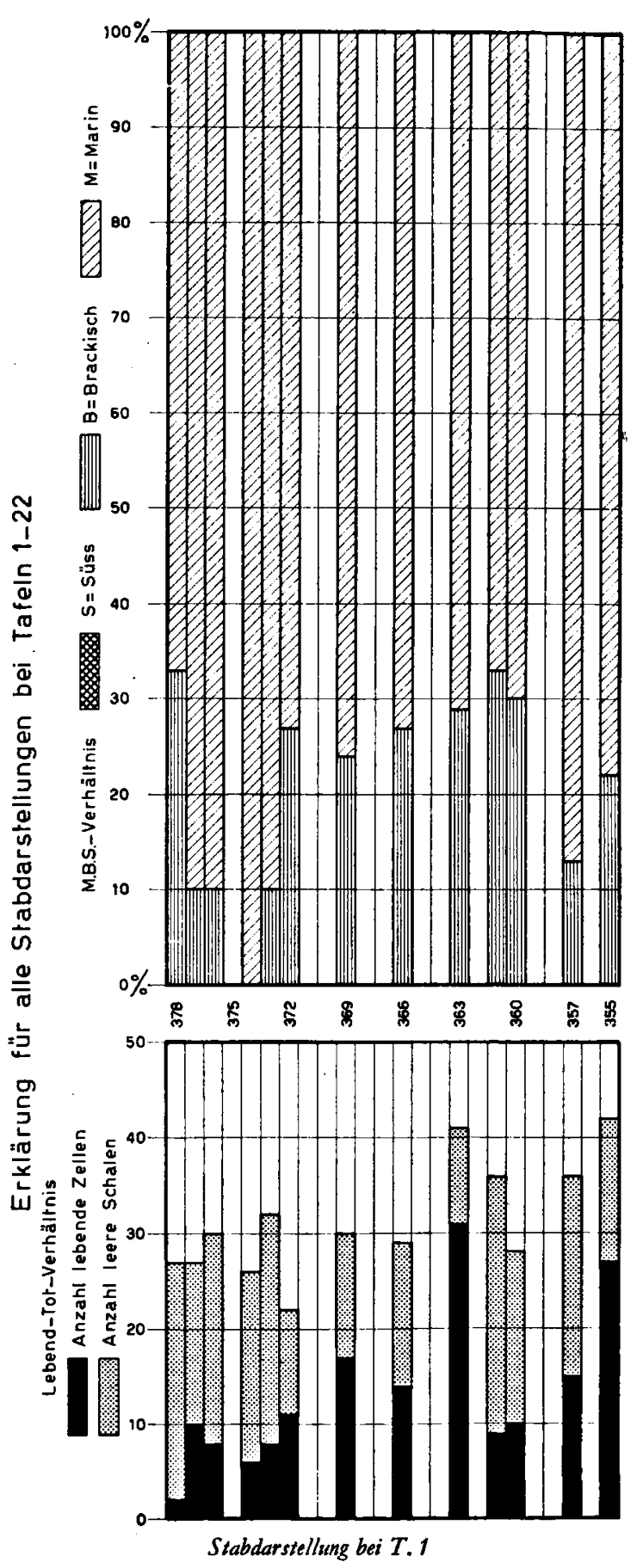




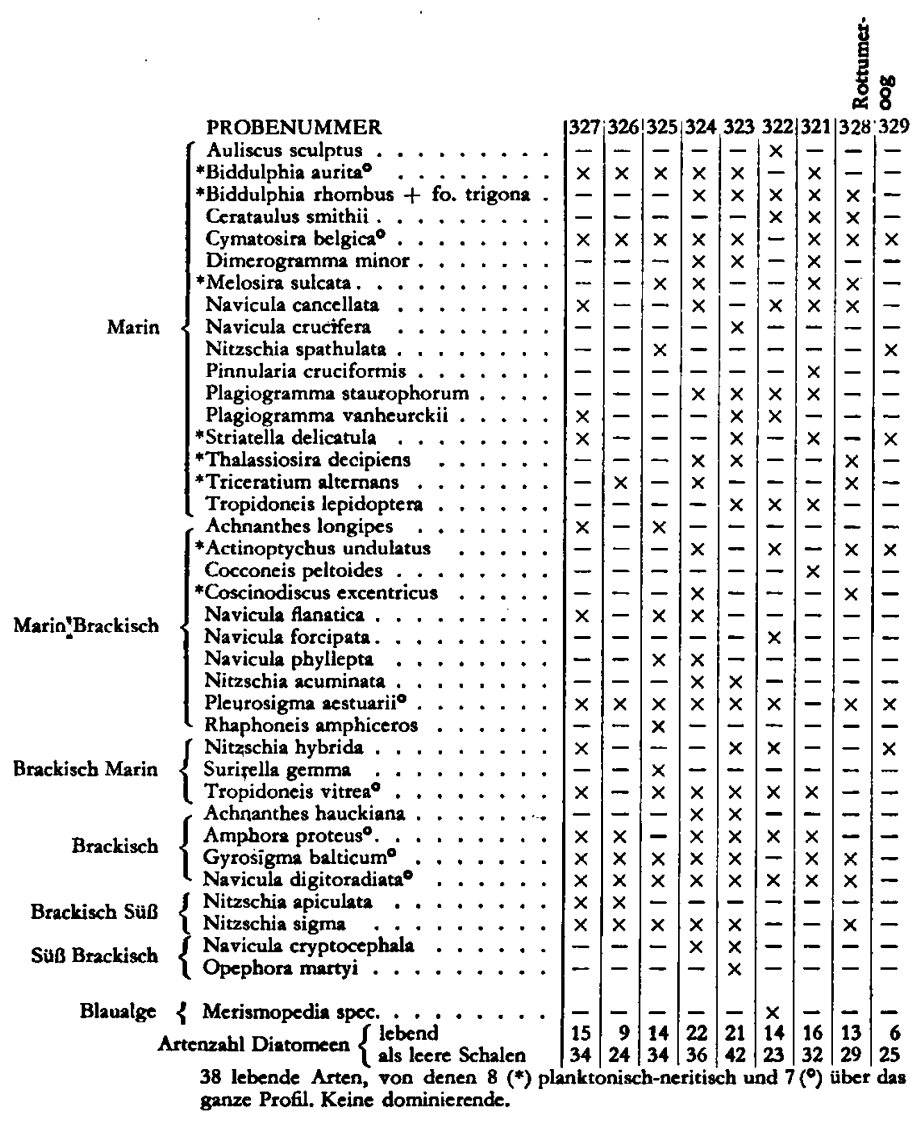

Tafel 2. Profil 2 (VI), Sparregat NW $\rightarrow$ SO und Rottumeroog, 12 August 1954.

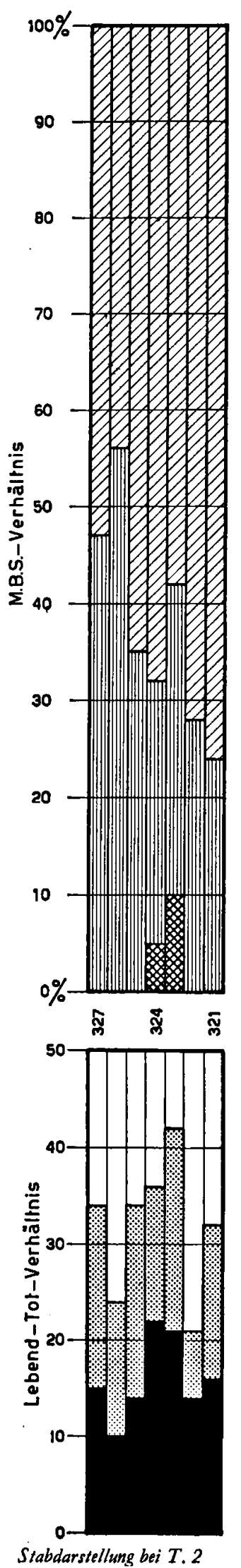




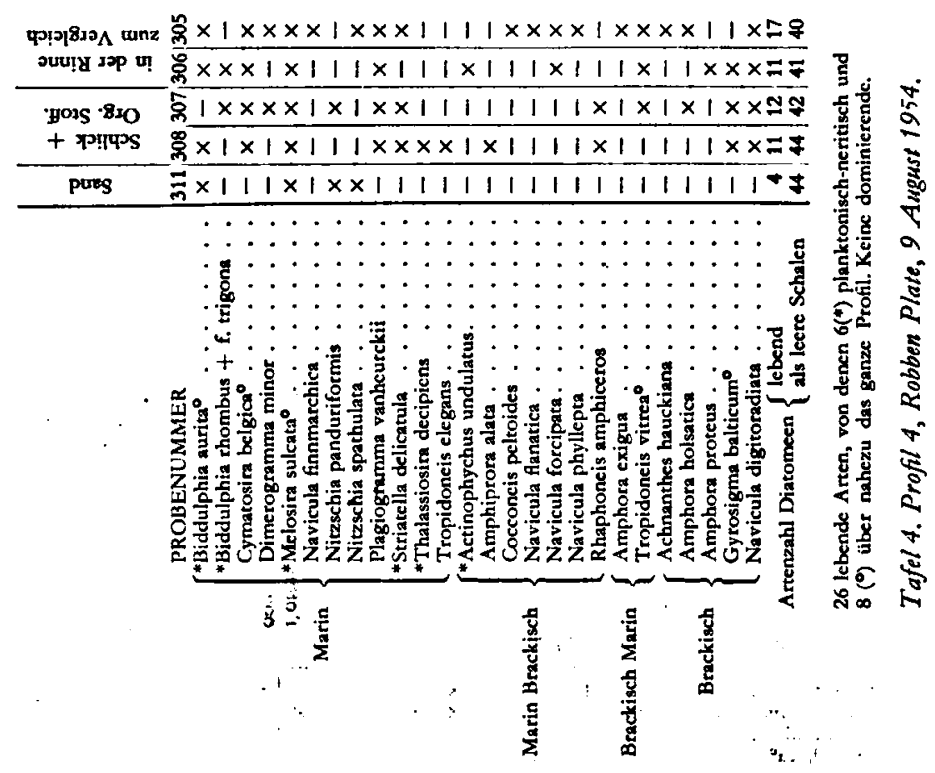

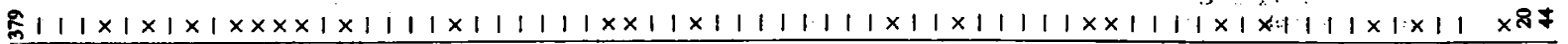

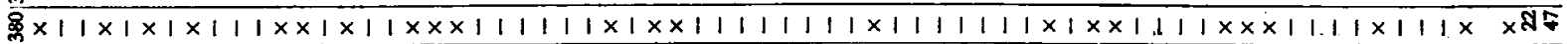

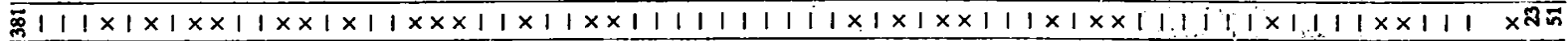

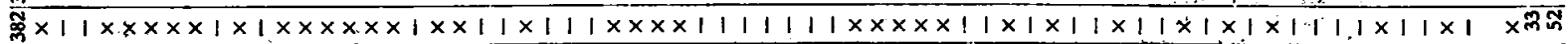

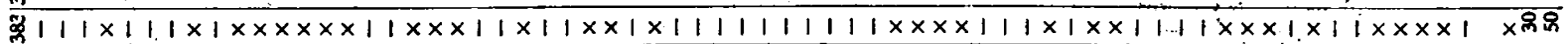

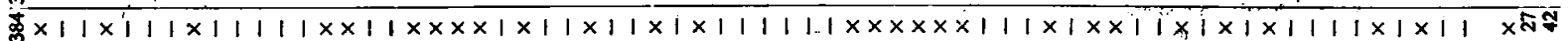

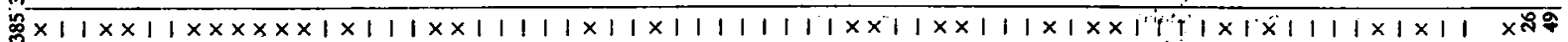

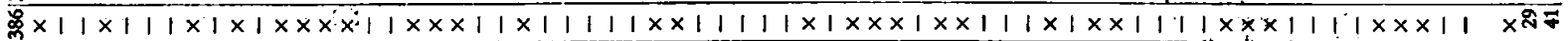

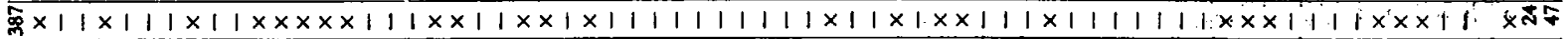

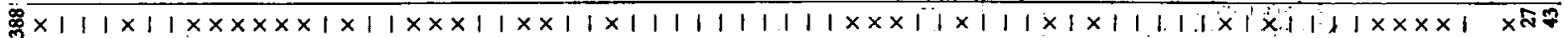

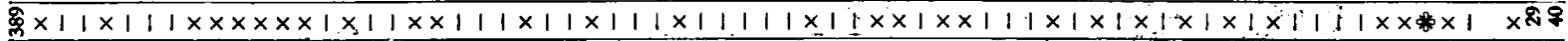

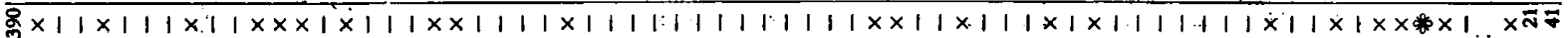

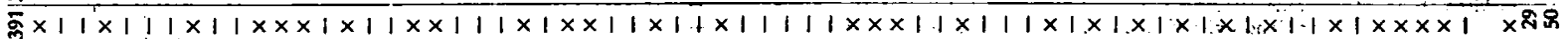

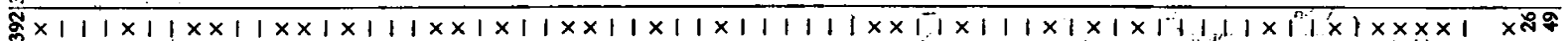

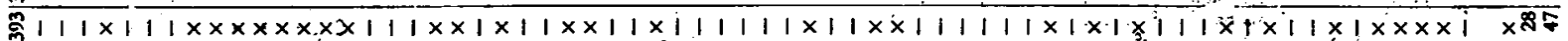

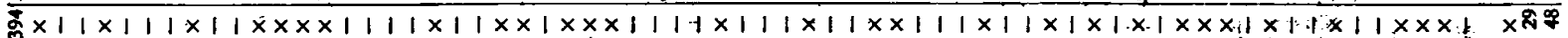

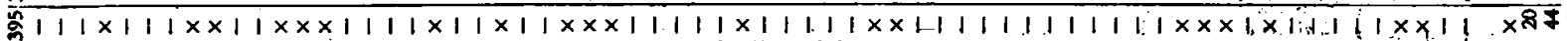

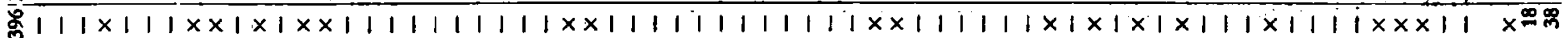
$5|1| \times 1,1 \times x|1 \times 1 \times 1| 1 \times x|1 \times 1| x \times 1|1| 1|1| 1 \times 1 \times x \times 1 \times 1|1| \times|\times 1 \times 1 \times 1 \times 1 \times 1| \times 1 \times 1 \times 11 \times 87$

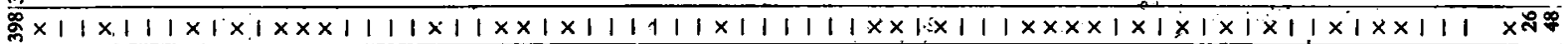

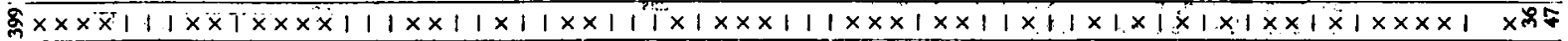

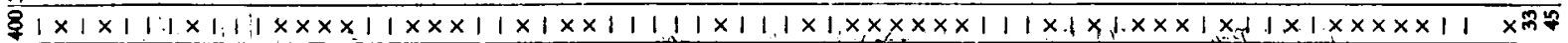

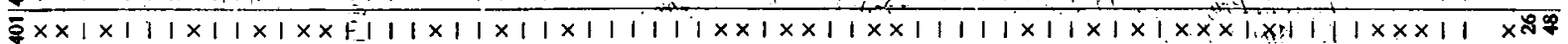

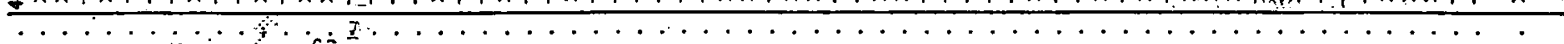

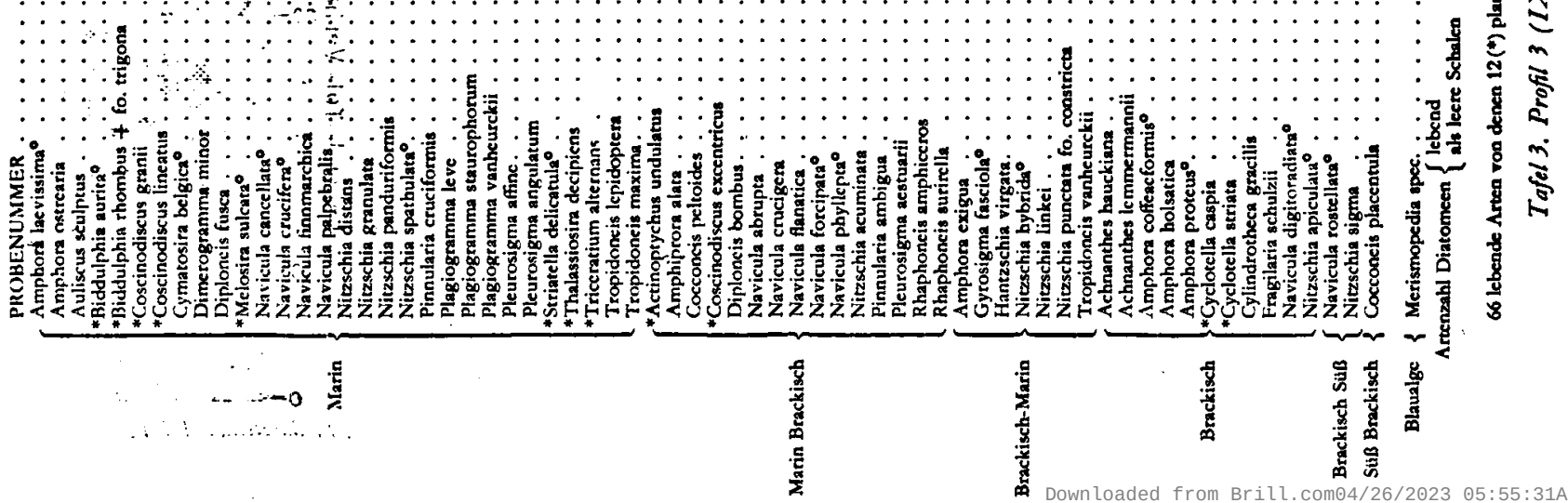


DIATOMEEN
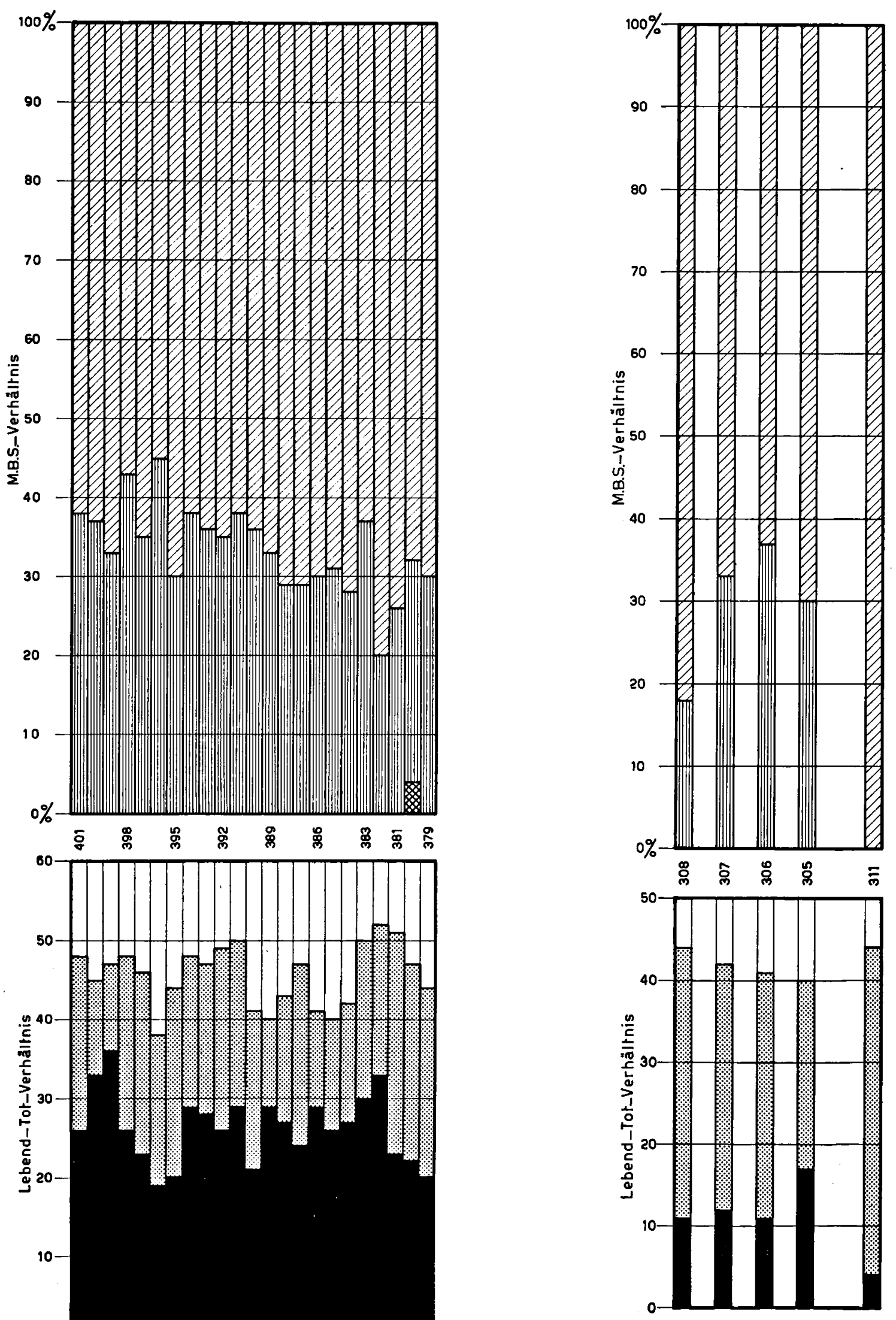


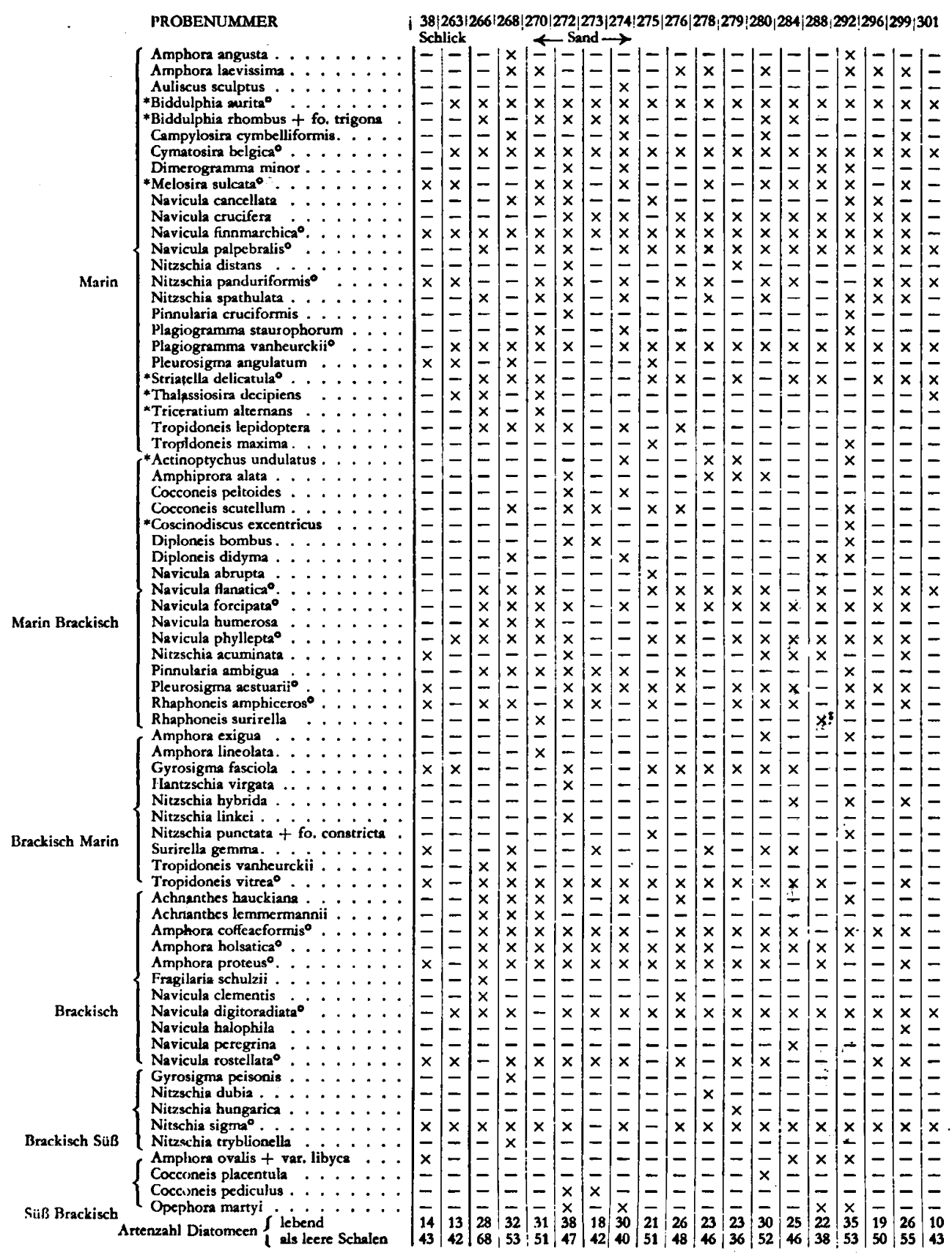

72 lebende Arten von denen $8\left({ }^{*}\right)$ planktonisch-neritisch und $20(9)$ nahezu über das ganze Profil. Keine dominierende.

Tafel 5. Profil 5 (V), Paap Plate, 5-6 August 1954. 

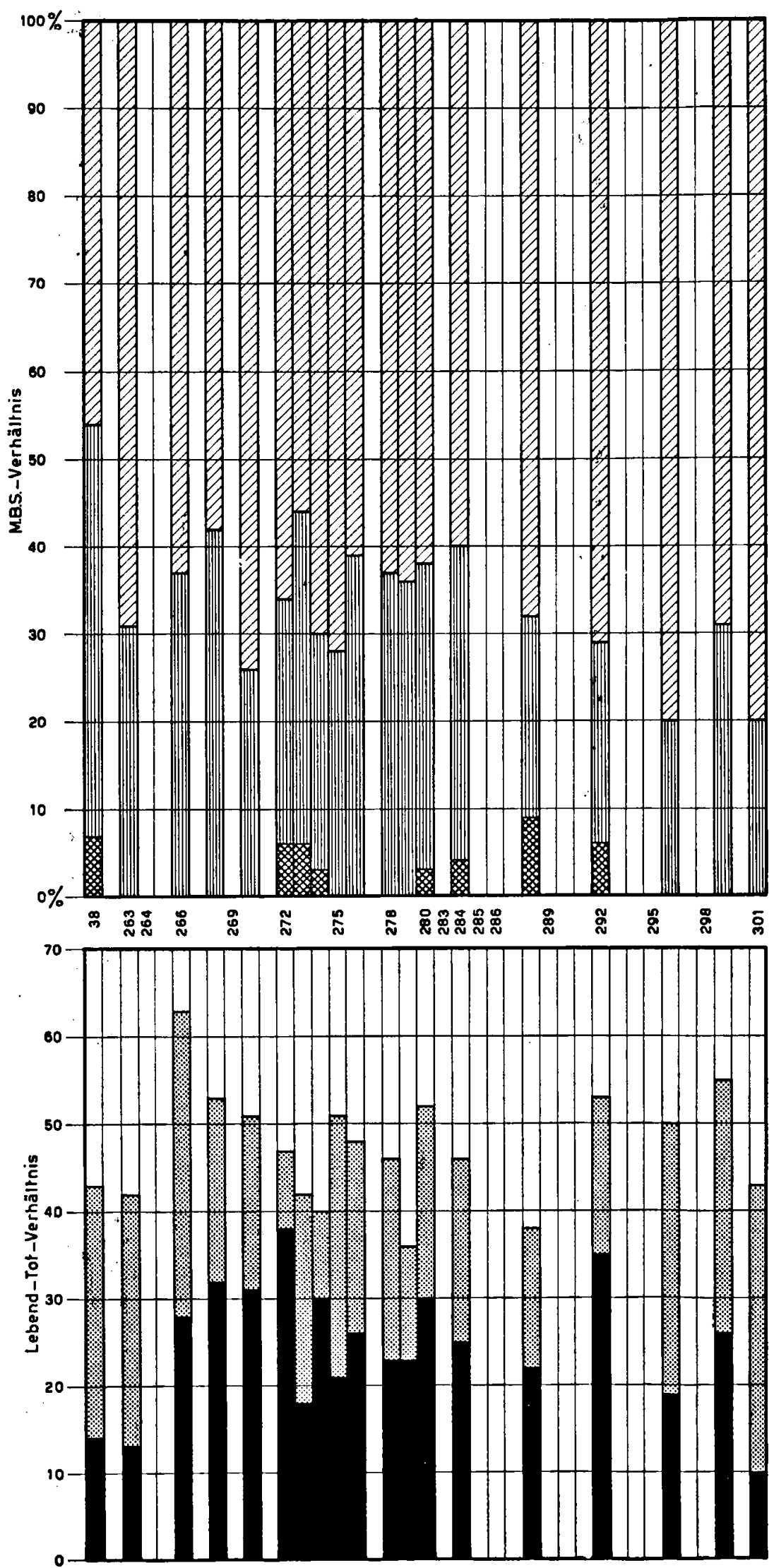

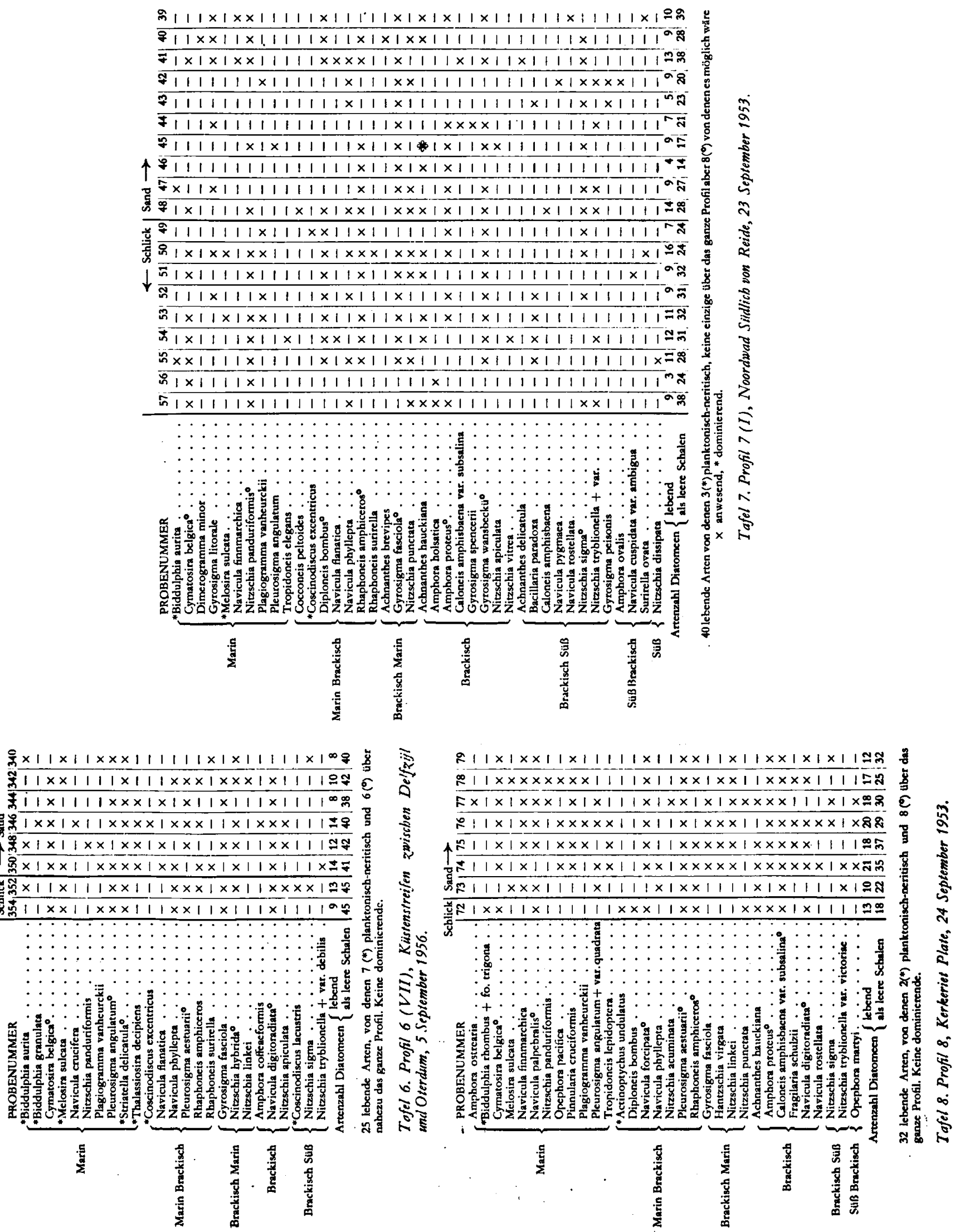

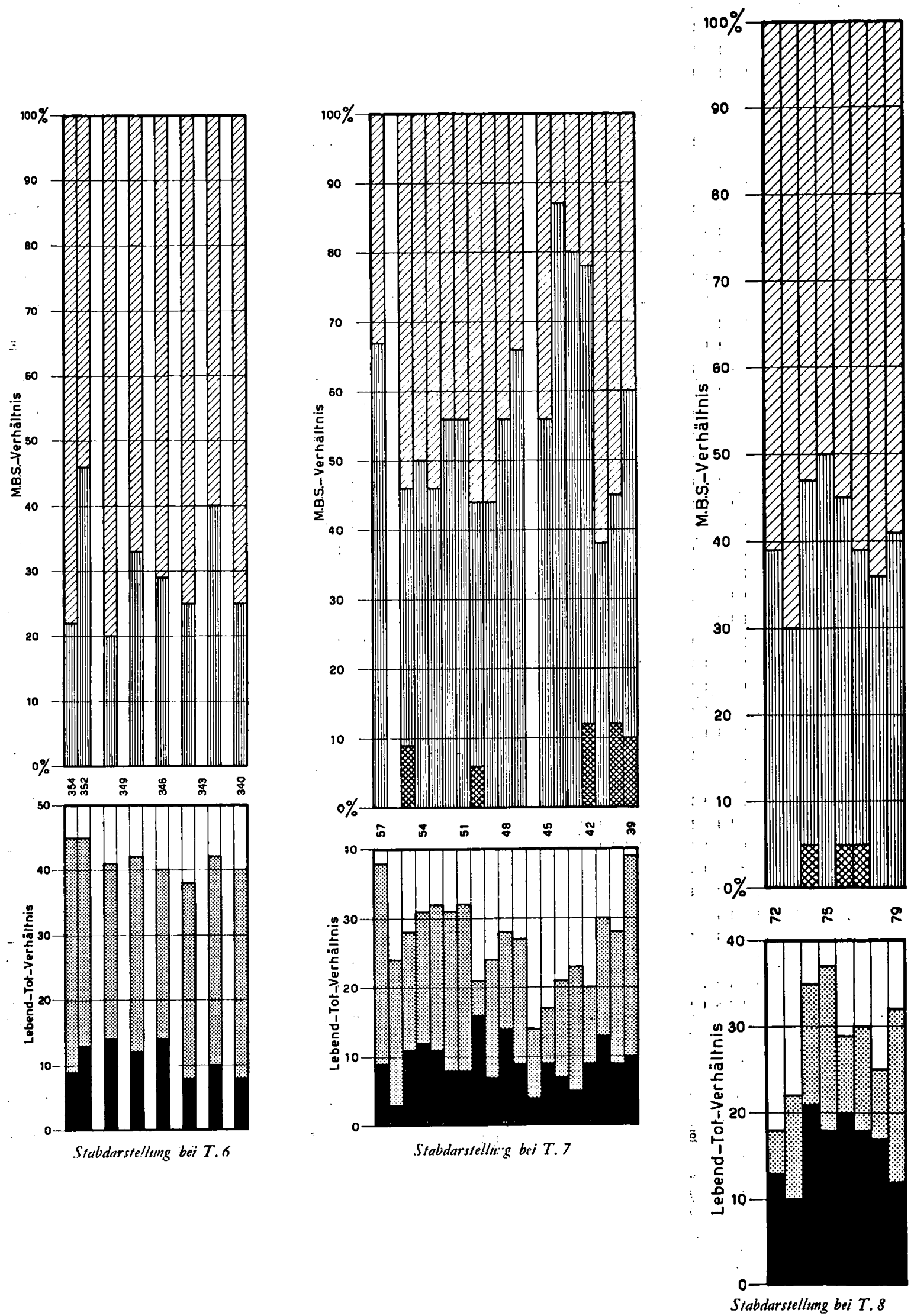

Stabdarstellirg bei T. 7 
$\stackrel{\Phi}{0} 1111111111 \times 1 \times 111111111111111111111111 \times 111111111111 \times 1111111111 \times \times 111100$ $2 \times \times 11 \times \times 111 \times \times 1 \times \times \times \times 1 \times \times 111111111 \times 1 \times 1 \times \times \times 1 \times 11111111 \times 111 \times \times 1 \times 1 \times \times \times 11 \times 1111 \times 1125$

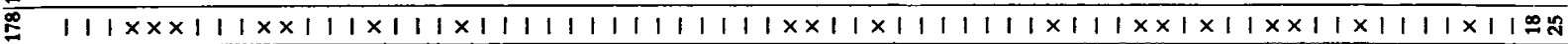

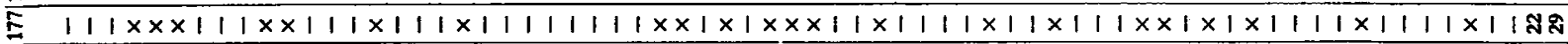

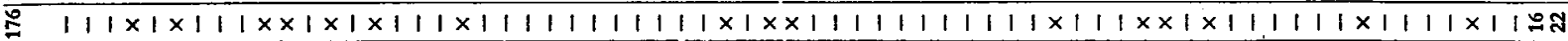

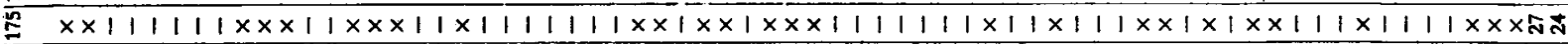

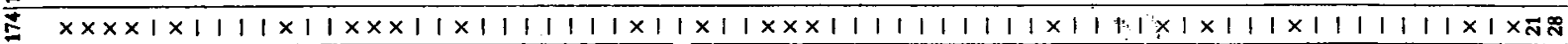

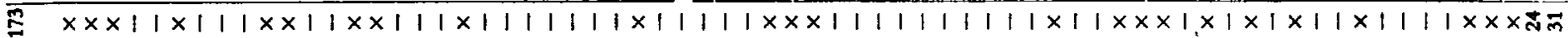

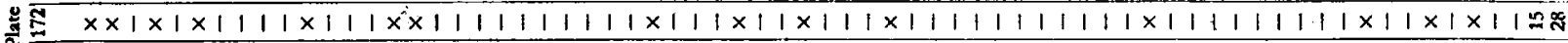

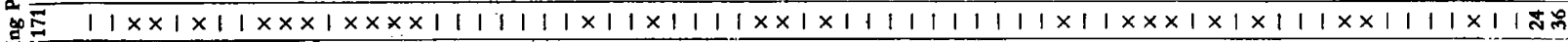

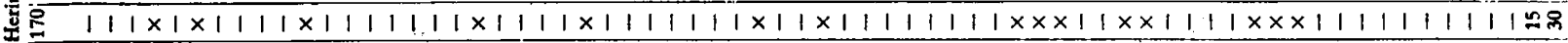

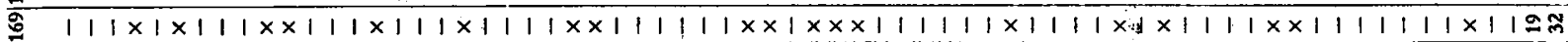
$111 \times 1 \times 11111111 \times x+11111111111111 \times 1111 \times 111111 \times 11111,1 \times 11111111111111110 \mathrm{~m}$

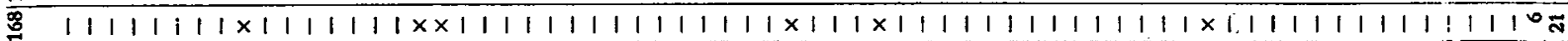

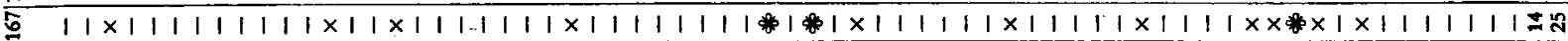

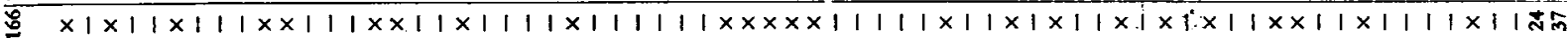

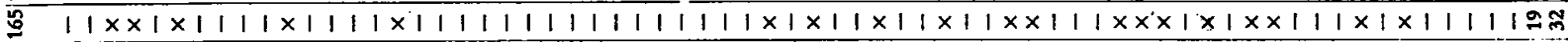
$81111111111111111111111111111111111111 \times 111111111111 \times 1111111111111111 \sqrt{2}$

g $1111 \times \times 111 \times \times 1 \times 1111 \times \times 1111111111111 \times 1 \times 111111111 \times 11111 \times 1111111111111111=8$

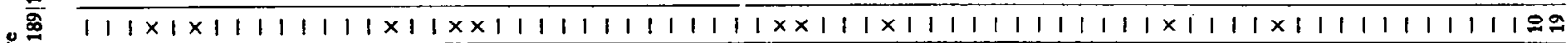

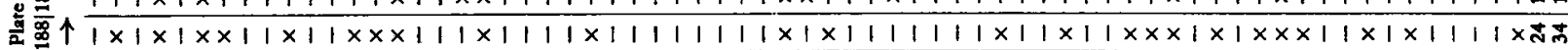

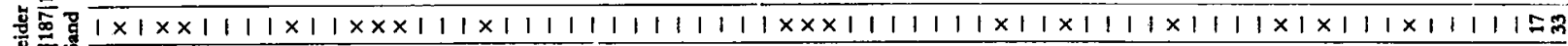

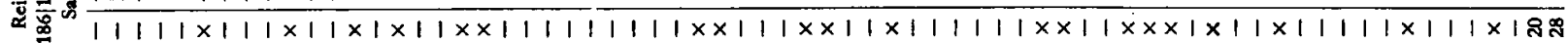

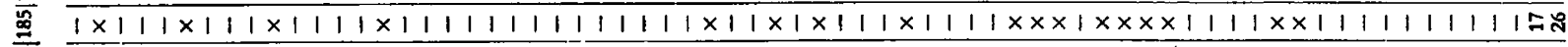

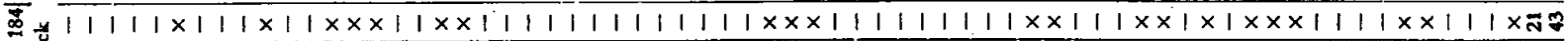

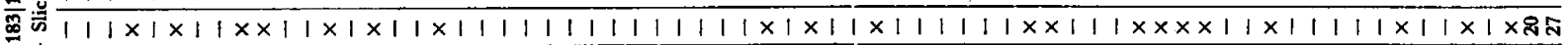

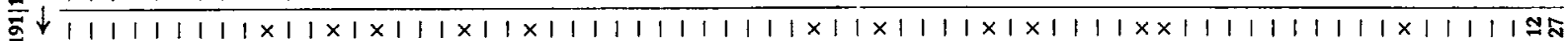

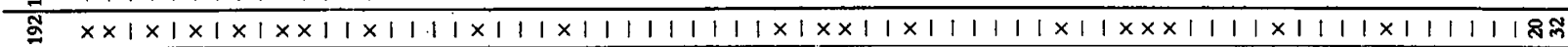

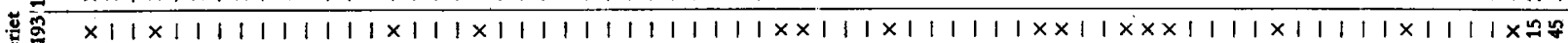

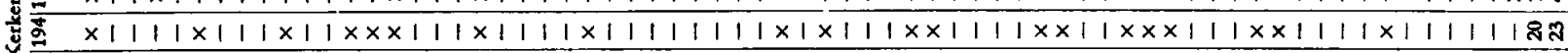

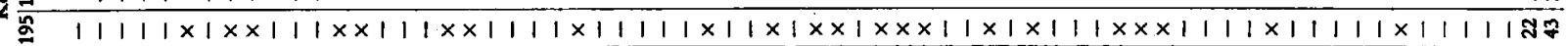

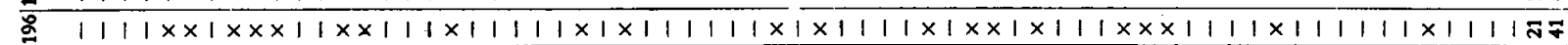
ఏ $111111111111 \times 1111111111111111111 \times 1 \times 1111 \times 111 \times 111111 \times 11 \times x 111111 \times 1111108$ $\$ 111 \times 1 \times 111111 \times 11111 \times 111111 \times 11111111 \times 111111111 \times 11111 \times 1111 \times 1111 \times 11111198$ $201111 \times \times 1 \times 1111 \times \times \times 11 \times 11111111111111 \times 1 \times 11 \times 1111 \times 1 \times \times 1111 \times 11 \times 1 \times 1 \times 11 \times \times \times 11 \times 1 \times 8$ 8

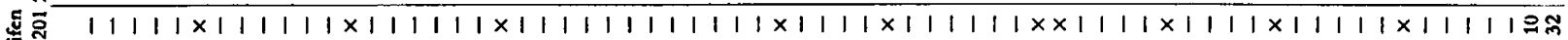

$1111 \times x 11111111 \times 11111111111111111111111111111 \times \times 111 \times \times 1111111111 \times 111110 \pi$

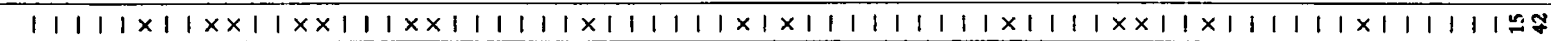

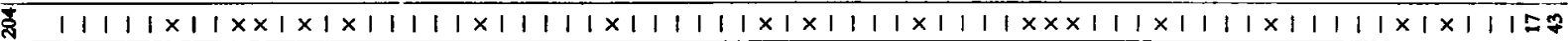

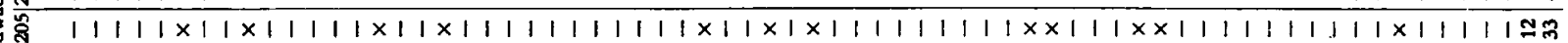

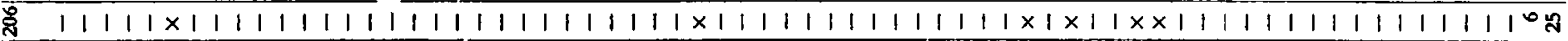

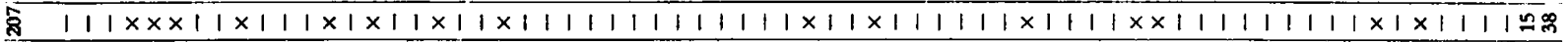

o $11111 \times 1111111 \times x 1111111111111111111 \times 1111111 \times 1 \times 1111111 \times 1111111 \times 11111100$

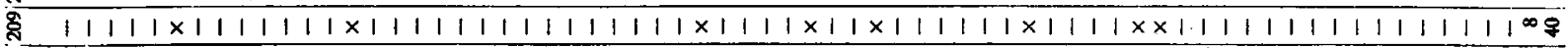

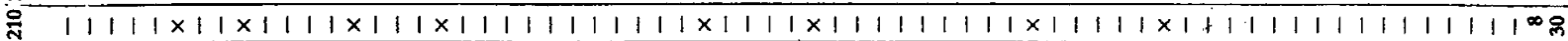

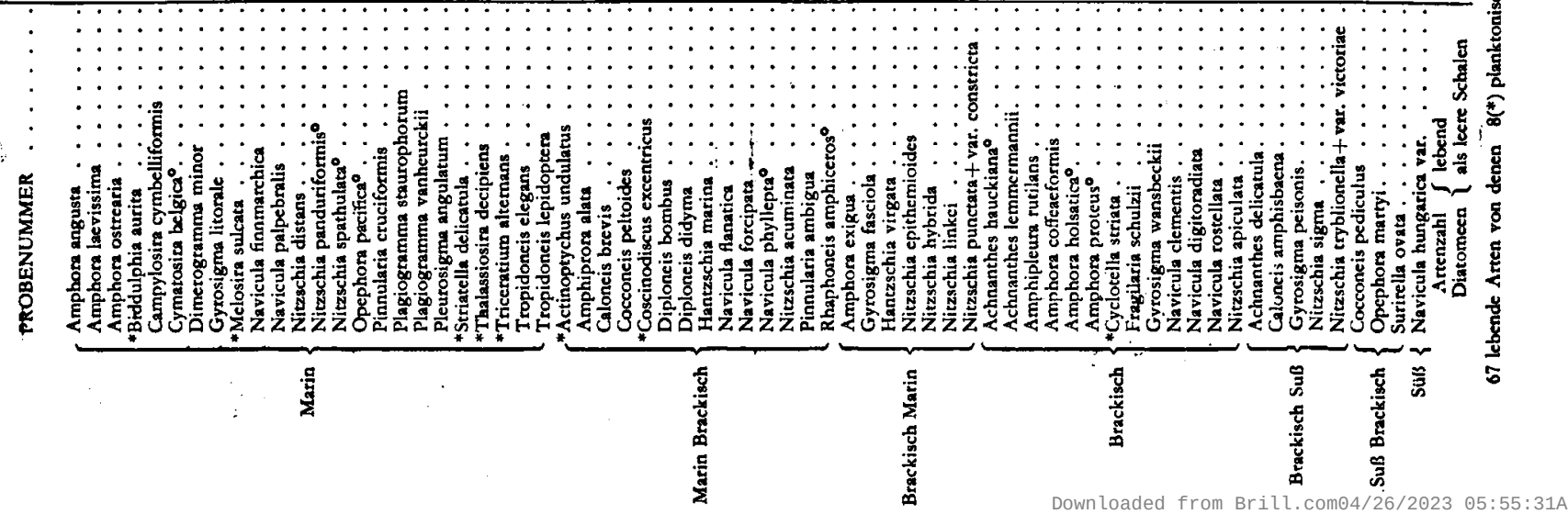




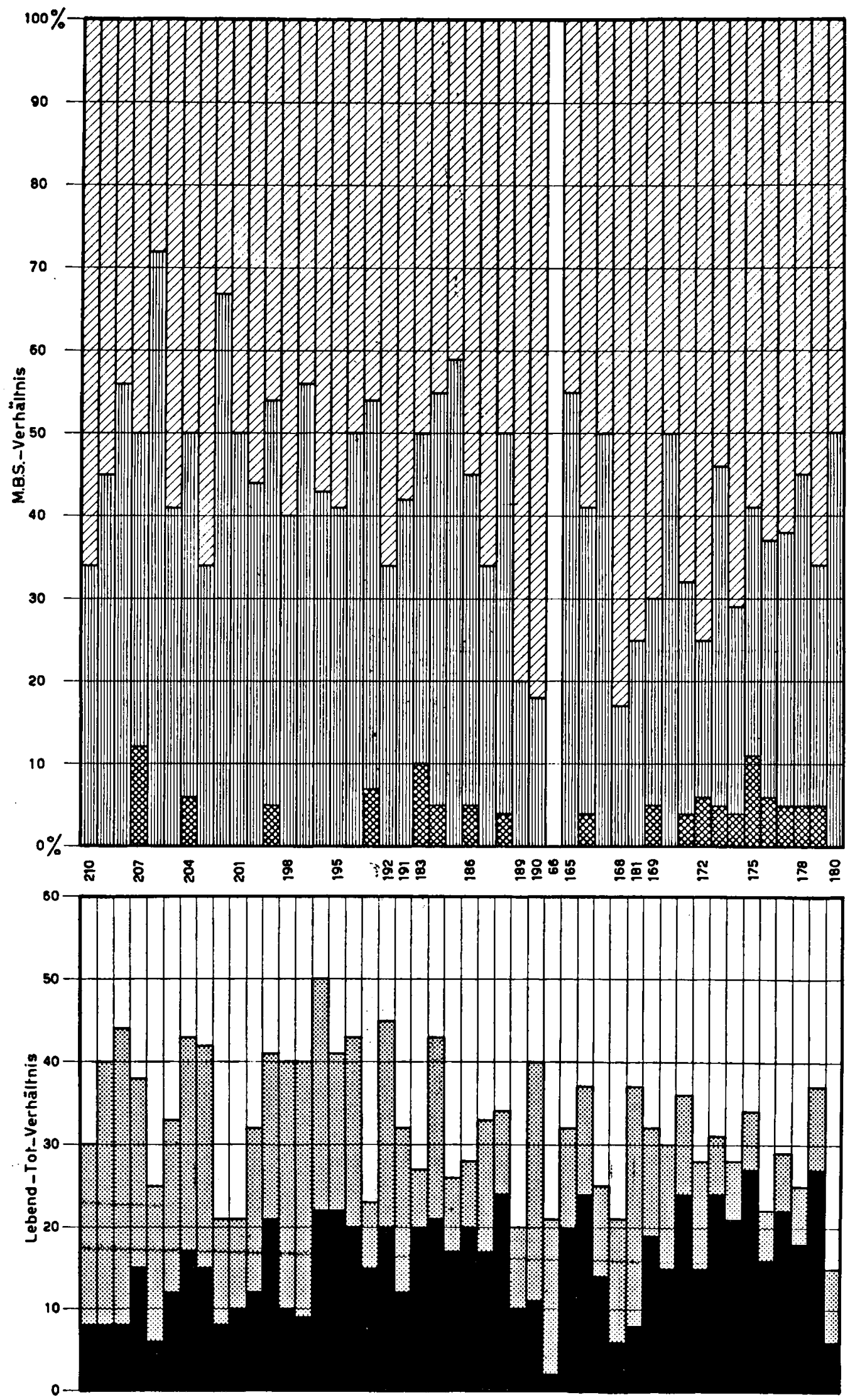




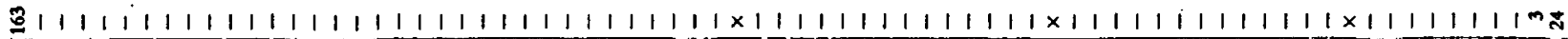

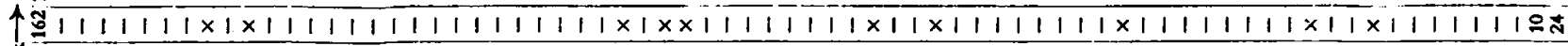

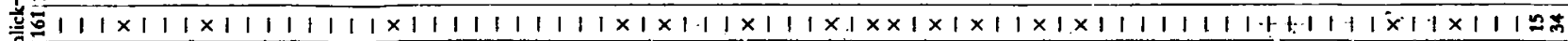
象 $1111111 \times \times \times 111111 \times 1111111111 \times 1 \times 111 \times 111111 \times 11 \times \times 1 \times 1,1 \times \times 1111 \times 111 \times 1111111 \times 1100$

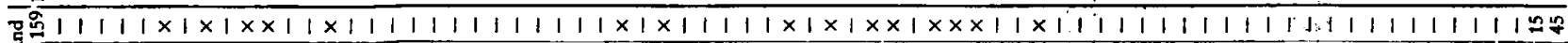

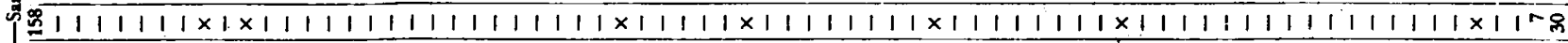
$\sqrt{5111111 \times 1 \times 11 \times 1 \times 111 \times 1111111111 \times 111 \times 111111 \times 111 \times 11 \times 1 \times 1 \times 1111 \times 1 \times 11111111 \times 11120}$ \$11 $1111 \times 1 \times \times 11111 \times 1 \times 11111111 \times \times \times 11111 \times 1 \times \times \times 11 \times \times \times 11 \times 111 \times 1111 \times 11111 \times 1111111198$ 至11 $1 \times 111 \times 11111111 \times 1 \times 111111111 \times \times 11 \times \times 1 \times 1 \times 11 \times 1 \times \times \times 11 \times 111 \times 1111111111,111 \times 1 \times 11197$

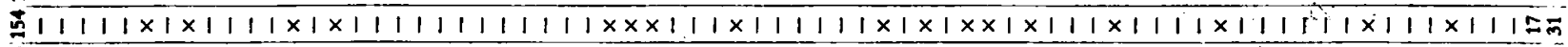

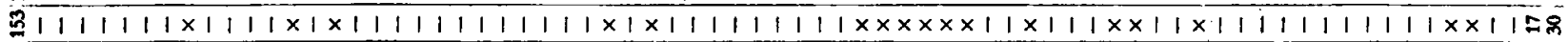

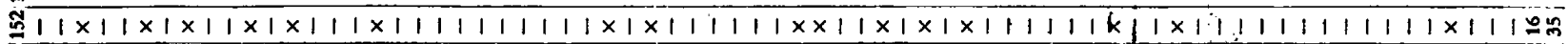
$=111 \times 111 \times 1 \times 11 \times \times \times 1 \times 1 \times 11111111 \times \times \times 11111 \times 1 \times 1 \times \times \times \times \times \times 11 \times 1 \times 1 \times 1 \times 1 \times 11111111 \times 111 \times \times 1189$ $81111111 \times 1111 \times 11111 \times 11111111 \times 1 \times 1111111 \times 1 \times 1111 \times 11111111111111111 \times 1111111195$ $91 \times 11111 \times 1111 \times \times \times 111 \times 1111 \times 11111 \times 1111111 \times 1 \times \times 1 \times \times \times 111111 \times 11 \times 11,11,1 \times \times 1 \times 1111195$

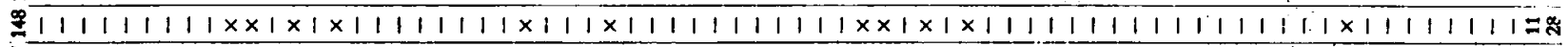

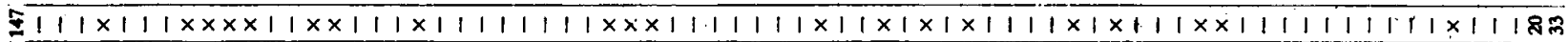

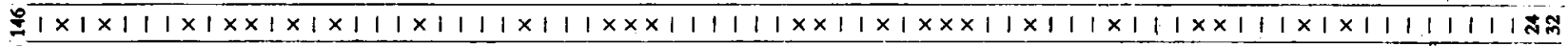

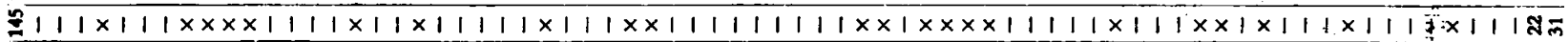

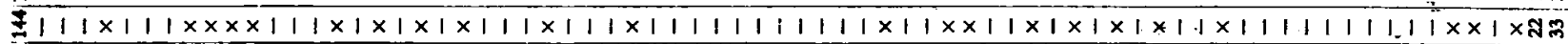

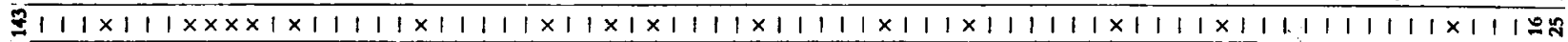
\$

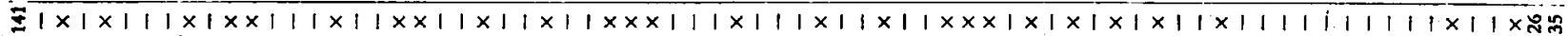

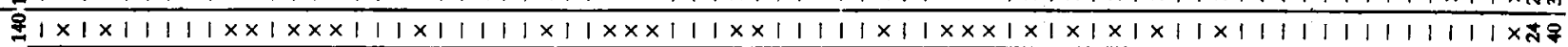

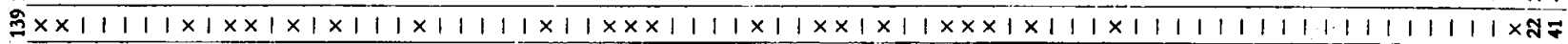
$911 \times 111 \times 1 \times \times 1 \times 1 \times \times 1+\times 1111 \times \times 11 \times \times \times 1111111111 \times 1 \times \times \times 11 \times 111 \times 1 \times \times 1 \times 11111 \times 1111 \times 11 \times 3 \times$

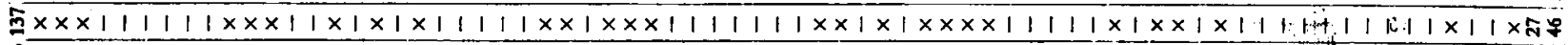

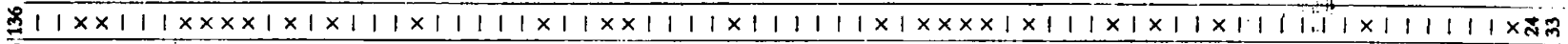

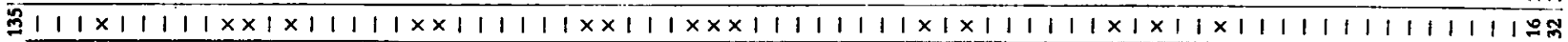
$\$ 11111 \times 1 \times 11 \times 111 \times 1 \times 1 \times 11111 \times 111 \times 11111111111 \times 1 \times 1 \times 111111 \times 1 \times 1111111111111111125$ 111 $111 \times \times \times \times 111 \times 1 \times 1 \times \times 1111111 \times \times \times 111 \times 111111 \times 111 \times 11 \times 111 \times 1 \times 11111111 \times 1111 \times 11180$

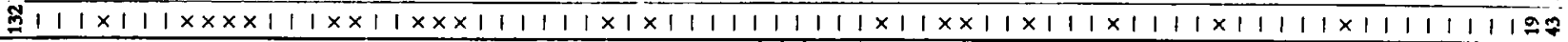
$5111 \times 111 \times 1 \times \times 111 \times 1 \times 1 \times 1111111111 \times 1111111111 \times 111 \times \times 11111 \times 11111111111 \times 111 \times 11 \times 2 n$ s11 $1 \times 111 \times 11 \times 1111111 \times 11111111 \times 11111111111 \times \times 111 \times 111111 \times 1111111111 \times 1111111198$ \$1 $1 \times x|\times 1 \times 1| \times 111 \times 1 \times 1 \times x \mid 111111 \times 1 \times 111 \times 111111 \times 1 \times \times \times 11 \times 111 \times 1111 \times 1111111111111198$

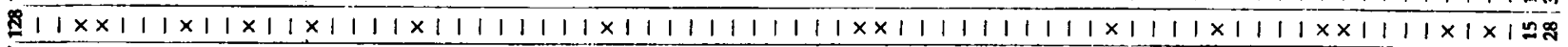

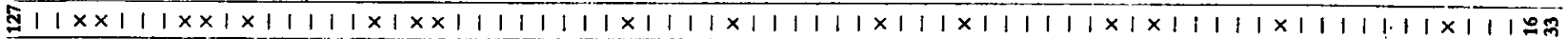

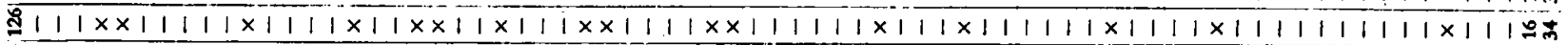
211 $1 \times 111 \times 1 \times x|1| 1 \times 1|\times x| 111111 \times x \mid 1111111111 \times 111 \times 111111 \times 1 \times 11111111 \times 1111111158$

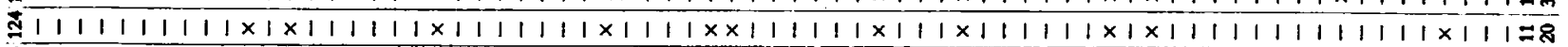
A1 $1 \times x \mid 1 \times 111 \times 1111 \times 11111111111 \times 11111 \times 1111 \times \times \times 111 \times 11 \times 111 \times 11111111111111111119 \pi$ đI1 $1 \times x 11111 \times 1111111 \times \times 111 \times 111 \times 1111 \times \times 1111111111 \times 111111 \times 1 \times 111111111111111119 m$

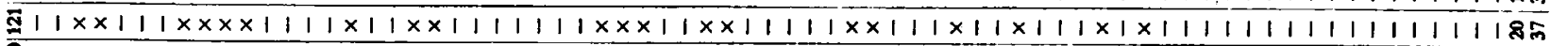

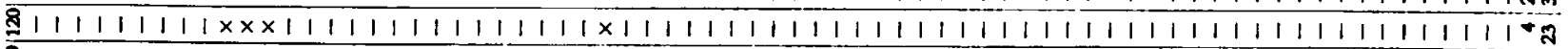

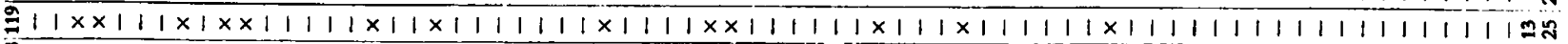

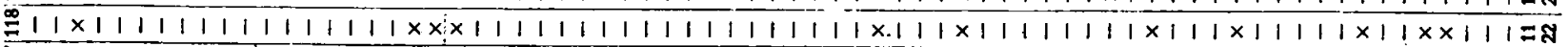

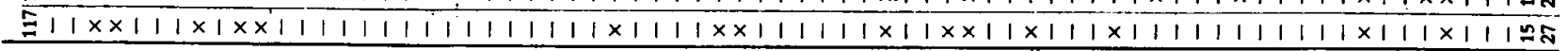

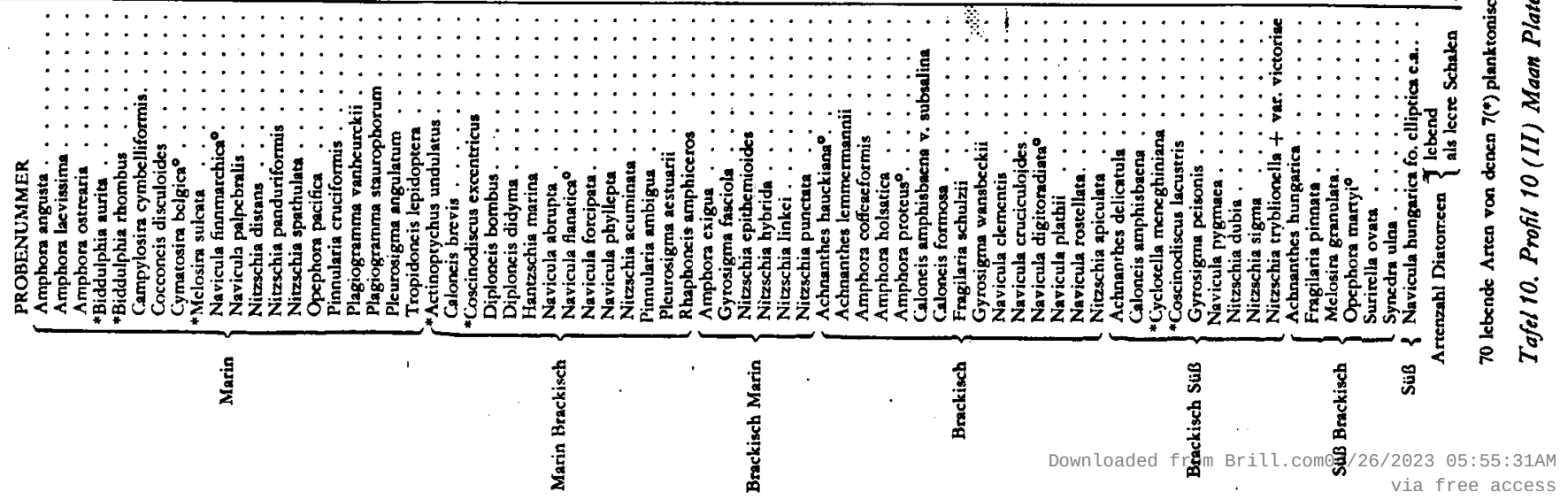




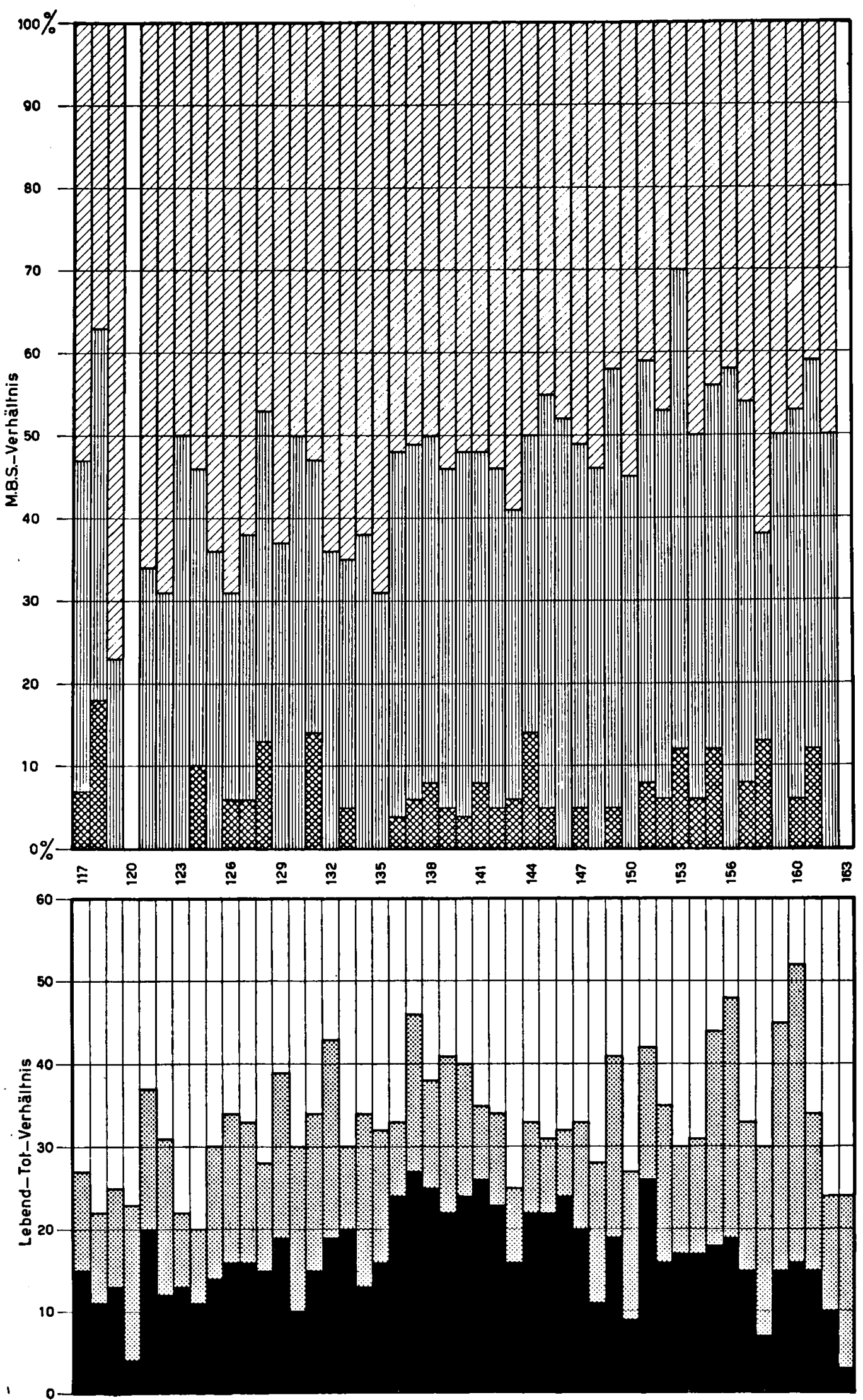




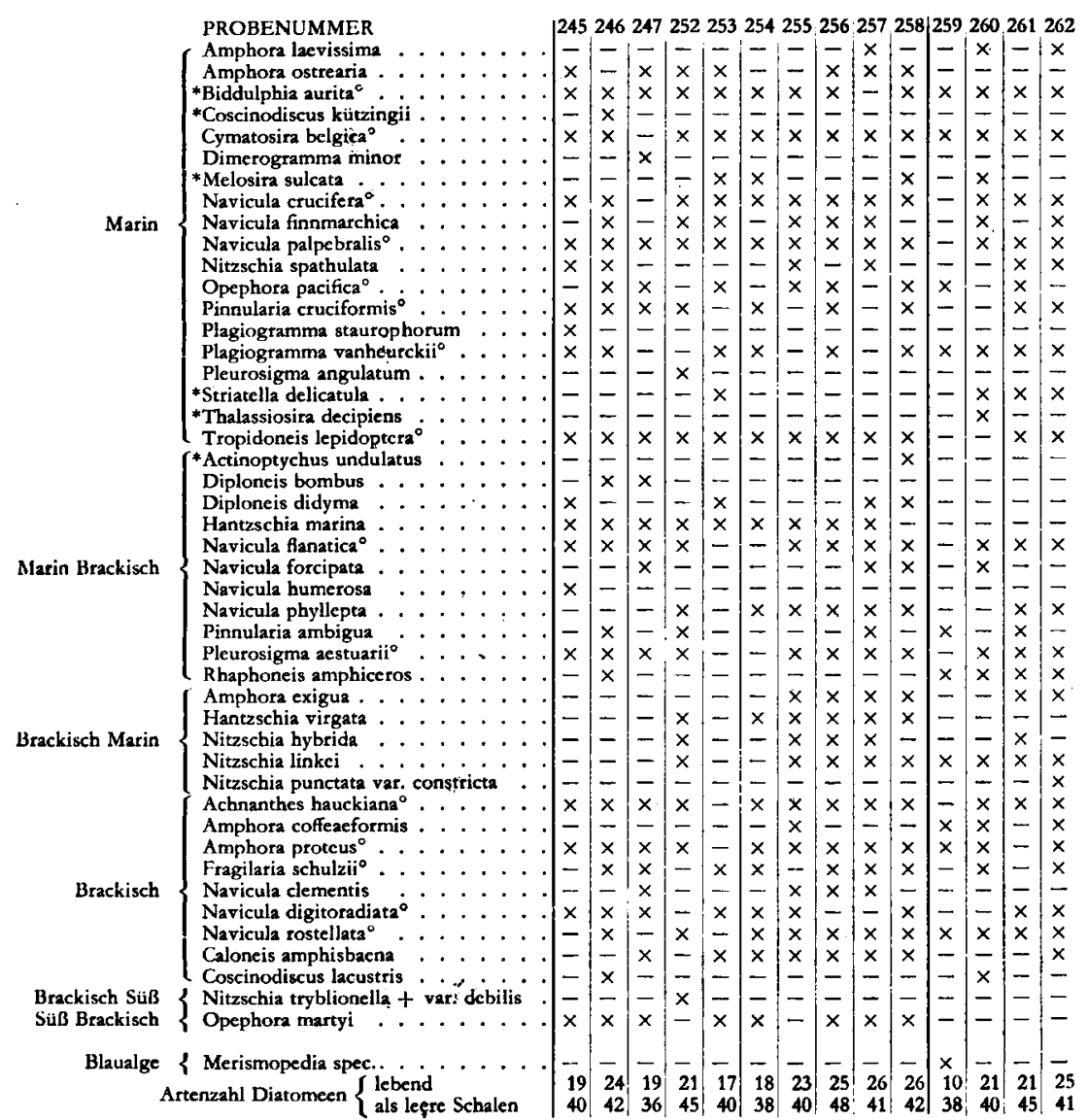

Alle Proben aus Priclen; 46 lebende Arten von denen $6\left(^{*}\right)$ planktonisch-neritisch und $15\left(^{\circ}\right)$ übet nahezu das ganze Profil. Keine dominicrende.

Tafel 11. Profil 11, Hoogzand Plate, 2 August 1954.
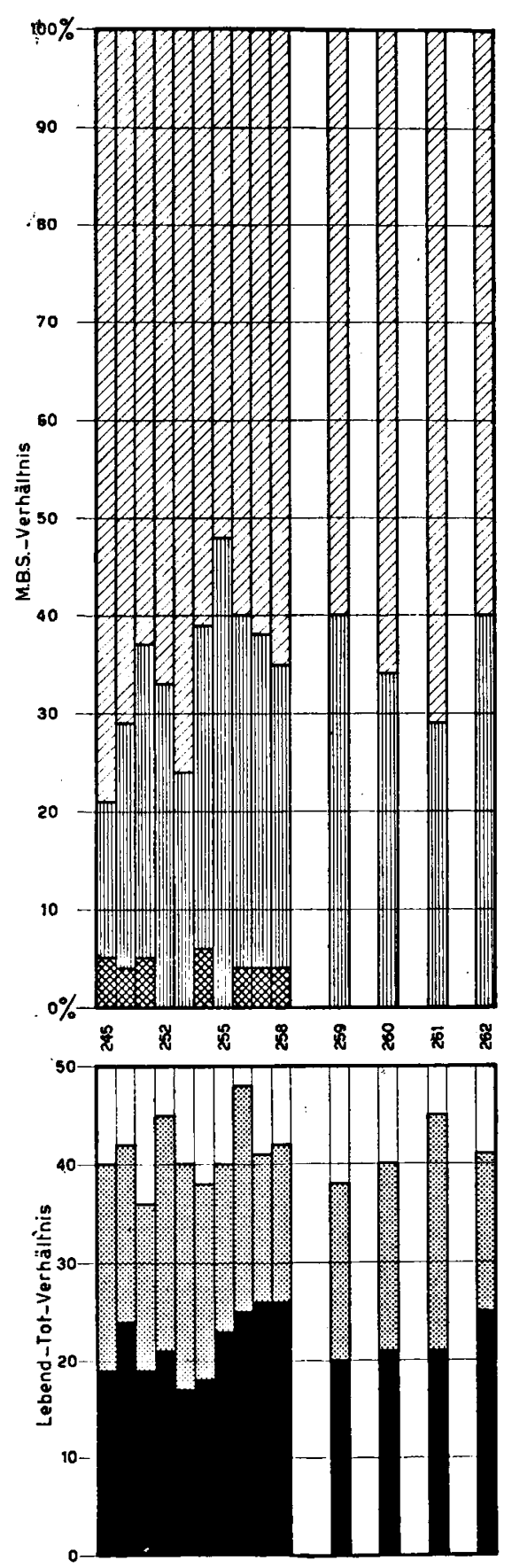

Stabdarstellung bei T.11 


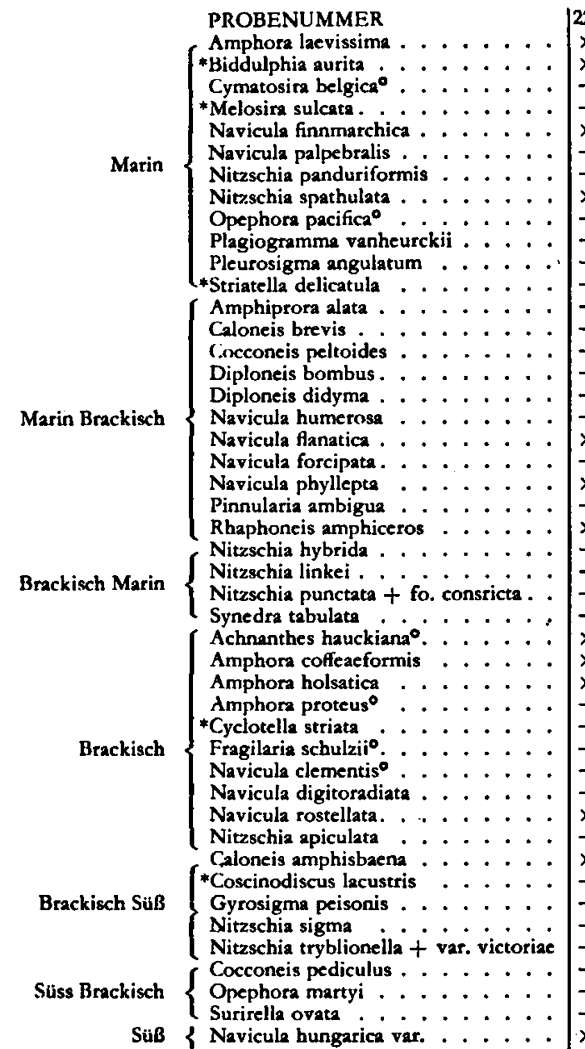

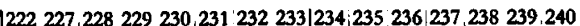
Amphora laevissima $\ldots . . .$.
Biddulphia aurita $\ldots . .$.

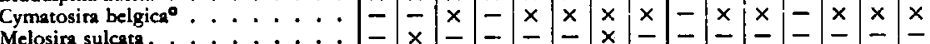

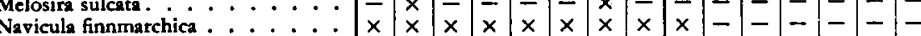

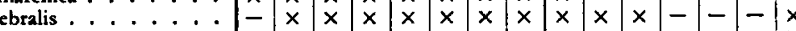

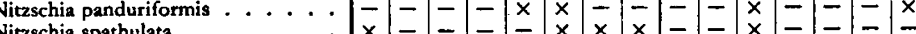
Nitzschia spathulata....... $\times \bar{x} \bar{x} \bar{x} \bar{x} \times \frac{x}{x} \bar{x} \bar{x} \times \bar{x}=\bar{x} \bar{x}$

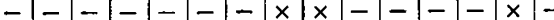

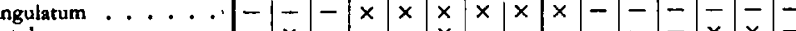
$-x---x---1-$

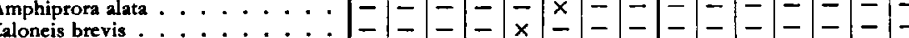

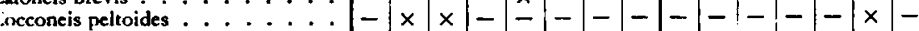
$-\bar{x}=-\bar{x}-\bar{x}-\mid x-x \times$ $x=x-x-x=1-1=$

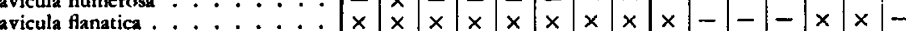

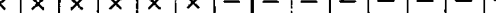

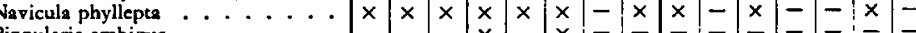

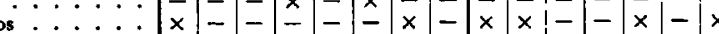
$-\times \times-\times \times \times \times \times \times \times \times-1$ $-1---1 \times-1-0-1-1-$

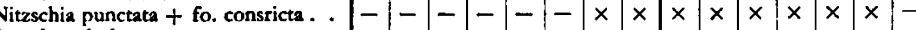
$\bar{x} \bar{x} \bar{x} \bar{x} \bar{x} \times \bar{x} \times \bar{x}-\bar{x}=\frac{\bar{x}}{\bar{x}} \bar{x}$

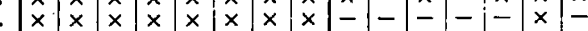

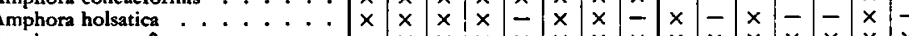

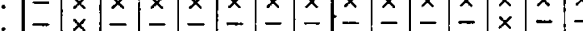

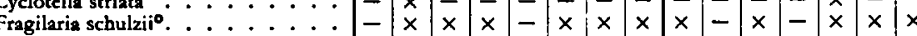

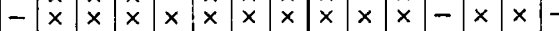

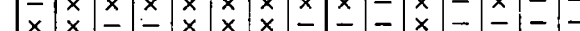
$-----x------$

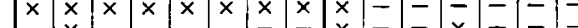

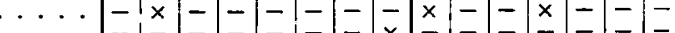
Gyrosigma peisonis........ $\overline{-} \bar{x} \bar{x}=-\bar{x} \bar{x} \times \bar{x} \bar{x} \bar{x} \bar{x} \bar{x}=-$

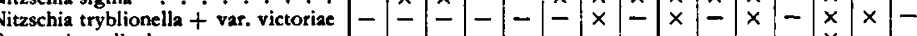
$-\bar{x} \bar{x}-\bar{z} \bar{x} \bar{z} \bar{x} \bar{x} \bar{z} \bar{x}-\bar{x}$

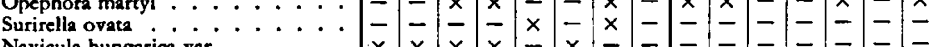
SüB \{ Naviculs hungarica var. . . . . .

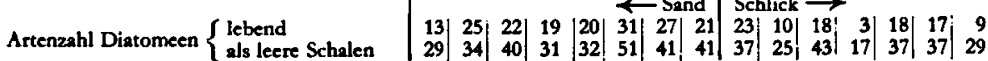
46 lebende Arten von denen $5\left({ }^{*}\right)$ planktonisch-neritisch und $6\left(^{\circ}\right)$ über nahezu das ganze Profil Tafel 12. Profil 12 (IV), Geise Plate, 29 Juli 1954.
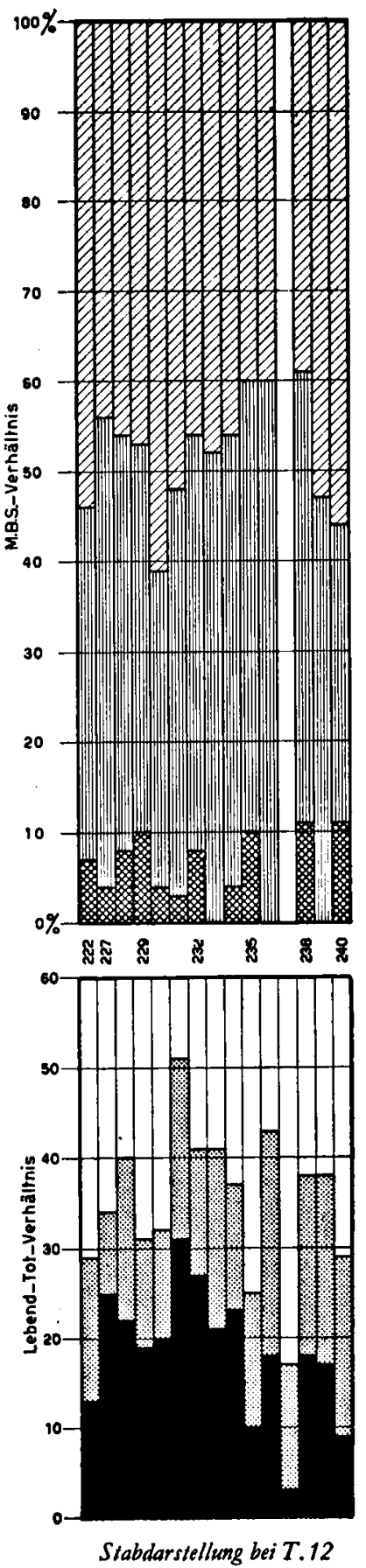


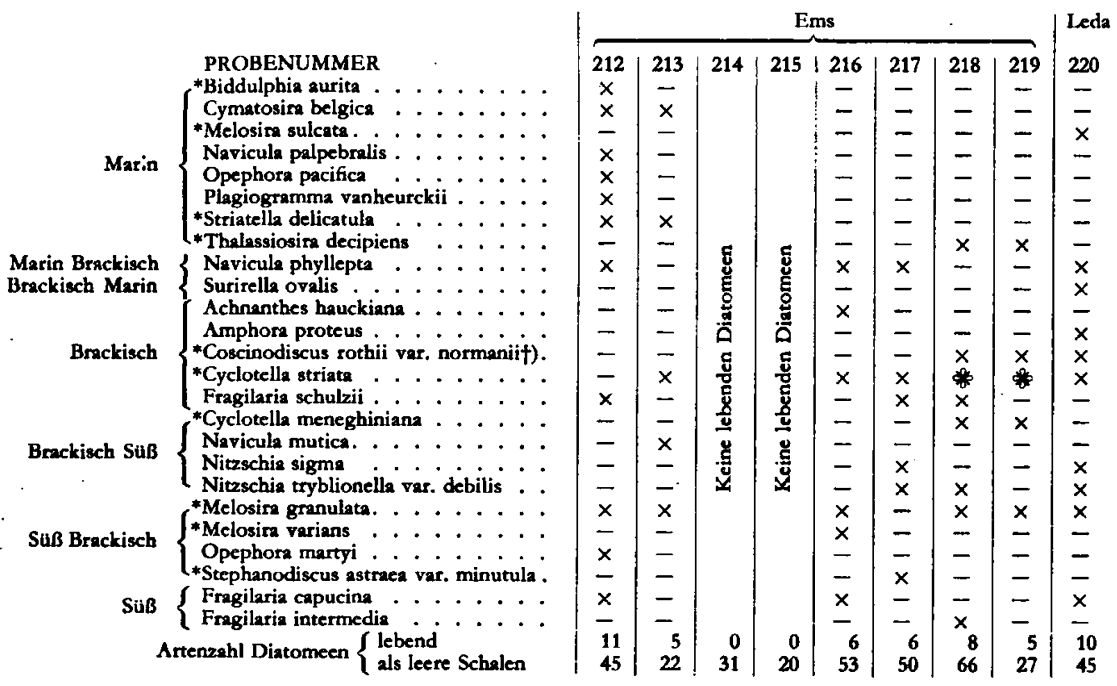

25 lebende Arten von denen $10\left(^{*}\right)$ planktonisch-neritisch; $\times$ anwesend dominierend

t) In Zusammenhang mit der von Hustedt entdeckten Strukturübereinstimmung von Coscinodiscus rothii var. normannii mit Arten des Genus Actinocyclus ist diese Varietät bei diesem Geschlecht untergebracht worden und trägt heute den Namen Actinocyclus normannii. Beobachtungen über die ökologischen

Umstände unter denen diese Diatomee lebt, haben es wahrscheinlich gemacht, dass sie in die Brackwassergruppe B gehört und nicht als Marin Brackisch (MB) betrachtet werden muss.

Tafel 13. Profil 13, Ems und Leda bis Leer, 26 Juli 1954.
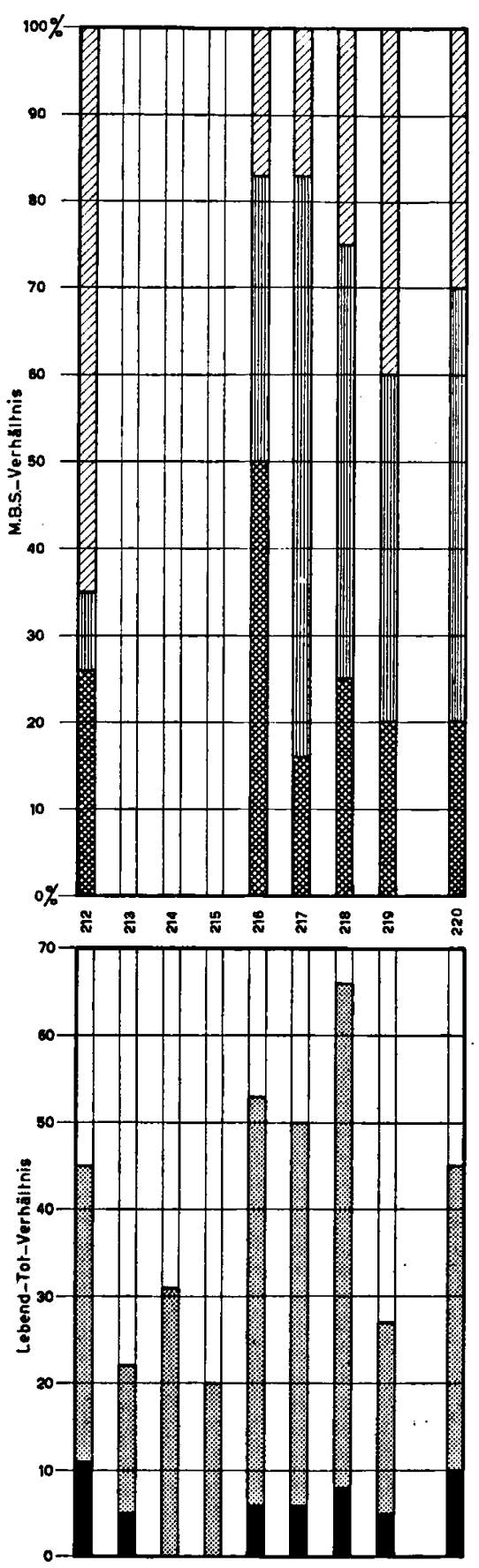

Stabdarstellung bei T.13 


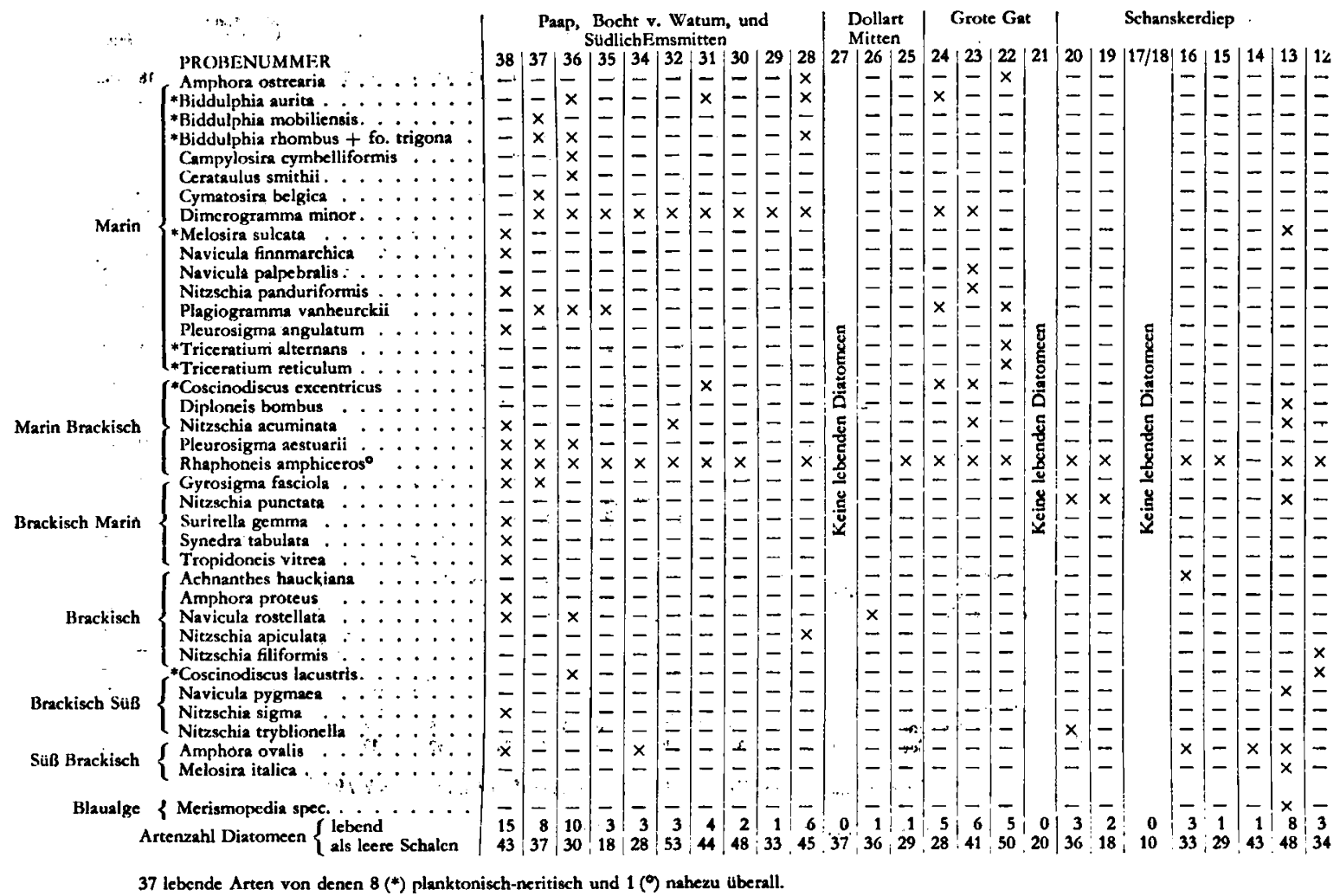

Tafel 14. Profil 14, Rinnen qwischen den Platen im Dollart und in der Ems, 17-19 September 1953.

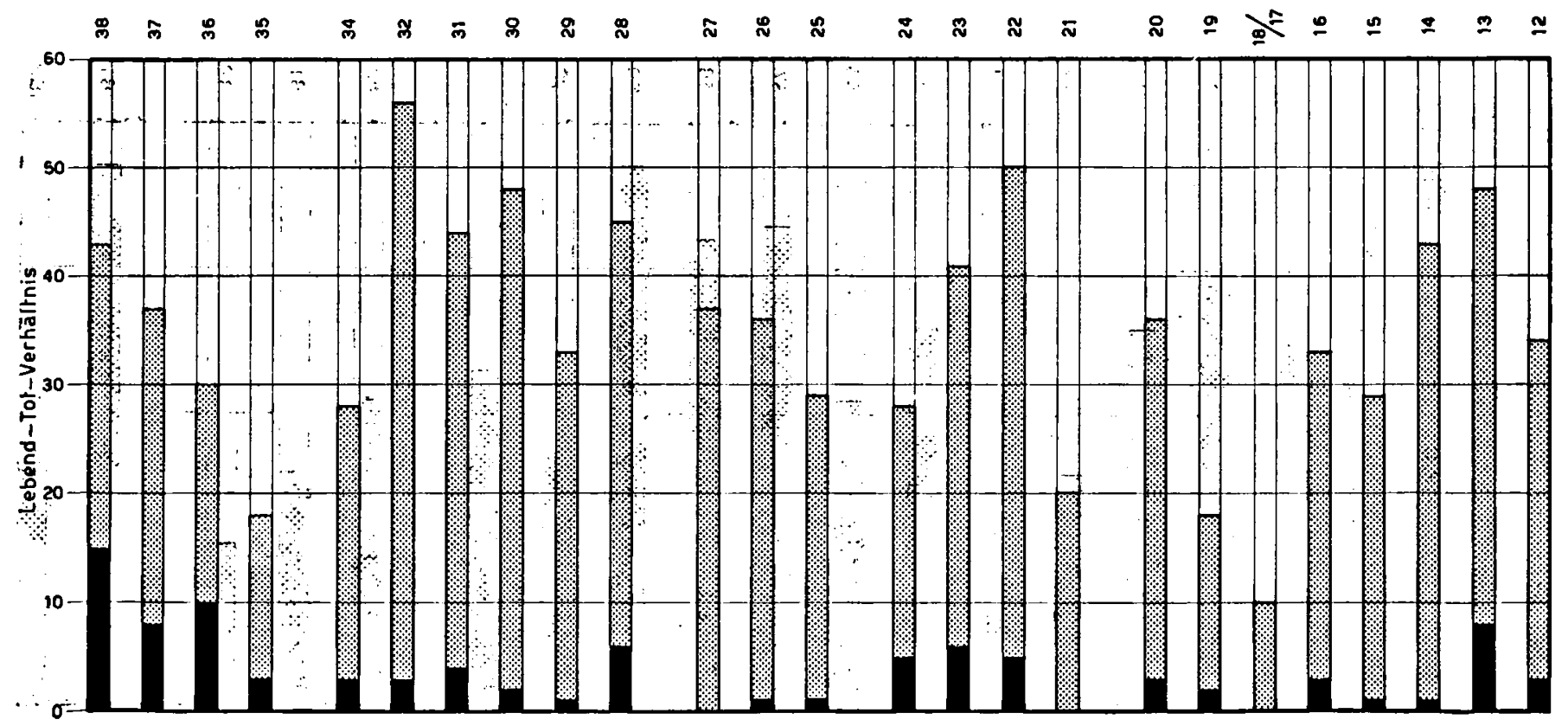

Stabdarstellung bei T: 14. Wegen den geringen :Artenzabl ist dio M.B.S,:Vexbälinis wenig deutlicls und deshalb ausgelassen 


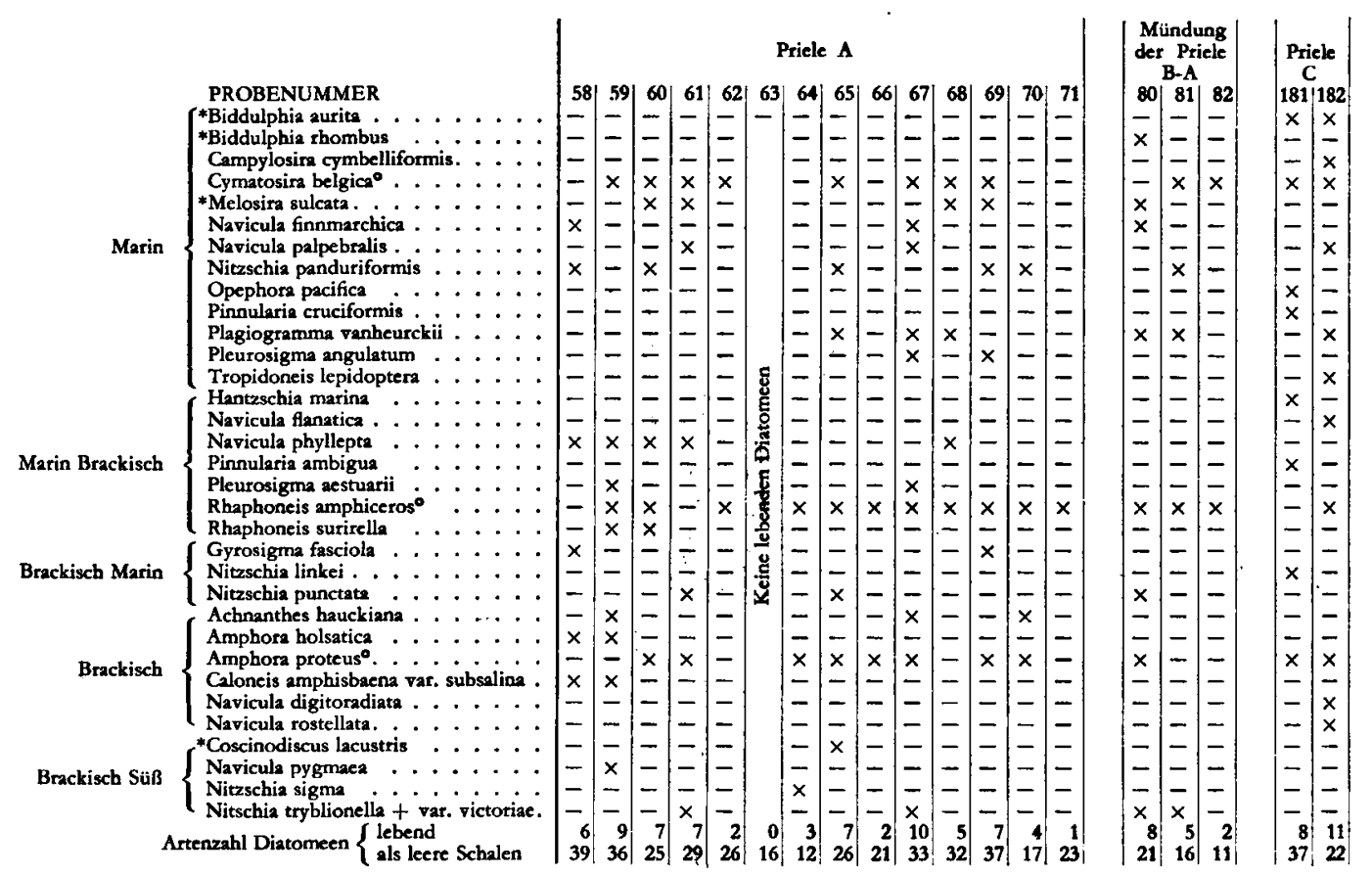

Tafel 15. Profil 15, Prielen sidllich von Reide, 24-25. September 1954 und 23 Juli 1954.

33 lebende Arten, von denen $4\left(^{*}\right)$ planktonisch-neritisch und $3\left({ }^{\circ}\right)$ nabezu überall.

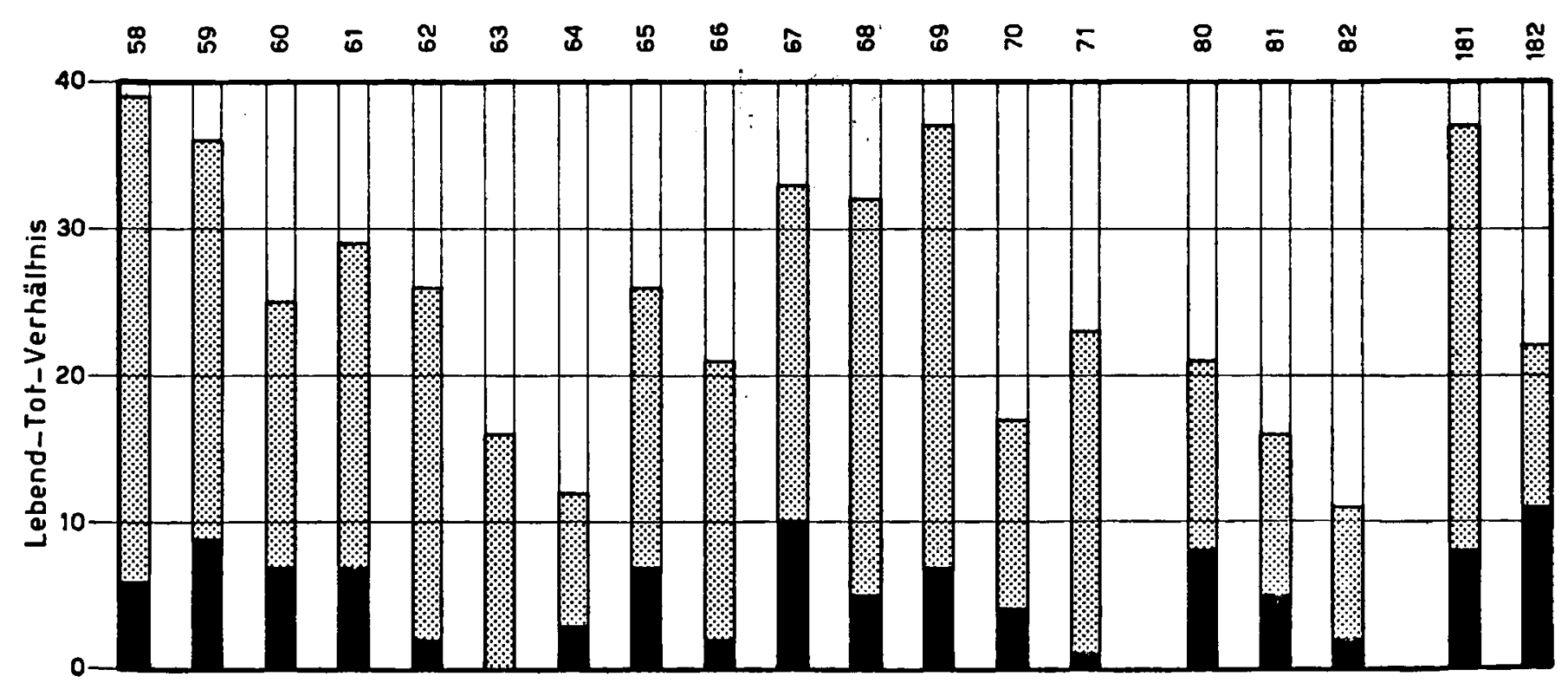

Stabdarstellung bei T.15. Wegen der geringen Artenzabl ist die M.B.S.-Verbältnis wenig deutlich und deshalb ausgelassen 


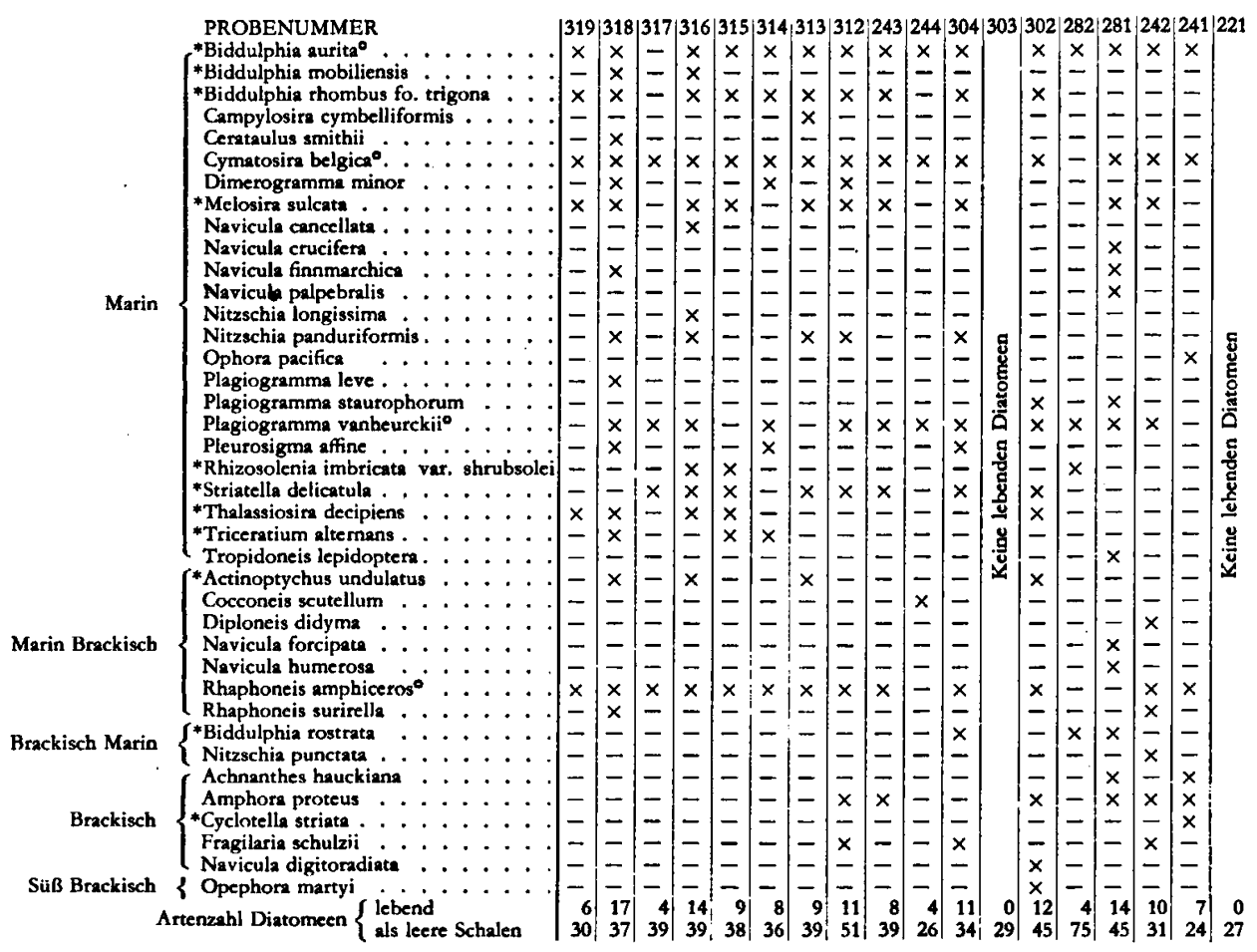

39 lebende Arten von denen 11 planktonisch-neritisch $\left(^{*}\right)$ und $4\left(^{\circ}\right)$ nahezu überall.

Tafel 16. Profil 16, Grosse Stromrinnen Ems-Bocht van Watum-Oost Friesche Gaatie-Oude Westereems, 17 Juli und 12 August 1954.
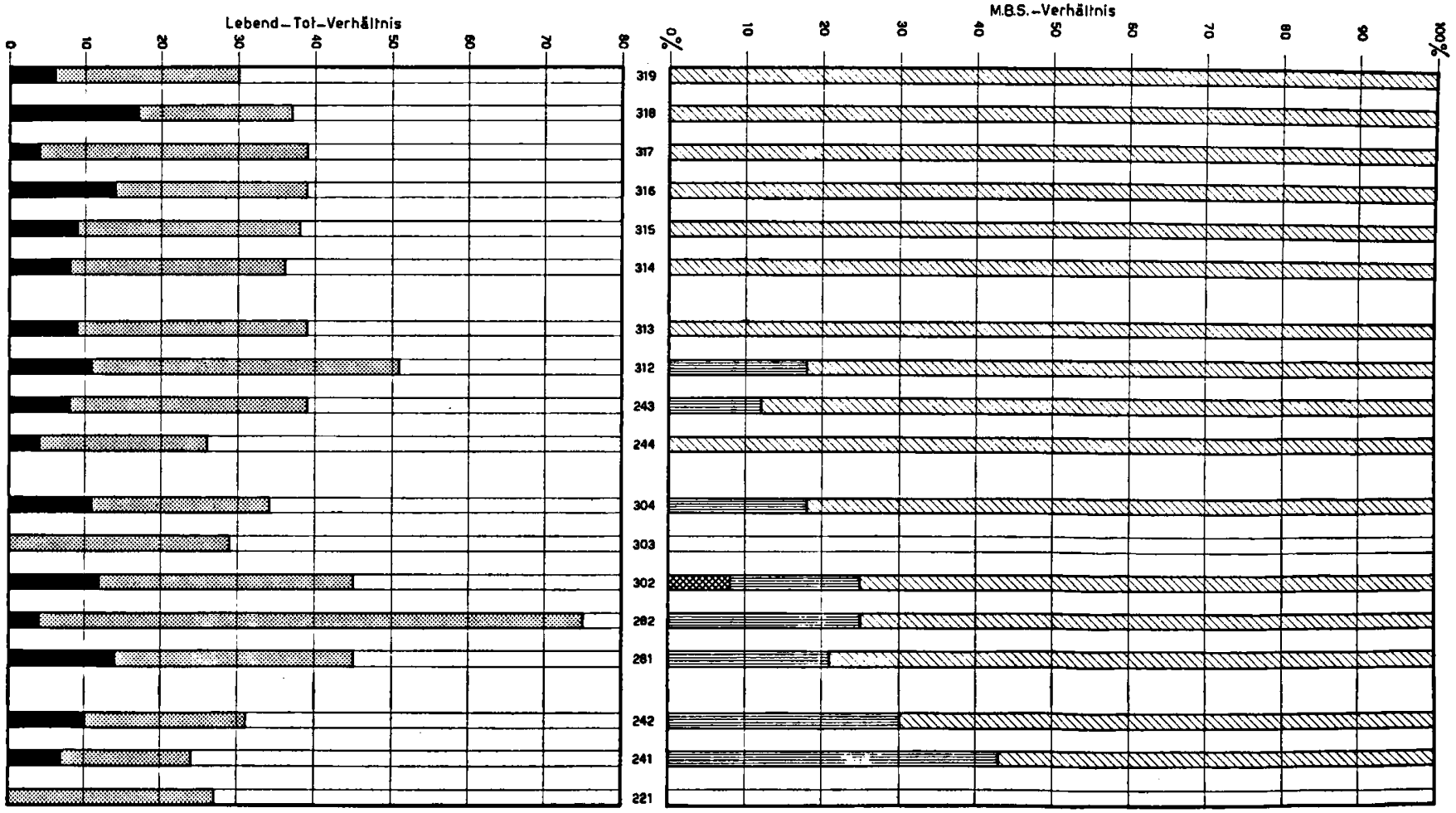

Stabdarstellumg bei T.16 

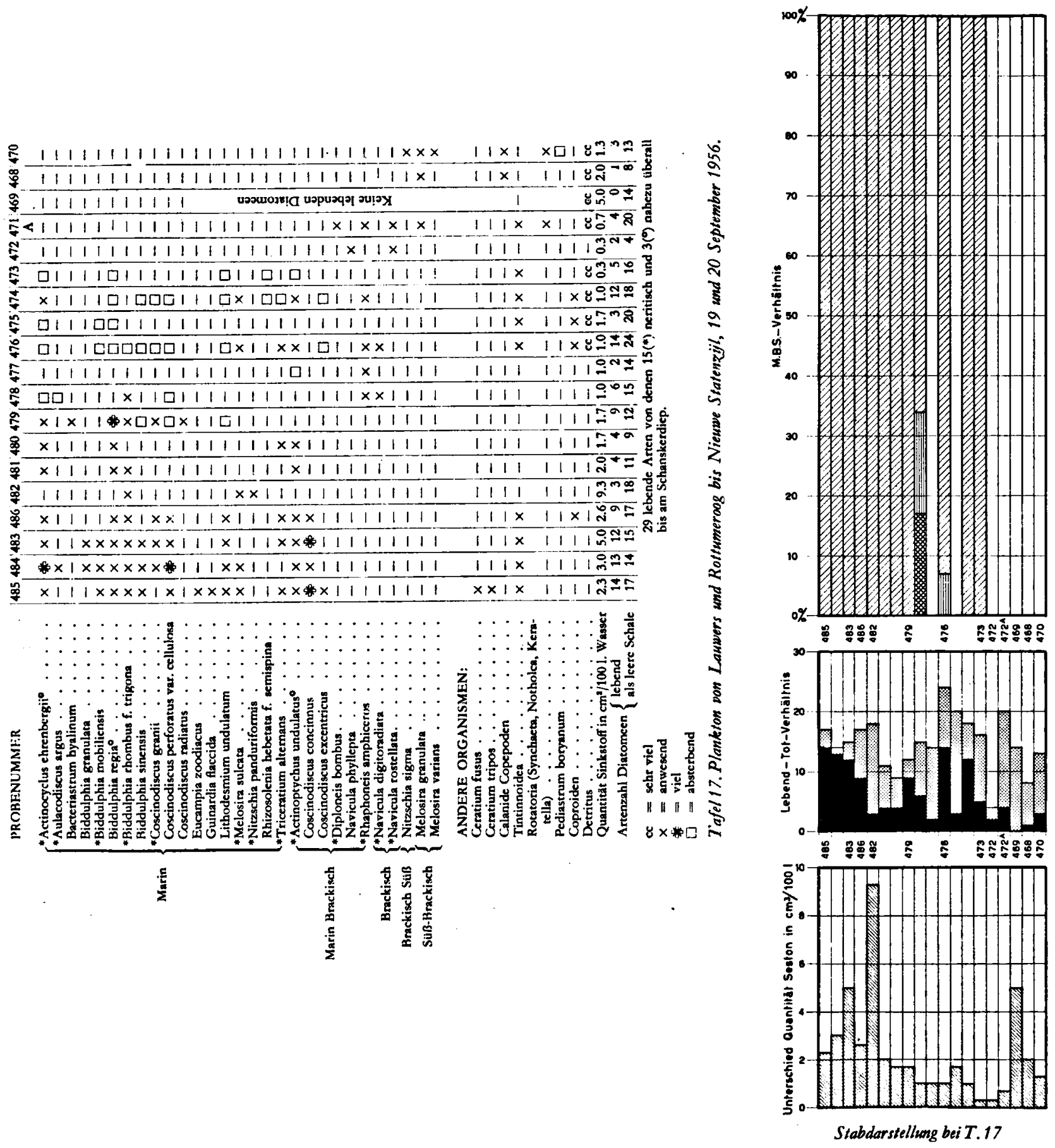


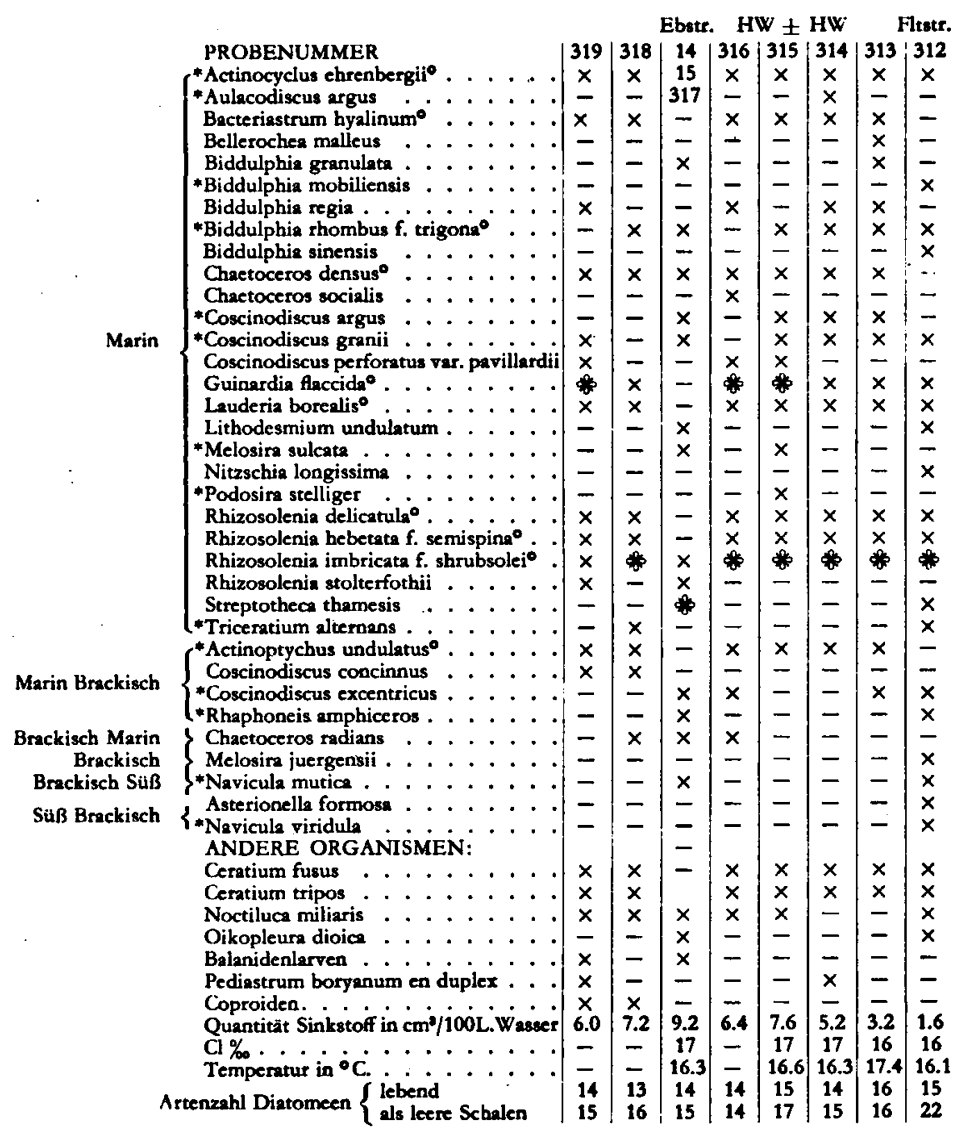

35 lebende Arten, von denen $14\left(^{*}\right)$ neritisch und $10\left(^{\circ}\right)$ auf \pm allen Stationen.

Tafel 18. Plankton "Oude Westereems" und "Bocbt van Watum" 12 Augustus 1954.
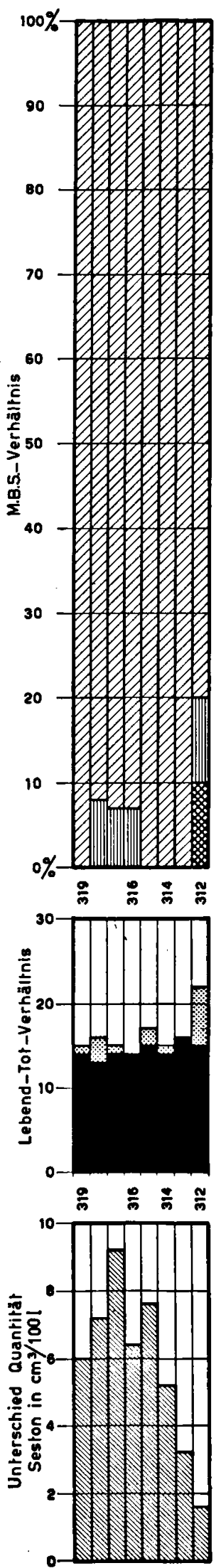


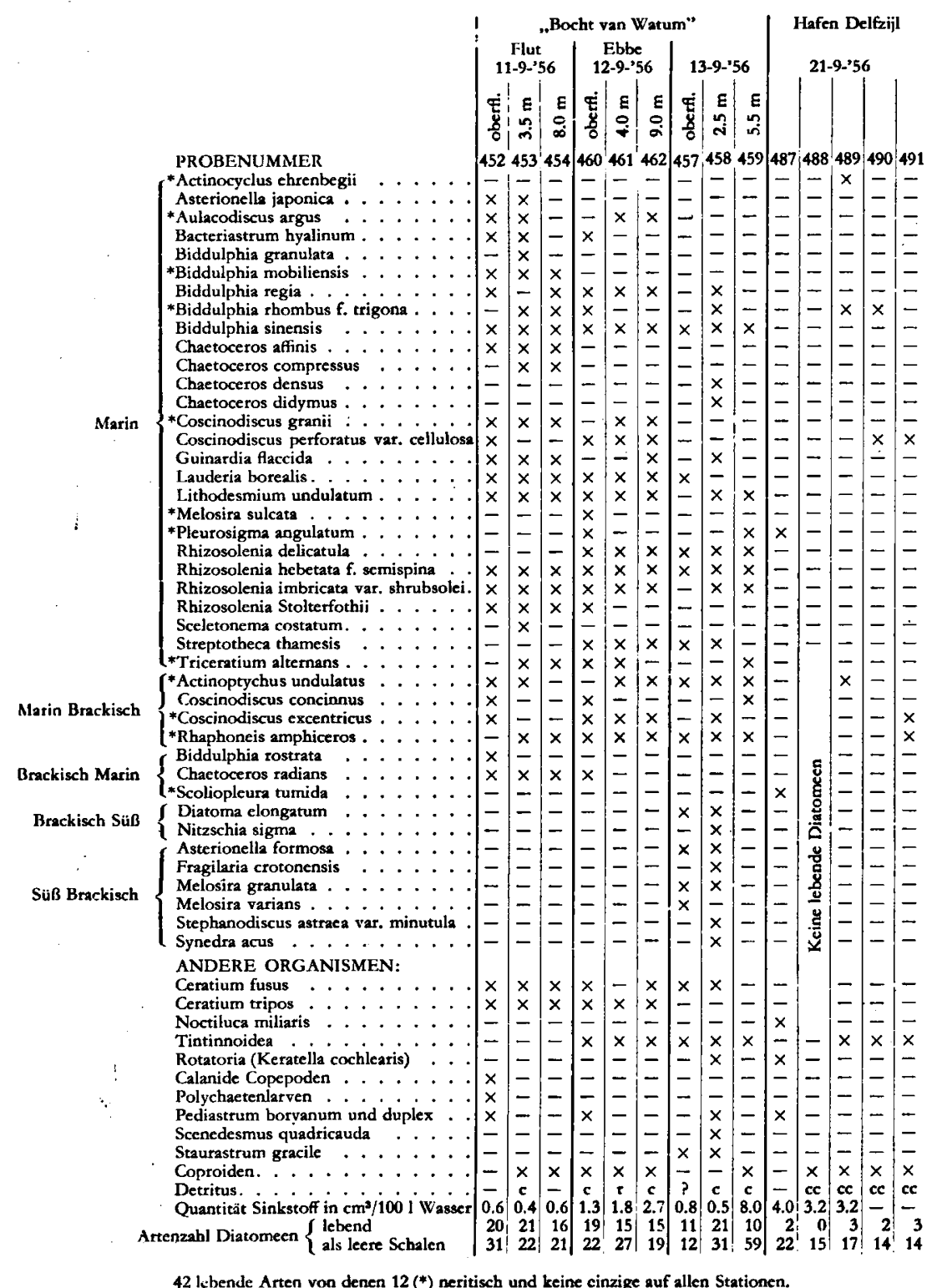

42 lichende Arten von denen $12\left(^{*}\right)$ neritisch und keine cinzige auf allen Stationen.

Tafel 19. Plankton "Bocbt van Watum" und Hafen Delfzijl, 11-13 und 21 September 1956.
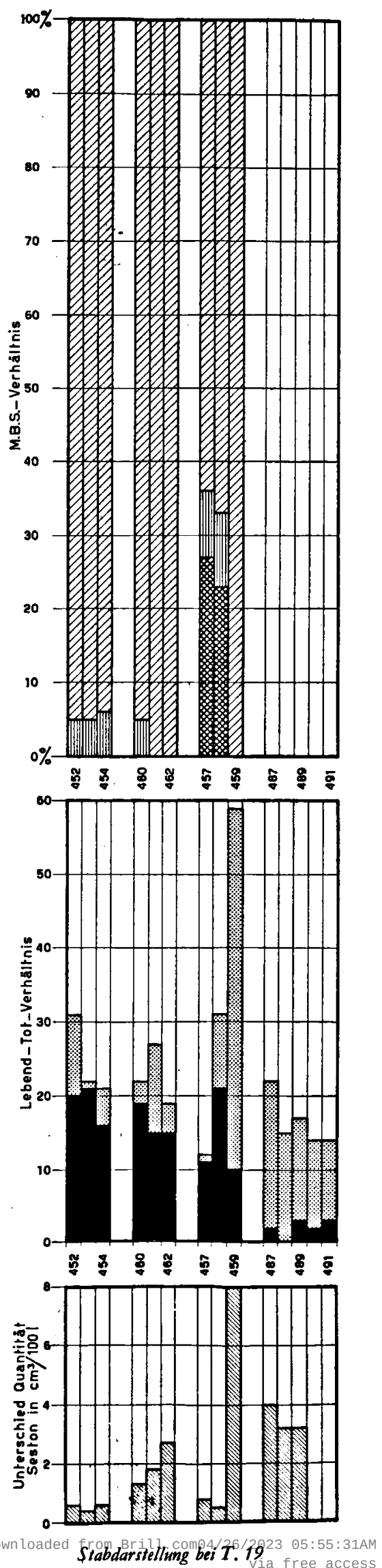


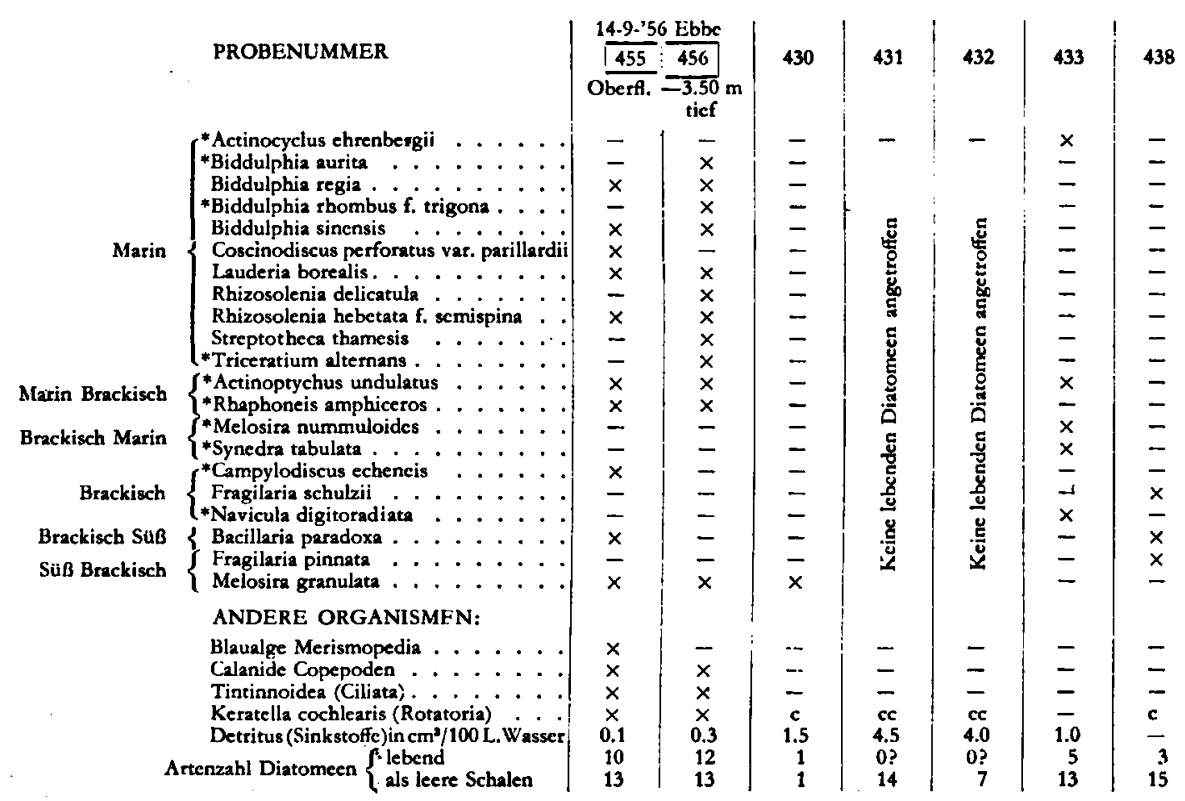

21 lebende Arten, von denen $10\left(^{*}\right)$ neritisch-benthonisch und kcine cinzige auf nahezu allen Stationen. Keine dominicrende; $X$ anwesend, $c$ viele, $c c$ sehr viele.

Tafel 20. Plankton, "Mond van de Dollart" (Nr. 455-456, 14 Sept. 1956) und von Termumten bis Kerkeriet (Nr.430-438, 18 Sept. 1956).
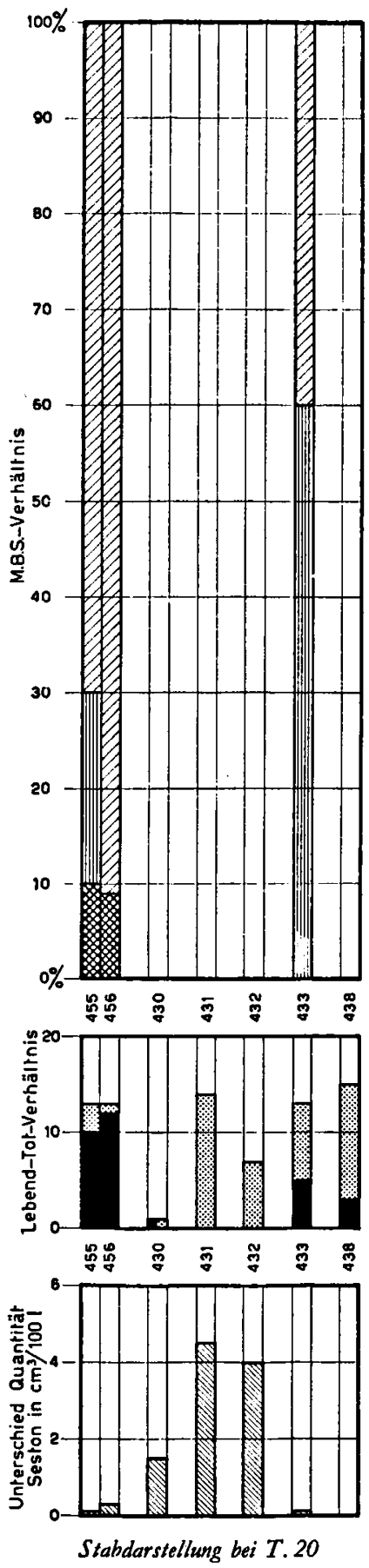


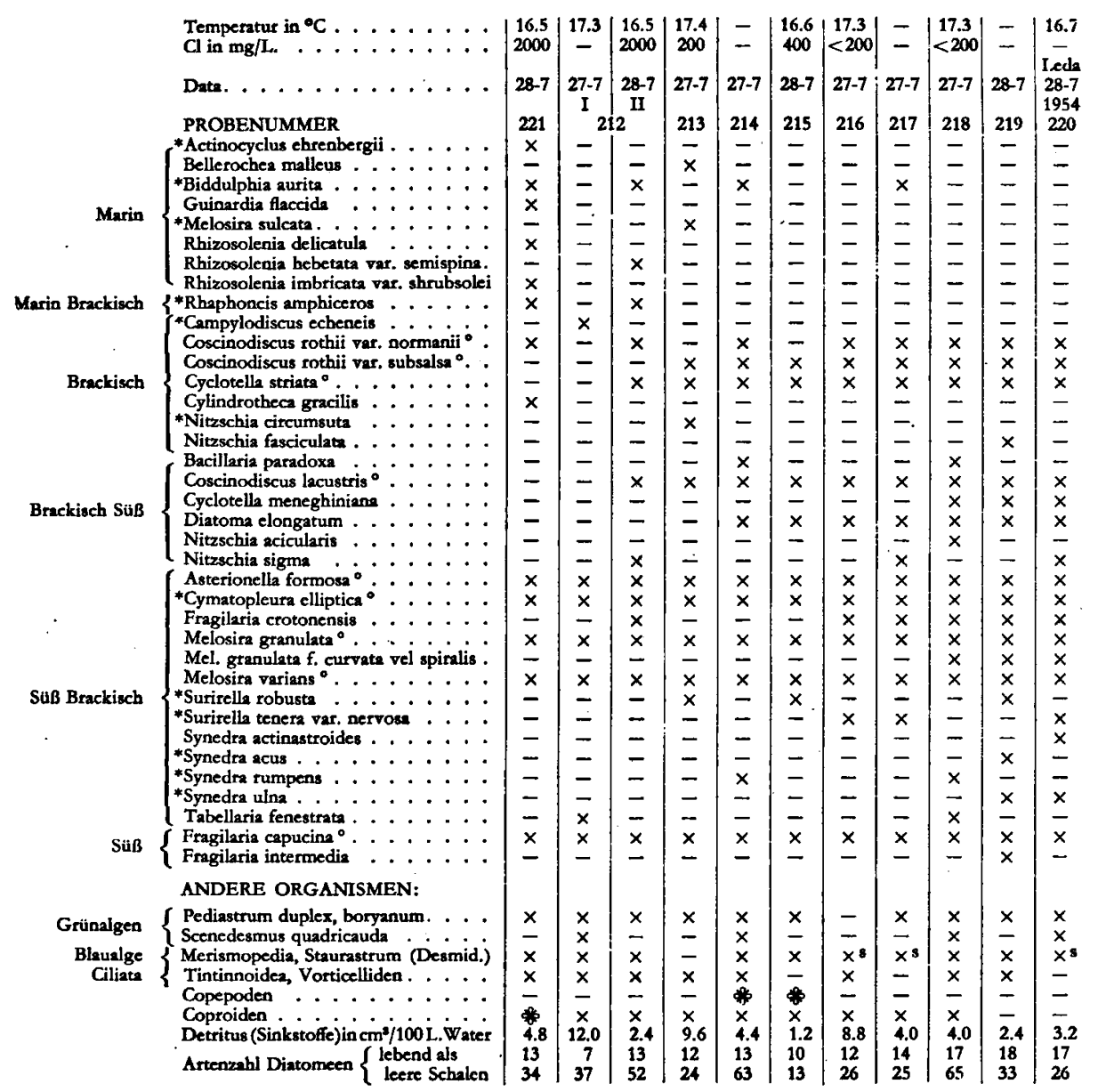

37 Arten, von denen $12\left(^{*}\right)$ neritisch-benthonisch waren und 24 auch im Jahre 1956 wahrgenommen wurden ( $\left.{ }^{\circ}\right) .9$ Arten kamen auf nabezu allen Stationen vor; $x$ anwesend dominierend.

Tafel 21. Plankton Oberfäacbe Ems (Emden-Leer) und Leda, 27 und 28 Juli 1954.
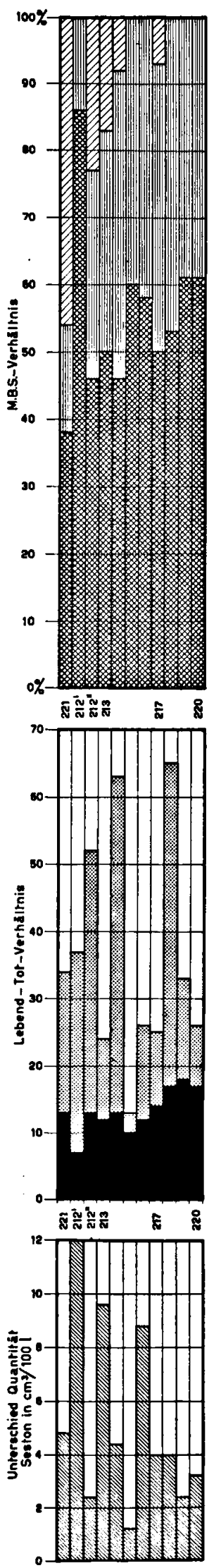

Stabdarstellueng bei T. 21 


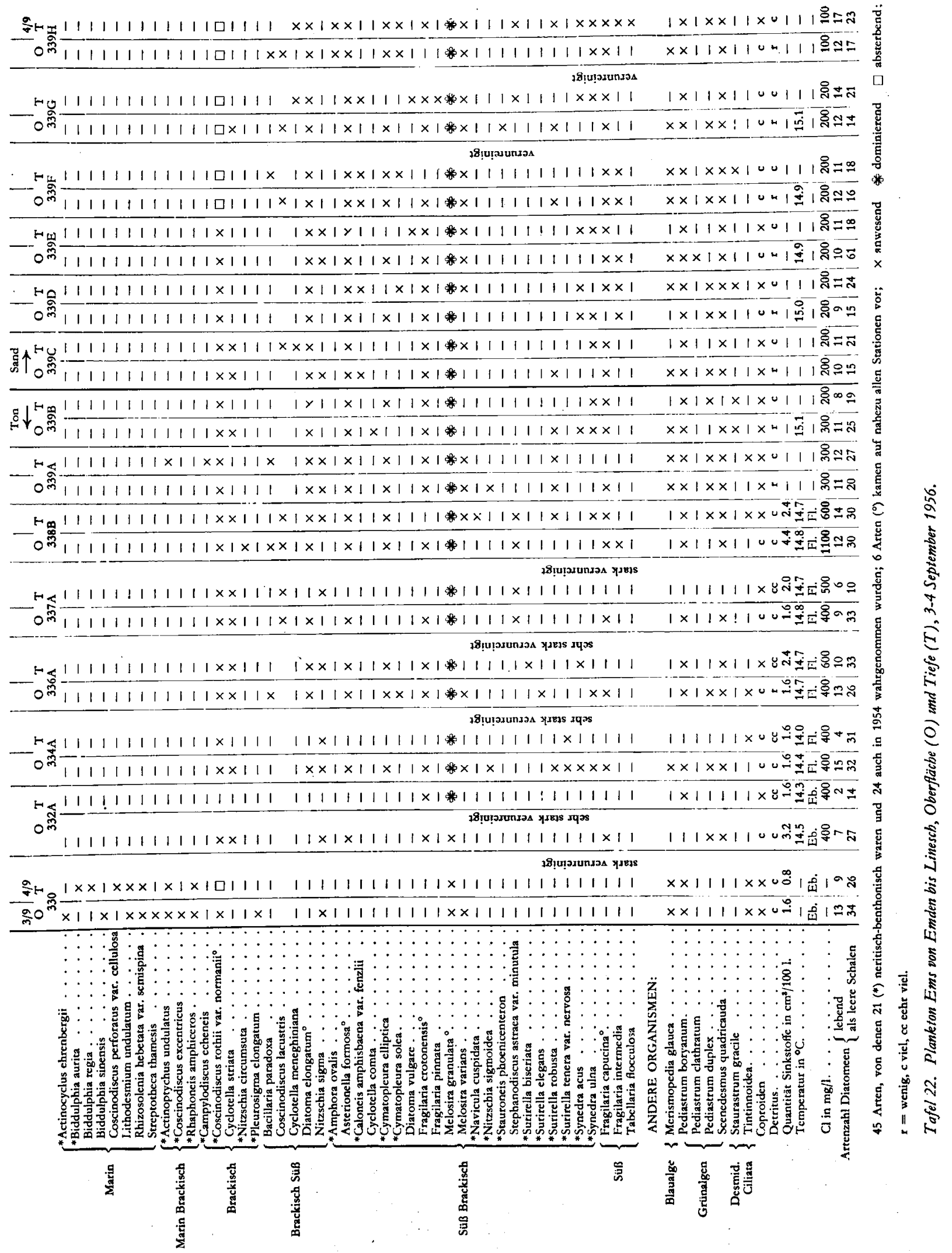

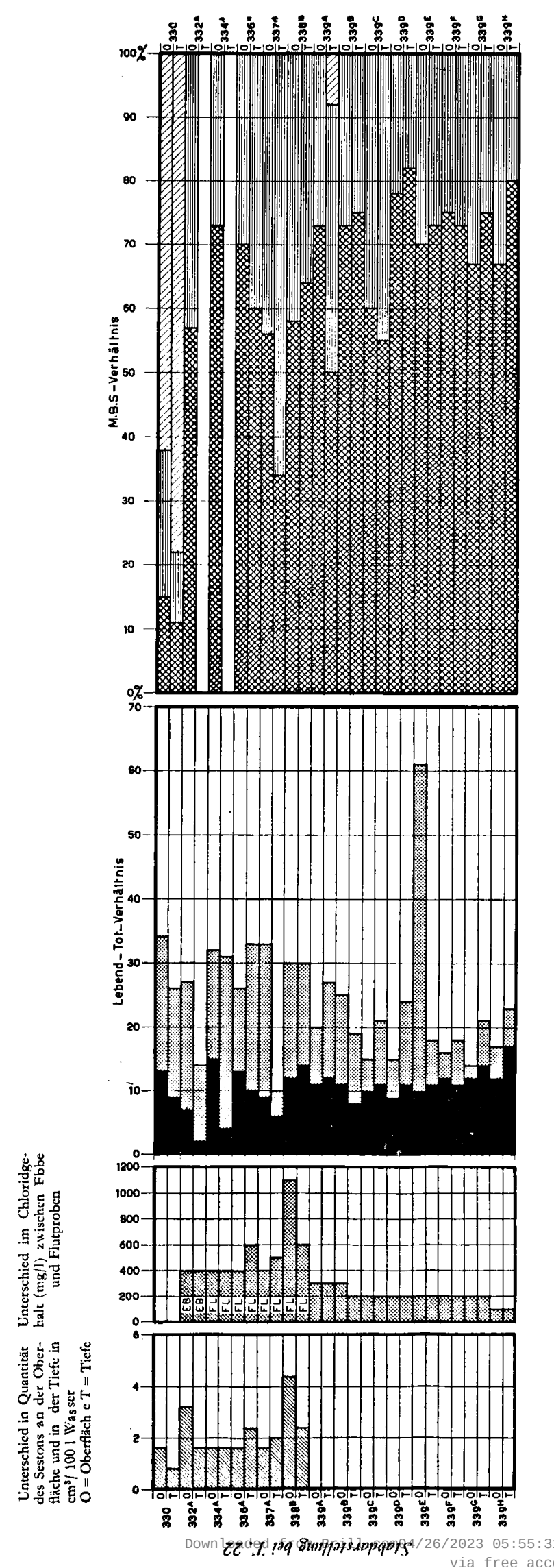




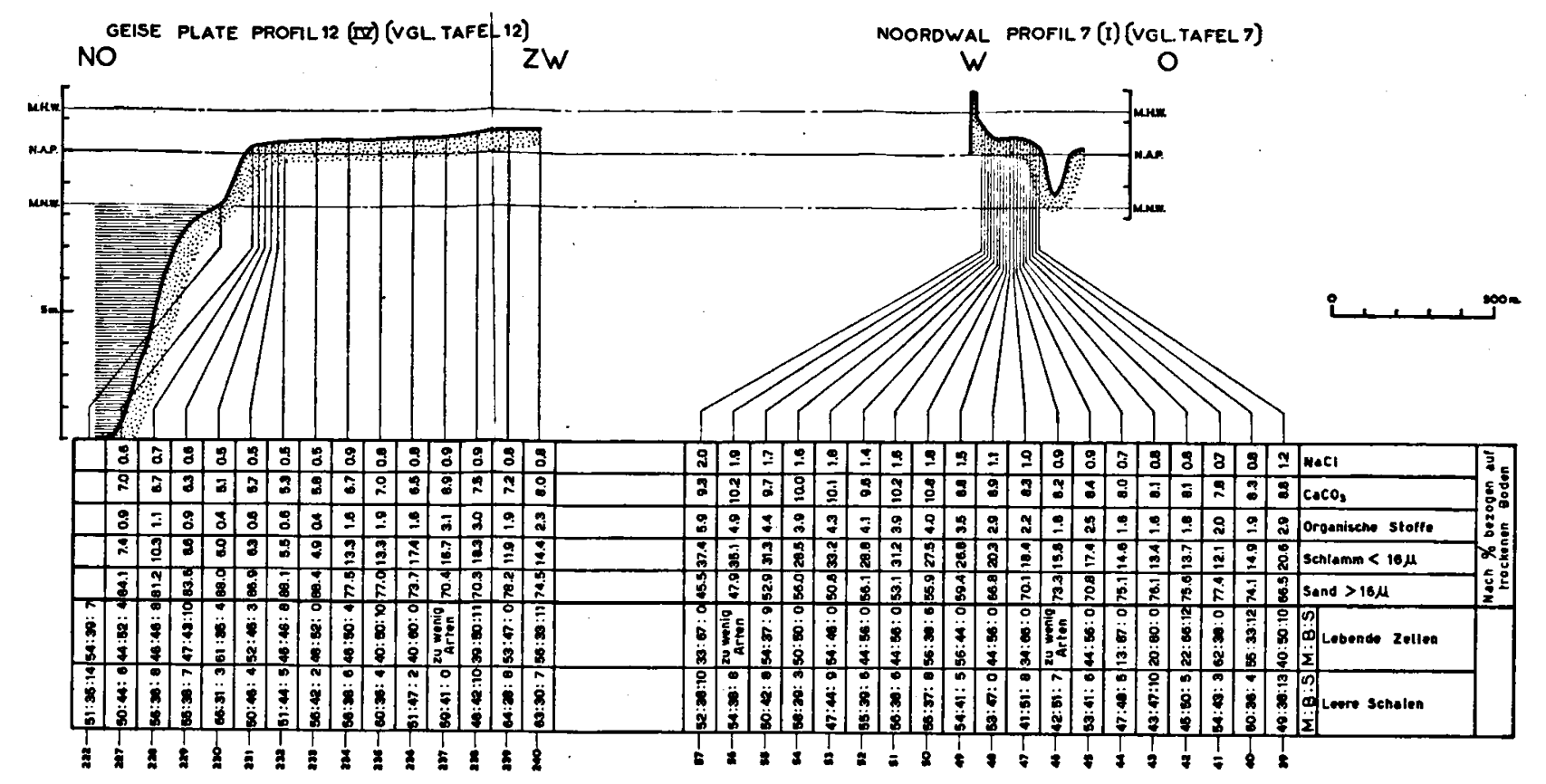

Tafel 23. Geise Plate Profil IV (Vgl. Tafel 12) Noordwad Profil I (Vgl. Tafel 7).

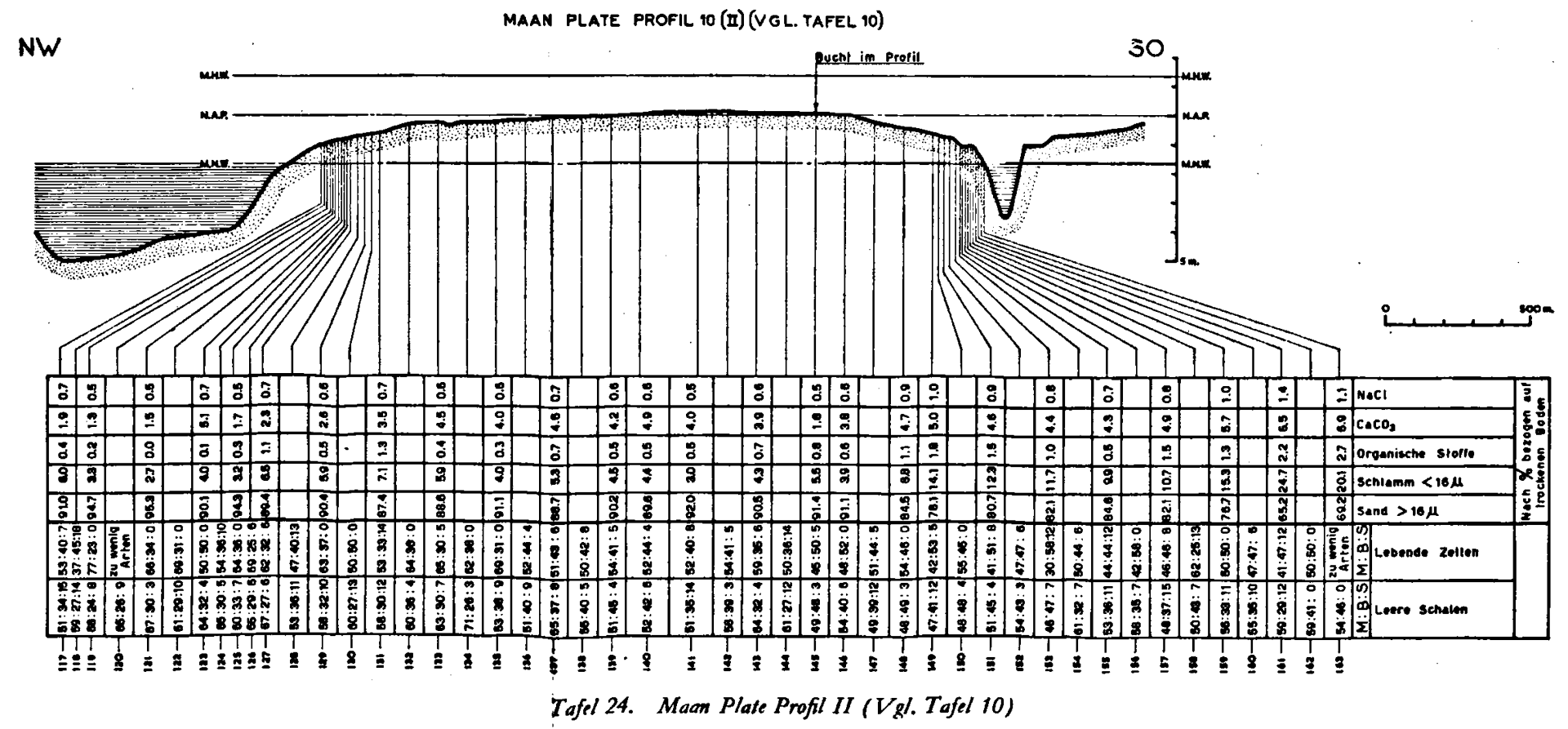




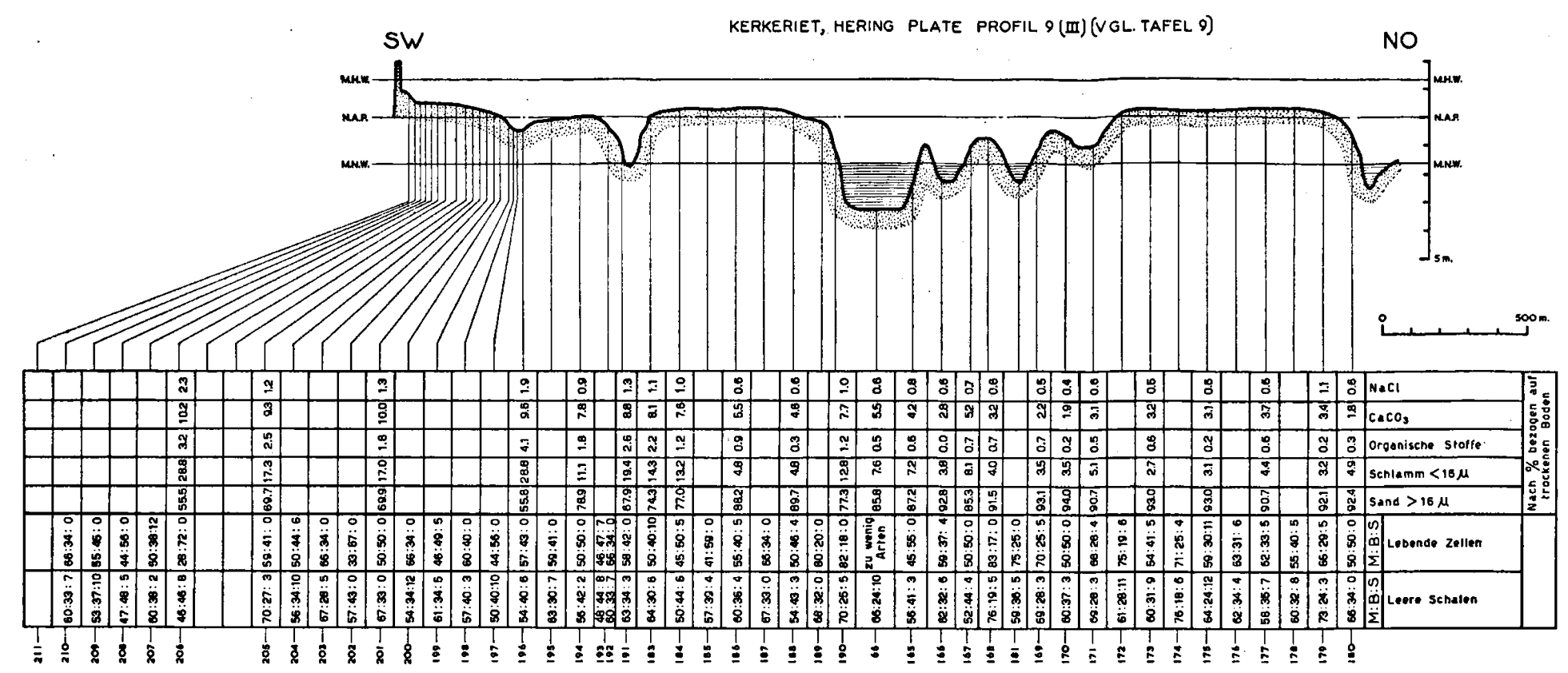

Tafel 25. Kerkeriet, Hering Plate Profil III (Vgl. Tafel 9)

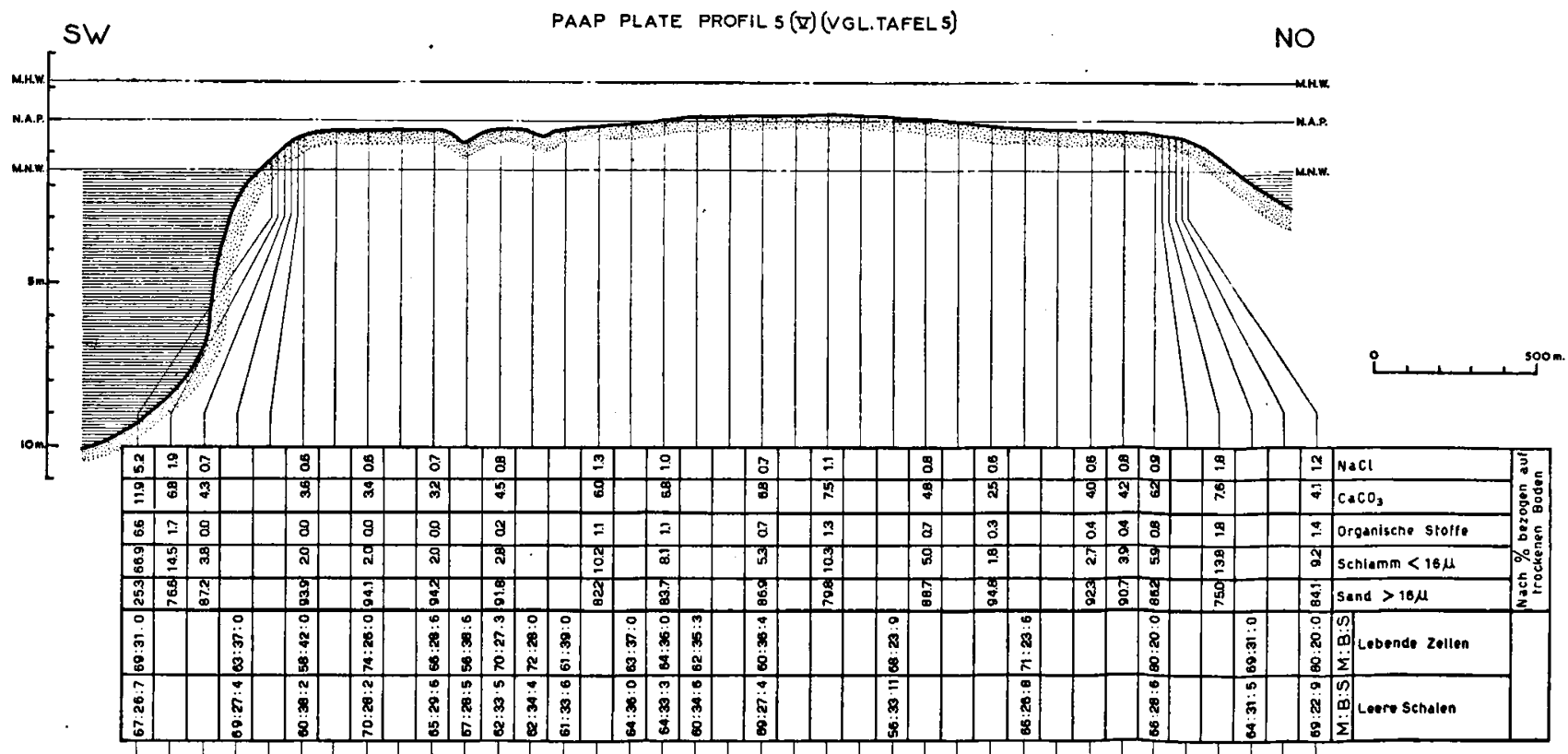

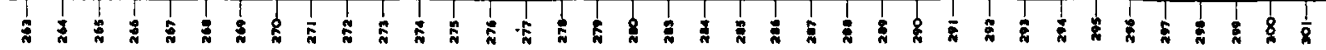

Tafel 26. Paap. Plate Profil V (Vgl. Tafel 5) 

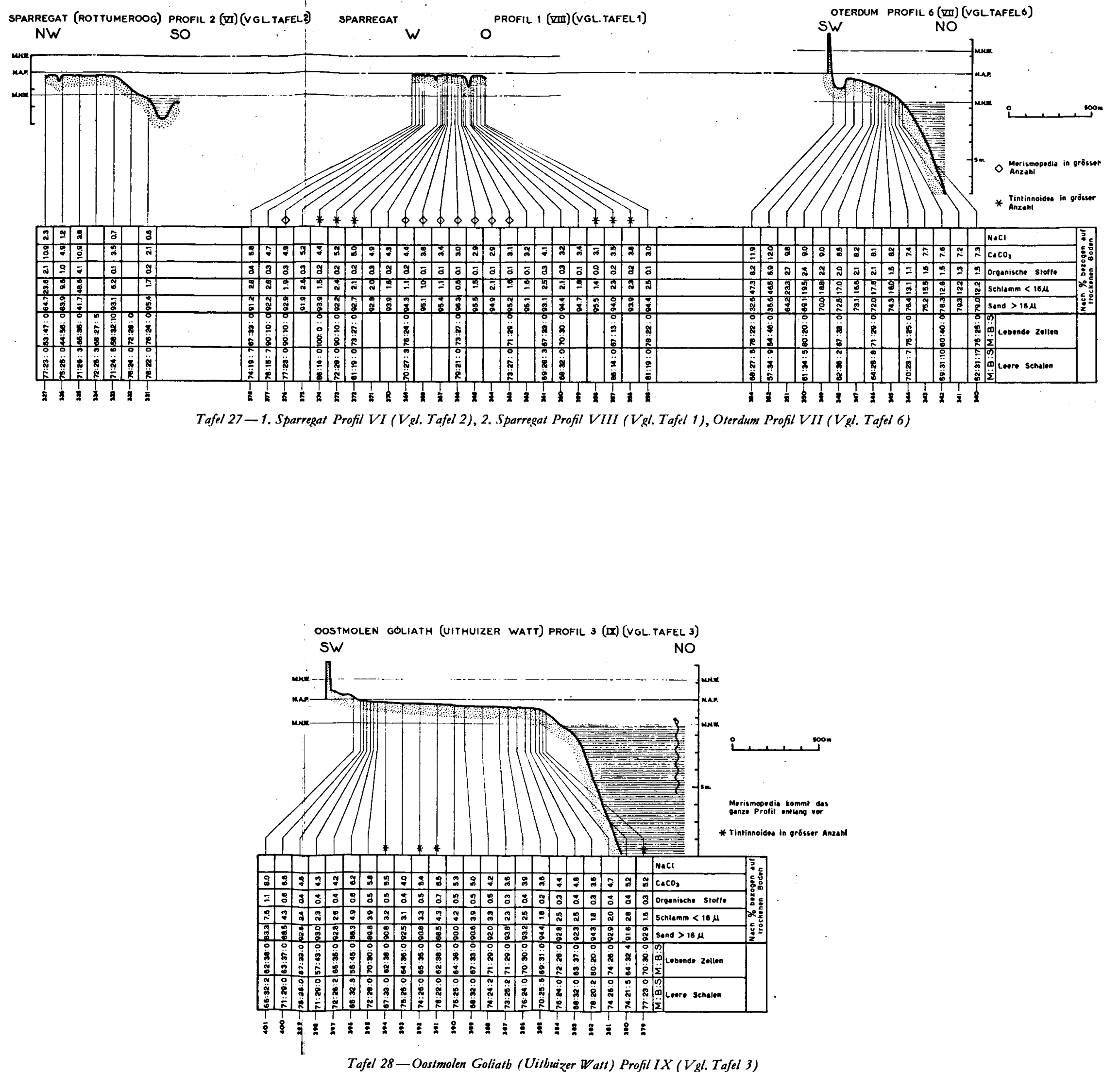
TAFEL A

Ausschließlich /ebend im Bodenmaterial und im Plankton des Dollart-Emsgebietes angetroffene Diatomeen. * lebend sowohl im Plankton wie im Bodenmaterial: 39 Arten, die ubrigen nur im Bodenmaterial; $x$ von denen auch als leore Schalen im Plankton: 41 Arten (Vgl, dic I.iste der leeren Schalen, Tafel B). $\mathrm{E}=$ Ems, $\mathrm{L}=$ Leda. $\mathrm{C}=$ Tafel C, $\mathrm{D}=$ Tafel $\mathrm{D}$.

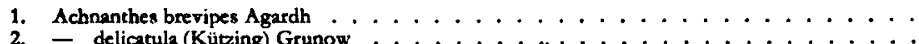

2. - delicatula (Kützing) Grunow $\ldots \ldots$

- hungarica Grunow

- lemmermannii Husted

- longipes Agardh

Actinoptychus undulatus (Bailey) Ralfs

Amphipleura rutilans Trentepobl

Amphiprora alata (Ehrenberg) Kütring

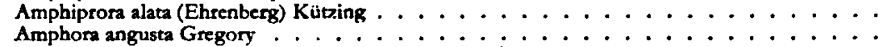

- coffeaeformis (Agardh) Küzzing $\ldots \ldots \ldots$

- exigua Gregory . . . . . . . . . . . . . . . . . . . . . .

- holsatica Hustedt.

- laevissima Gregory

lineolats Ehrenberg

- ovalis Kützing + var. lybica Ehrenberg $x \ldots \ldots \ldots$

Aulacodiscus argus (Ehrenberg) $\mathrm{A}$. Schmidt $\ldots \ldots \ldots$

Auliscus sculptus (W. Smith) Ralfs $x \ldots \ldots \ldots \ldots$

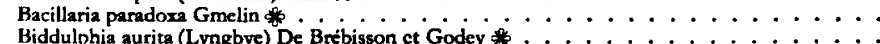

Biddulphia aurita (Lyngbye) De Brébisson ct Godey * . . . . . . . . . . .

- granulata Roper

- rhombus (Ehrenberg) w. Smitb $x+$ fo trigona Cleve $\ldots \ldots$

Caloneis amphisbaena (Bory) Cleve $x \ldots \ldots \ldots$

- amphisbaena (Bory) Cleve var, subsalina (Donkin) Cleve $\times \ldots \ldots \ldots$

- formoss (Gregory) Cleve

Campylosira cymbelliformis (A schmidt) Grunow $x \ldots \ldots \ldots$

Ccrataulus smithii Ralfs $\times \ldots \ldots \ldots$

Cocconeis pediculus Ehrenberg $x \ldots \ldots \ldots \ldots$

- peltoides Hustedt $\times$

- placentula Ehrenberg $x^{\prime} \ldots \ldots \ldots \ldots$

Coscinodiscus excentricus Ehrenberg o . . . . . . . . . . . . . .

- granii Gough . . . . . . . . . . . . . . . . . .

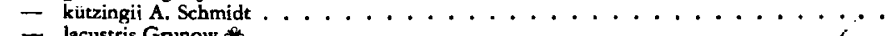

- lacustris Grunow . . . . . . . . . . . . . . .

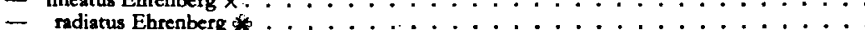

- rothii var, normanil (Gregory) Van Heurck . . . . . . . . . . . . .

Cyclotella caspia Grunow . . . . . . . . . . . . .......

- mencghiniana Kützing $\ldots \ldots \ldots \ldots \ldots$

Cylindrotheca gracilis (De Brebisson) Grunow $\ldots \ldots \ldots$

Cymatosira bea

Dimerogramma minor (Gregory) Ralfs $\mathrm{x} \ldots$

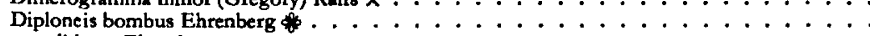

- didyma Ehrenberg $X$

Fragiaria (Gregory) Clevc $\ldots \ldots \ldots \ldots \ldots$

- intermedia Grunow

- pinnata Ehrenberg o . . . . . . . . . . . . . . . .

- schulzii Brockmann q

Gyrosigma balticum (Ehrenberg) Rabenhorst $x \ldots \ldots \ldots \ldots$

- litorale (W. Smith) Cleve $x \ldots \ldots \ldots \ldots$

- peisonis (Grunow) Hustedt . . . . . . . . . . . . . . .

- spencerii (W. Smith) Cleve

. wansbeckii (Donkin) Cleve ......................

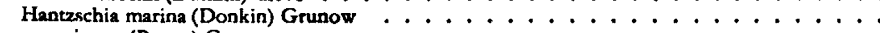

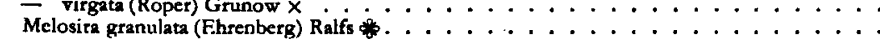

- sulcata (Ehrenberg) Kürzing di

- Varians Agardh *

Navicula abrupta Donkin $x \ldots \ldots$

- cancellate Donkin $x$.

- clementis Grunow $x$

- cruciculoides Brockmann $\ldots \ldots$

- crucifera Grunow . . . . . . . . . . . . . . . . .

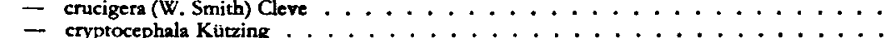

- cryptocephala Kützing cuspidata Kützing var. ambiguz (Ehrenberg) A. Cleve $\ldots \ldots \ldots$

- - digitoradiata (Gregory) Ralfs $\ldots \ldots \ldots \ldots$

6. - finnmarchica (Cleve \& Grunow) A. Cleve $\times \ldots \ldots \ldots \ldots . \ldots . \ldots$

- flanatica Grunow X

- forcipata Greville

$\ldots \ldots \ldots \ldots$

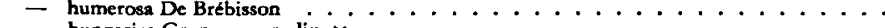

- hungarica Grunow, var. div $x \ldots \ldots \ldots \ldots$

- mutica Kützing $\ldots \ldots \ldots \ldots \ldots \ldots \ldots$

- peregrina (Ehrenberg) Kützing $x \ldots \ldots$

- peregrina (Ehrenberg) Kützing var. meniscus (Schumann) Cleve . . . . . . .

- phyllepta Kützing . .......................

- plathii Brockmann $\ldots \ldots \ldots \ldots \ldots \ldots \ldots$

88. - pygmaea Kutzing $\times$

Auf Profil (Tafel) Nr.

$5,7,8$

D, $1,2,3,5,7,8,9,10, \mathrm{~F}$.

$1,3,7,8$

$D, 1,2,3,6,7,8,9,11$

$7,3,70$

$3,2,3,8$

C, $1,3,4,7,8,9,10$

$1,2,3,7,8,9$

C. $1,2,3,5,7,8,10$

C. $1,6,8,9$

3,5

C,D, 1, 2, 3, 5, 6, 7, 8, 9, 10, J.

D, 1, 3

5 ,

C,D, 1, 2, 3, 4, 5, 7, 8, 9, 10, E. 4

C,D, 1, 2, 3, 6, 8

$5,7,8,9,1$

$5,6,8$
$7,8,10$

8

3, 7,8

$3,7,10$

D, $1,2,3,5,7,10$

1,3

$C, D, 1,3,4,5,7,8$

C, 1

$4,8,9,10$

1

E, L

$1,7,8, E, L$

C,D, 1, 2, 3, 4, 5, 6, 7, 8, 9, 10, E

C,D, $1,2,3,5,7,9$
$1,3,5,6,7,8,9,10$

$3,7,8,9,10$

E, 1

E

$1,3,6$,

C, $1,3,4,5,6,7$

C, 1,

$3,7,7,8,10$

$5,7,8$

C, $7,8,9$

C, $1,3,6,7,9$

$8, \mathrm{E}, \mathrm{L}$

C,D, $1,2,3,4,5,6,7,8,9,10, \mathrm{~L}$

$1,3,8$

C, D, 1,3

$3,7,8,9,10$

1

C,D, 1, 2, 3, 4, 6, 7, 8, 9, 10

C, $1,2,3,5,6,7,8,9,10$

C,D, $1,2,3,6,7,8,9,10$

3

$3,9,10$

$7,8,10$

C, $1,3,6,7,8,9,10, \mathrm{E}$

C

C,D, 1, 2, 3, 4, 5, 6, 7, 8, 9, 10, E, L

5,8

C, $1,3,5,6,7,8,9,10$ im Gebiet

III

I. II, III, IV

III

II, II

I, 11, III

II, II

II, III

I, II, III

I, II, III

I, II, III

ii

II, III, IV

I, II, III, IV

I. II

IIII IV

I, II, III, IV

I, II

I, II III, IV

III, IV

III

III

II, III

II, III, IV

II, III, III

I, II, III IV

II, III

I, II, III

I, II, III

II, III, IV

II, III, IV

I, II

III, IV

III, IV

II, II, IV

II, III

I, II, III, IV

II, III

II, III, IV

I, II IV

IV

III, IV

II. III, IV

I. II, III

I, II, III

II, III

III

I, III
I, II, II, IV
II, III, IV

1, II, III, IV

II, III, iv

I, II,

I. II III, IV

III J, III

II

III

I, II, IJ

I, II. III

I, II, III

II JI,

II, III

III, IV

I, II, III, IV

II.

I, II, III, IV

III, IV 


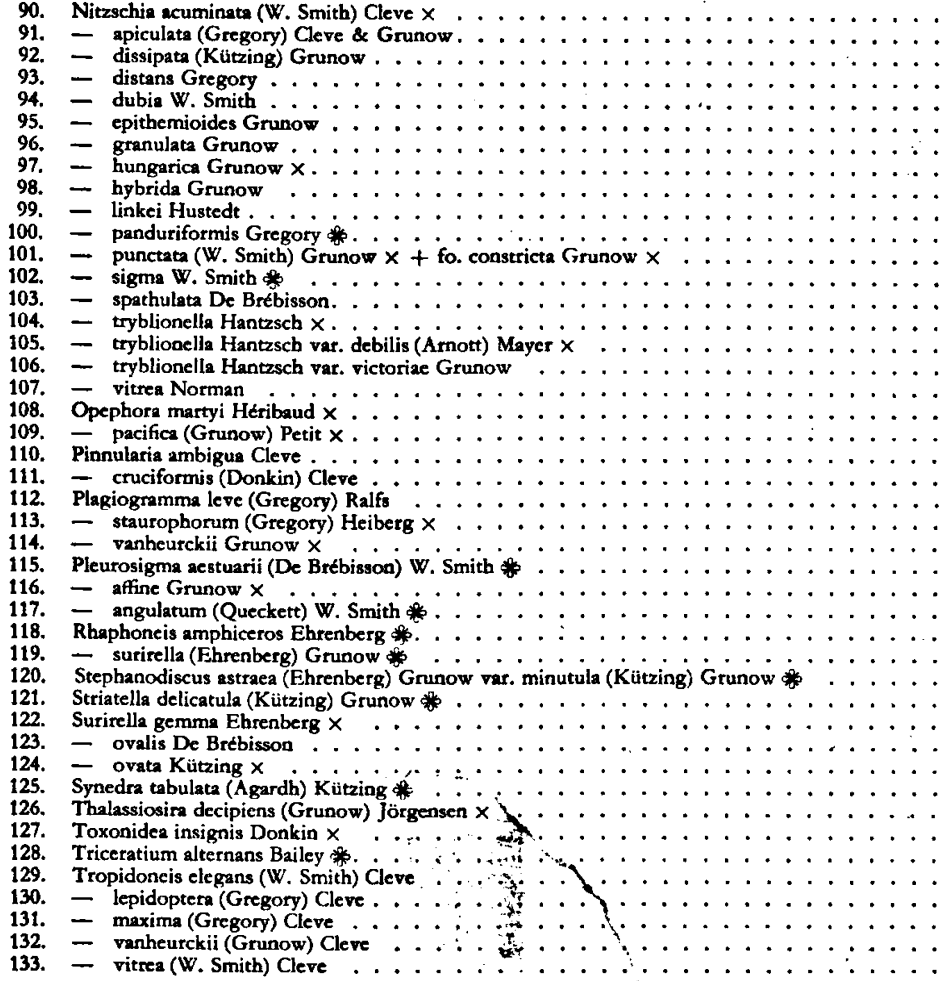

Die W/ahrgenommene Artenzahl ist folgenderweise zu verteilen:

Marin.

Brackisch

Brackisch

Brackisch Sï

Sïß Brackisch

$\mathrm{SüB}$

Total .

41
23
14

14

25

12

133 Arten
D, $1,3,6,7,8$

C, D, 1, 4, 5, 7, 8, 10

$1,3,7,8$

3,8
7,8

3

C, D, 1, 3, 4, 7, 8, 9, 10

C, $1,3,4,6,7,8,9,10$

C. $1,2,3,4,5.6,7$,

D, $1,2,3,4,5,6,7,8,10, E, I$

C,D, $1,3,7,8,9,10$

3,5

$C, 4,9, E, L$
$6,7,8,10$

$6,7,8$

D. $3,6,7,8,9,10, \mathrm{E}$

$6,7,8,9,10, \mathrm{E}$

C, $1,3,7,8,9,10$

1

D, $1,3,8,9$

C,D, $1,2,3,4,5,6,7,8,9,10$

C,D, $1,3,4,6,8,9$,

$1,3,4,5,6,7,8,9,10$

$1,3,4,5,6,7,8,9,10$
D, $1,2,3,4,5,6,7,8,9,10$

C, $1,3,4,5$

C,D, 1, 2, 3, 4, 7, 9, 10, E

C.D,

5,7

$5,7,8,10$

$\mathrm{C}, \mathrm{D}, 1,2,3,4,7,9, \mathrm{E}$

C,D, 1, 3, 7

$2,5,7$

C, D, 1, 3, 6, 7, 8, 9

C, 1,3

C,D, 2,3
I, II, III
I, II, III

III

II, III

III

II, IV

I, II, III

I, II, III

II, III, IV

II, III, IV

1, II, JII

I, II, III, IV

III

I, II, III, IV

I, II, JII

I. II, III

I, II, III

I. II, III, IV

I, II, III

II , 111

II, III

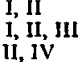

II, IV II, III, IV

I, II, III, IV
I, II, III, IV
IV

III, IV

III

I, II, III, IV

I, II II, III

I, II, III

I, II, III

II 11

I, II

Neben den mit * bezeichneten Arten wurden lebènd im Plankton noch angetroffen:

Asterionella formosa Hassall warden lebènd im Plankton noch angetroffen:

2. - japonica Cleve

Bellerochea malleus (Brightwell) Van Heurck

5. Biddulphir sinensis Greville . . . . . . . . . . . . . . . . . . . . . . . . . . . . . .

Caloneis amphisbaena (Bory) Cleve var. fenzlii Grunow . . . . .

Chaetoceros affinis Lauder

- compressus La

- densus Cleve

- didymus Ehrenber

- radians Schütt

- socialis Lauder

Eucampia zoodiacus Ehrenberg

Fragilaria crotonensis Kitton

Guinardia flaccida (Castracane) Peragallo

Lauderia bomalis Gran.

Lithodesmium undulatum Ehrenber

Melosire grenulata (Ehrenberg) Ralfs f. curvate vel spiralis Grun.

- juergensii C A A

- nummuloides (Dillwyn) C. A. Agardh

Navicula viridula Kützing

Nitzschia acicularis W. Smith

- Eascizulata Grunow

- longissima (De Brébisson) Raiff

- sigmoidea (Ehrenberg) W. Smith

Pleurosigma elongatum W. Smith

Rhizosolenia delicatula Cleve

- hebetata (Bailey) Gran f. semispina (Hensen) Gran

- stolterfothii Pcragallo

Streptotheka thamesis Shrubsole

Surirella biseriata de Brébisson

- elegans Ehrenberg

- robusta Ehrenberg.

- tenera Gregory var. nervosa Mayer

Synedra rumpens Kützing

Tabellaria flocculosa (Roth) Küzing im Plankion vorkamen

im Gebiet

II,

I, II

I, II

II

I, II

11

I, II

UI, $1 \mathrm{~V}$

I, II, III

I, II, III

I, II, II

II

III

IV

IV

IV

I, II, III

I, II, II

1, II

II, II

IV

IV

IV 
TAFEL $B$

Ausschließlich als leere.Scbalen im Bodénmaterial und im Plankton des Dollart-Emsgebictes angetroffene Diatomcen. Ausschließlich als leere, Scbalen im Bodénmaterial und im Plankton des Dollart-Emsgebictes angetroffene Diatomcen.
$X$ als leere Schalen sowohl im Plankton wie im Bodenmaterial: 38 Arten, dic übrigen nur im Bodenmatcrial;

* von denen auch lobend im Plankton: 22 Arten (Vgl. die Liste der lebenden Arten, Tafel A).

E $=$ Ems, L = Leda.

1. Achnanthes brevipes Agardh var. intermedia (Kutzing) Cleve . . . . . . . . . .

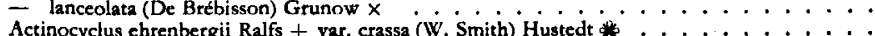
Actinoptychus splendens (Shadboard) Ralfs $\times \ldots \ldots \ldots \ldots$ Amphora truncata Gregory . . . . . . . . . . . . . . . .

Anomoeoneis sphaerophora (Kützing) Pfitzer $\ldots \ldots$

Autiscus caelatus Bailey $\ldots \ldots \ldots$

Biddulphia regia (Schultze) Ostenfeld $\ldots \ldots \ldots$

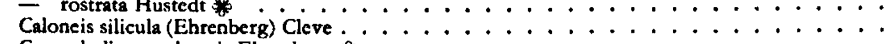

Campylodiscus echeneis Ehrenberg $\ldots \ldots \ldots$. . . . . . . . . . .

Cerataulus turgidus Ehrenberg $x$

Cocconeis britannica Nägeli

- diminuta Pantocsek.

- disculus (Schumano) Cleve

Coscinodiscus argus Ehrenberg a

- centralis Ehrenberg $x \ldots \ldots \ldots$

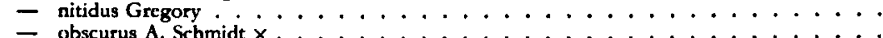

- oculus-iridis Ehrenberg . . . . . . . . . . . . . . . .

- perforatus Ehrenberg var. pavillardii (Forti) Hustedt . . . . . . . . . . .

$\overrightarrow{\text { Cyclotella comta (Ehrenberg) Kützing div. } \ldots \ldots \ldots \ldots} \ldots$

Cymatopleuta (Ehrenberg) Kützing

- solea (De Brébisson) W. Smith W. Smith

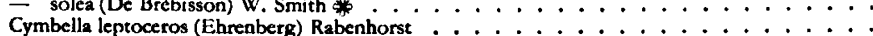

- sinuata Gregory $x$

Diatoma clongatum (Lyngbye) Agardh

- vulgare Bory qu

Dimerogramma marinum Ralfs

Diploneis aestuarii Hustedt $x$

- ovalis (Hilse) Cleve

- emithii (De Breve

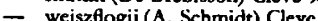

Epithemia sorex Kützing

- turgida (Ehrenberg) Kützing $x$

Eunotis formica Ehrenberg

- lunaris (Ehrenberg) Grunow $x^{\ldots} \ldots \ldots \ldots \ldots$

Fragilaria brevistriata Grunow $\times$

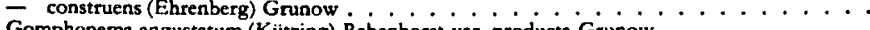

Gomphonema angustatum (Kützing) Rabenhorst var. producta Grunow . . . . . . . . . .

- longiceps Ehrenberg fo. succica Grunow . . . . . . . . . . . . . . . .

Grammatophora marina (I_yngbye) Kützing . . . . . . . . . . . . . . .

G oceanica Ehrenberg . . . . . . . . . . . . . . . . . .

Gyrosigma acuminatum (Kützing) Rabenhorst $x \ldots \ldots \ldots$. . . . . . . . . .

- attenuatum (Kützing) Cleve $x \ldots \ldots \ldots \ldots$

- distortum (W'. Smitb) Cleve

- eximium (Thwaites) Boyer

- scalproides (Rabenhorst) Cleve

Melosira distans (Ehrenberg) Kützing

- italica (Ehrenberg) Kützing $x$.

- moniliformis (Müller) Agardh $x$

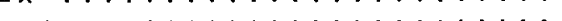

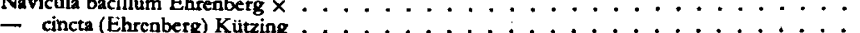

- cuspidata Kützing ${ }^{2}$

- elegans W. Smith

- gastrum Ehrenberg $\ldots \ldots \ldots \ldots$

- gracilis Ehrenberg

- lyra Ehrenberg $x$

一 marina Ralfs $\ldots \ldots$

- placentula (Ehrent

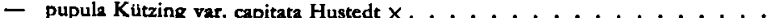

- pusilla W. Smith $x$

- rbynchocephala Kützing $\times$

- salinarum Grunow $x \ldots \ldots \ldots$

Nitzschia circumsuta (Bailey) Grunow ${ }^{\text {scutelloides }}$. Smith $\times \ldots \ldots$

- linearis W. Smith

- navicularis (De Brébisson) Grunow $x \ldots$

- obtusa W. Smith var, scalpelliformis Grunow

- parvula Lewis

- tryblionella Hantzsch var, levidensis (W. Smith) Grunow

Pinnularia gibba Ehrenberg $x \ldots \ldots$

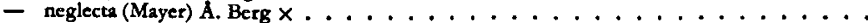

- nobilis Ehrenberg $\times$

- trevelyana (Donkin) Rabenhorst . . . . . ...

- viridis (Nitzsch) Ehrenberg $x \ldots$

Podosira stelliger (Bailey) Mann

Rhizosolenia imbricata Brightwell var. shrubsolei (Cleve) Van Heurck . . . . . . . .

Rhoicosphenia curvata (Kützing) Grunow $x \ldots \ldots$

Auf Profil (Tafel) Nr.

$4,5, \mathrm{E}$

,

5,9

3

8

$3,7,10$

$8, \mathrm{E}, \mathrm{I}$

$1,5,9$

8

5

C., 3, 7, 8

8

1,10

D, 7,8

C, 2,7

C, 2,7
D, $1,3,7,8,10, k$

7

E

3

4, E

C,D, $1,2,3,4,5,7,8,9,10$, L

C,D, 1, 2, 3, 4, 5, 8, 9, 10, E, L

$4,5,7$

$2,3,5,6,7,8,9$

C. $1,5,8,10$

5

E

$5,7, \mathrm{E}, \mathrm{L}$

E

E

5

$2,3,7,8, \mathrm{E}$

$5,7,8,9, \mathrm{E}$

5

7,8

4,7

$1,3,4,5,8,9,10$
$C, D, 2$

8, E

$4,7,8, E$

E

8,9

C, D

2, 5

$E$
10

$3,5,7,8$

4, E

D, 3, 7, 8

C.D. 1, 2, 3, 4, 5, 6, 7, 8, 9, 10, E, L

E

E

5

C, 2

C,D, 3, 5, 8, E, L

$C, D, 1,2,3,4,5,8,9,10$, E, L

$D, 3,4, E$

C, $3,5,8,10, E$ im Gebiet

II, III, IV

I, II, III, IV

I, II, III, IV

III

I, II, III

III, IV

II, III, IV

I, II, III, IV

I, II, III

III

I, II, III, IV

II, III

I, III

II, II, III

I, II, JII, IV

III, IV

IV

III

II, IV

III

I, II, III, IV

I, II, III, IV

II, III

II, II, III

I, II, II

III, IV

IV IV

III, IV

II, III

IV

IV

III

II, IIl, IV

III, IV

IIII, IV

III

II, III

II, III

I, II, III

III, IV

III, IV

II, III, IV

III, IV

IV,

III

I, II, III

II, III

IV

IIII, IV

IV,

II, IV

II, III, IV

I, II, III, IV

II

IV

III, IV

III, IV

III, IV

I, II

II, III, IV

I, II, IH, IV

I, II, III, IV 

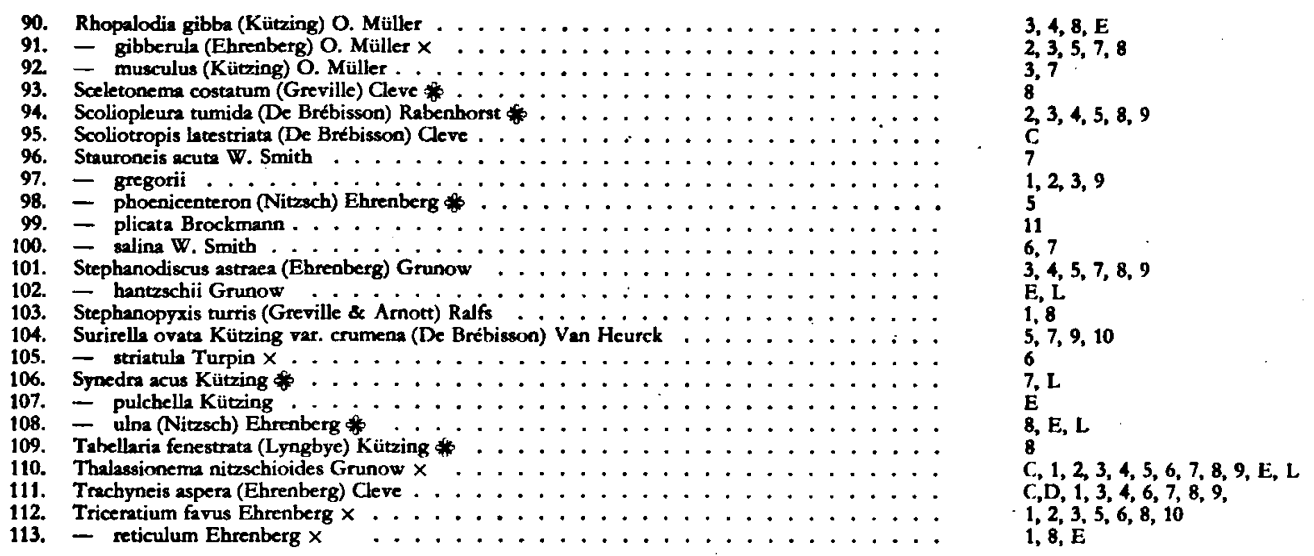

II, II, IV
II, III
II, III
II, III
II, III
I
III
II, III
III, IV
III
III
II, II
IV
II, III
III
II, III
II, III, IV
IV
III, IV
III, IV
I, II, III, IV
I, II, III
I, II, III, IV
II, III, IV

Die wahrgenommene Artenzahl ist folgenderweise zu verteilen:

Marin. . .

Marin Brackisch

Brackisch Marin

Brackisth

Brackisch Süß

SüB B

Total .

33
4
7
11
6
42
10

113 Arten

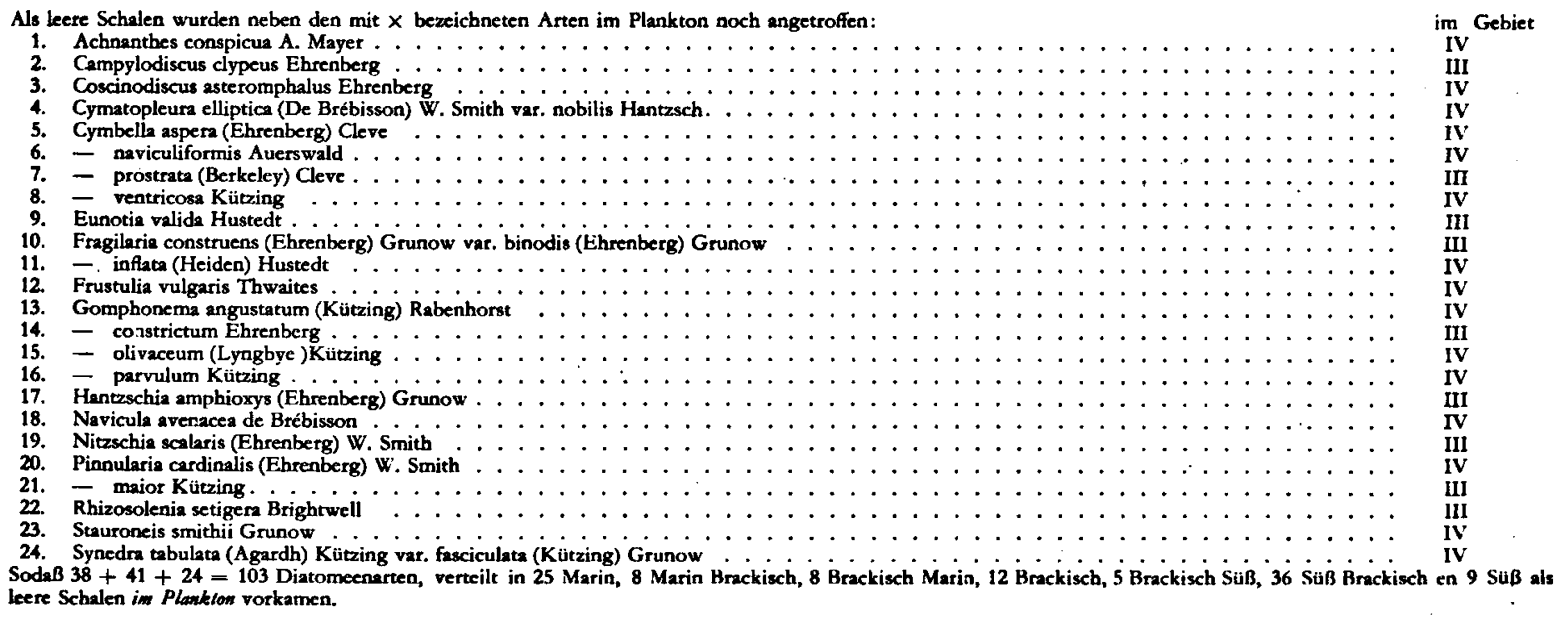




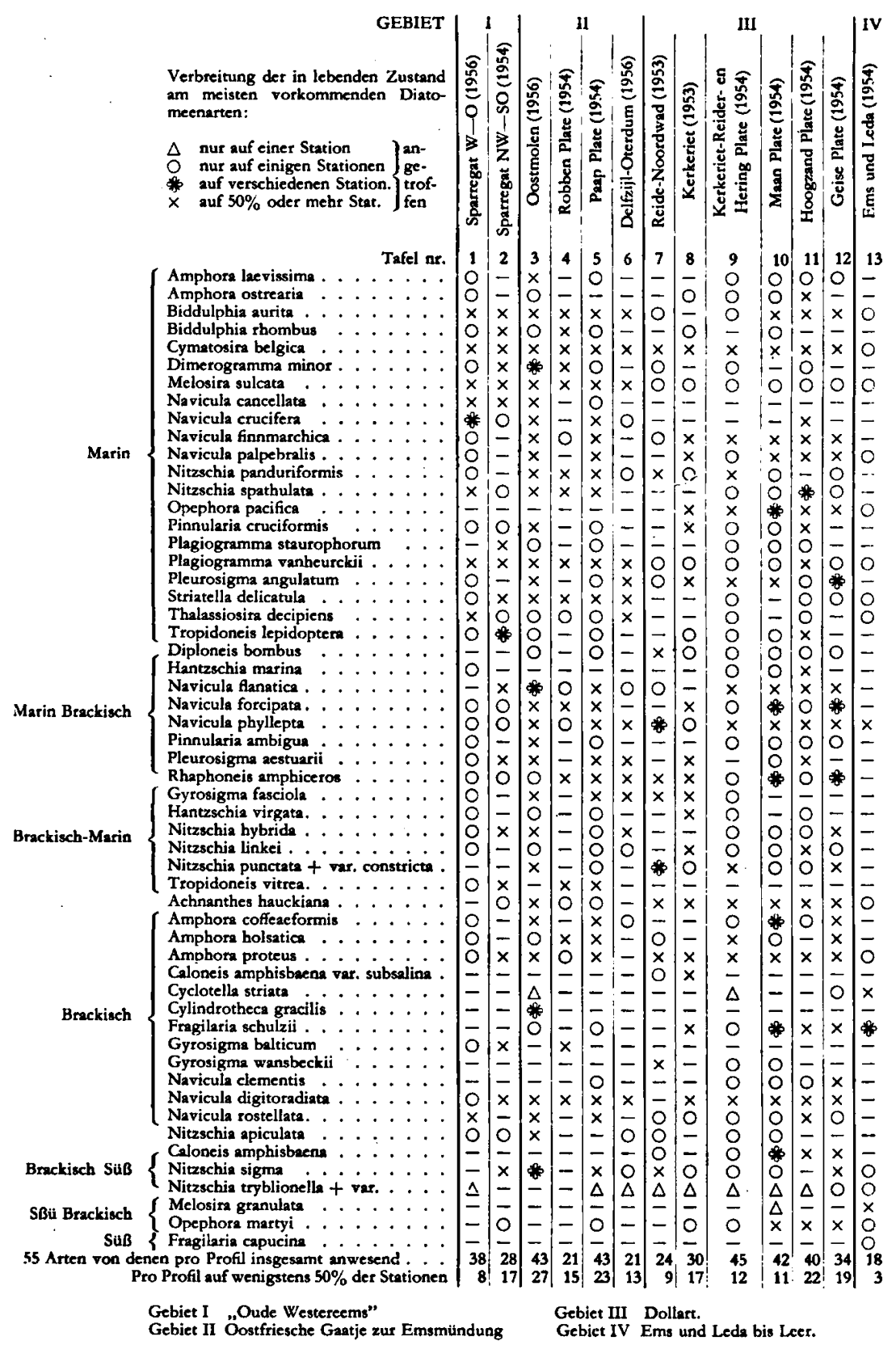

Tafel C. Verbreitung der in lebendem Zustand am meisten vorkommenden Diatomeenarten.

N.B. In den Tafeln C, D und 1-16 werden nut die lebenden Arten mit dem Namen genannt; von den als leeren Schalen vorkommenden Arten ist nur die Gesamtzabl erwähnt. 


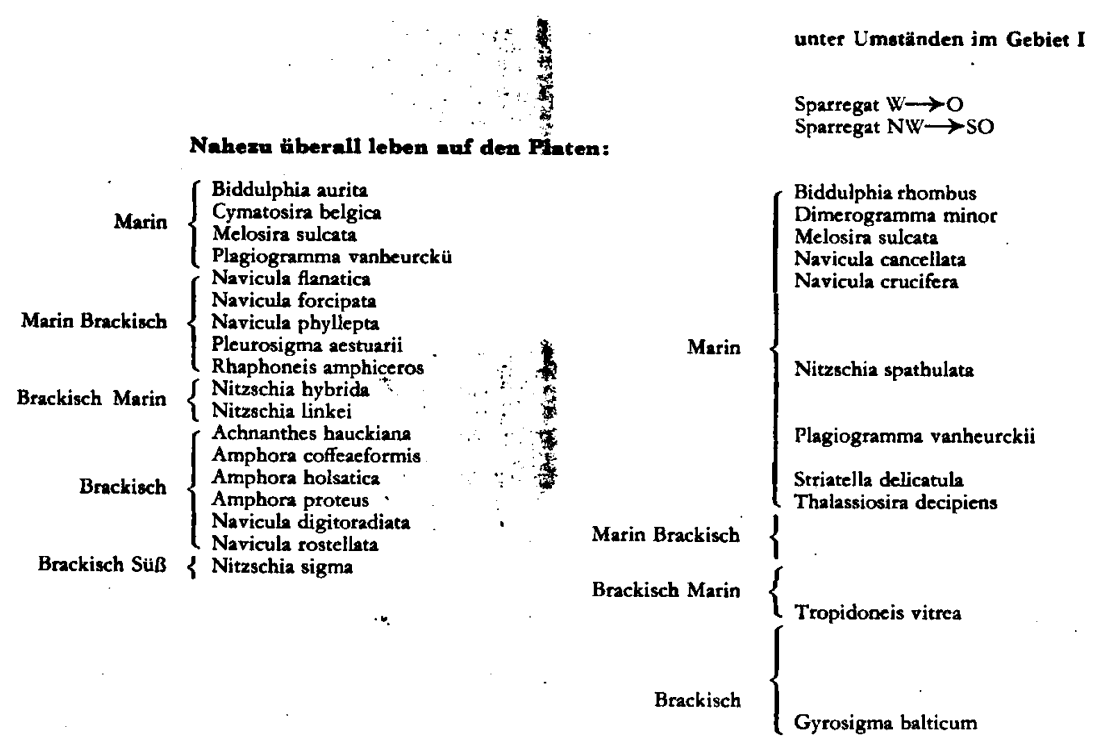

Aber mehr spezial:

unter Urhständen im Gebiet II

Oostmolen Goliath

Robben Plate

Paap Plate

Delfzijl-Oterdum

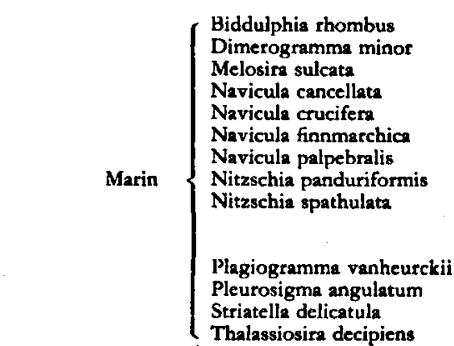

Marin Brackisch

\{

Brackisch Marin Gyrosigma fasciola

Nitzschia punctata f. constricta

Tropidoneis vitres

Achnanthes hauckiana

Brackisch

Amphora coffereformis

Amphora holsatica

Gyrosigma balticum

Tafel D. Verbreitung der im lebenden Zustand auf spezifiscben Milieus bescbränkten Diatomeenarten. 


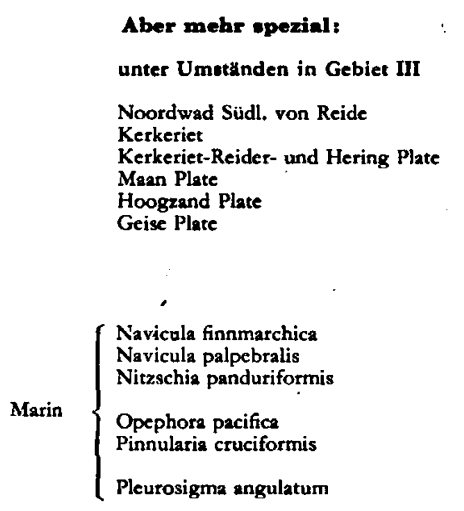

Marin Brackisch \{ Diploneis bombus

Brackisch Marin f Gyrosigma fasciola Gyrosigma fasciola
Nitzschia punctata $\mathrm{f}$. constricta

Brackisch $\left\{\begin{array}{l}\text { Achnanthes hauckiana } \\ \text { Amphora coffeaeformis } \\ \text { Amphora holsatica } \\ \text { Fragilaria schulzii } \\ \text { Gyrosigma wansbeckii } \\ \text { Brackisch SüB } \\ \text { SüB Brackisch }\end{array} \quad\left\{\begin{array}{l}\text { Caloneis amphisbaena } \\ \text { Opephora martyi }\end{array}\right.\right.$

unter davon abweichenden Umstünden:

\author{
( Amphora laevissima \\ Amphora ostrearia \\ Pinnularia cruciformis \\ Tropidoneis lepidoptera \\ Marin Brackisch
Brackisch Marin $\left\{\begin{array}{l}\text { Pinnularia ambigua } \\ \text { Hantzschia virgata } \\ \text { Nitzschia linkei }\end{array}\right.$ \\ Brackisch $\{$ Nitzschia apiculata
}

und unter sehr speziellen Umatänden:

Brackisch $\left\{\begin{array}{l}\text { Caloneis amphisbacna var. subsalina } \\ \text { Cylindrotheca }\end{array}\right.$ 